
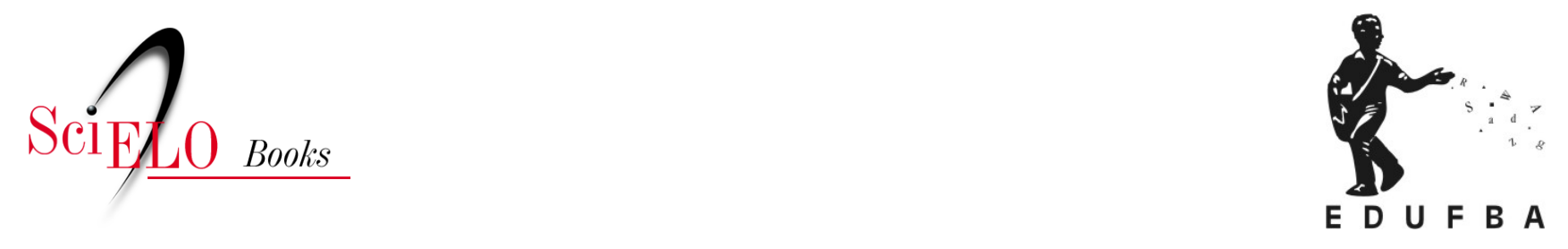

\title{
Planejamento e gestão em saúde: caminhos para o fortalecimento das hemorredes
}

Mariluce Karla Bomfim de Souza (Organizadora)

\section{SciELO Books / SciELO Livros / SciELO Libros}

SOUZA, M.K.B., comp. Planejamento e gestão em saúde: caminhos para o fortalecimento das hemorredes [online]. Salvador: EDUFBA, 2018, 163 p. ISBN 978-85-232-2027-3.

https://doi.org/10.7476/9788523220273.

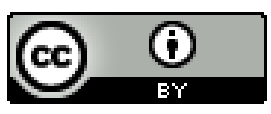

All the contents of this work, except where otherwise noted, is licensed under a Creative Commons Attribution 4.0 International license.

Todo o conteúdo deste trabalho, exceto quando houver ressalva, é publicado sob a licença Creative Commons Atribição 4.0. 


\section{Planejamento e gestão em sqúde}

caminhos para o fortalecimento das Hemorredes 
UNIVERSIDADE FEDERAL DA BAHIA

\author{
Reitor \\ João Carlos Salles Pires da Silva \\ Vice-reitor \\ Paulo Cesar Miguez de Oliveira \\ Assessor do Reitor \\ Paulo Costa Lima
}

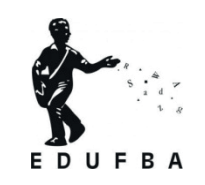

EDITORA DA UNIVERSIDADE FEDERAL DA BAHIA

\author{
Diretora \\ Flávia Goulart Mota Garcia Rosa \\ Conselho Editorial \\ Alberto Brum Novaes \\ Angelo Szaniecki Perret Serpa \\ Caiuby Alves da Costa \\ Charbel Ninõ El-Hani \\ Cleise Furtado Mendes \\ Evelina de Carvalho Sá Hoisel \\ José Teixeira Cavalcante Filho \\ Maria do Carmo Soares de Freitas \\ Maria Vidal de Negreiros Camargo
}


Mariluce Karla Bomfim de Souza

(Organizadora)

\section{Planejamento e gestão em saúde}

caminhos para o fortalecimento das Hemorredes 
2018, autores.

Direitos dessa edição cedidos à Edufba.

Feito o Depósito Legal

Grafia atualizada conforme o Acordo Ortográfico da Língua Portuguesa de 1990, em vigor no Brasil desde 2009.

\author{
Capa e Projeto Gráfico \\ Rodrigo Oyarzábal Schlabitz \\ Foto de Capa \\ @Freepik.com \\ Revisão \\ Ádila Marcele Freitas \\ Normalização \\ Juliane Nunes do Nascimento \\ Sistema de Bibliotecas - UFBA
}

Planejamento e gestão em saúde : caminhos para o fortalecimento das hemorredes /

Mariluce Karla Bomfim de Souza (organizadora).- Salvador: EDUFBA, 2018.

$163 \mathrm{p}$.

ISBN: 978-85-232-1755-6

1. Administração dos serviços de saúde. 2. Bancos de sangue - Brasil - Administração. 3. Pessoal da área de saúde pública - Educação. I. Souza, Mariluce Karla Bomfim de.

II. Instituto de Saúde Coletiva. Universidade Federal da Bahia.

CDD: 362.1

CDU: 614.2

Editora afiliada à

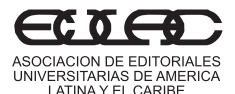

UIVERSITARIAS DE AMERICA LATINAY EL CARIBE

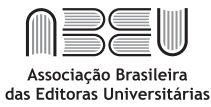

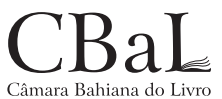

Câmara Bahiana do Livro

Editora da UFBA

Rua Barão de Jeremoabo, $\mathrm{s} / \mathrm{n}$ - Campus de Ondina

40170-115 - Salvador - Bahia | Tel.: +55 71 3283-6164

www.edufba.ufba.br / edufba@ufba.br 


\section{Agradecimentos}

O processo de cooperação técnica entre o Instituto de Saúde Coletiva da Universidade Federal da Bahia (ISC/UFBA) e a Coordenação Geral de Sangue e Hemoderivados do Ministro da Saúde (CGSH/MS) foi permeado por construções coletivas que marcaram todo o desenvolvimento dos cursos de Planejamento e Gestão em Saúde.

Agradecemos a todos(as) os(as) trabalhadores(as), gestores(as) e técni$\cos ($ as) das Hemorredes estaduais e, em geral, do Sistema Único de Saúde (SUS), pelo compromisso, competência e dedicação na produção do conhecimento, materializado na oportunidade de publicação deste livro. 


\section{Sumário}

9 Prefácio

11 Apresentação

15 Planejamento em saúde: concepções, "tentativas" e desafios para a prática

Ana Angélica Ribeiro de Meneses e Rocha

Mariluce Karla Bomfim de Souza

45 Política de Sangue no Brasil: desafios e iniciativas para a sua integração na rede de atenção à saúde

Mariluce Karla Bomfim de Souza

Glauciene Analha Leister

Junia Guimarães Mourão Cioffi

Cláudio Medeiros Santos

Helder Teixeira Melo

73 Gestão da qualidade e avaliação dos serviços de hematologia e hemoterapia na perspectiva do Programa Nacional de Qualificação da Hemorrede

Jane Terezinha Martins

Glauciene Analha Leister

Cláudio Medeiros Santos

89 A vigilância sanitária e a qualidade na atenção hemoterápica

Helder Teixeira Melo

Giselle Bissaro Barban Evangelista 
105 Estratégias metodológicas adotadas para os cursos em Planejamento e Gestão em Saúde

Mariluce Karla Bomfim de Souza

Jussara Cargnin Ferreira

125 Notas sobre a implementação dos cursos em Planejamento e Gestão em Saúde e caracterização das Hemorredes estaduais

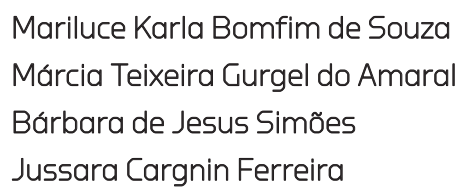

145 Cursos em Planejamento e Gestão em Saúde: uma proposta de educação permanente em saúde?

Mariluce Karla Bomfim de Souza

Isabela Cardoso de Matos Pinto

159 Sobre os qutores 


\section{Prefácio}

A qualificação da gestão pública com vistas à oferta de produtos e serviços relacionados ao sangue, atendendo aos padrões técnico-científicos de excelência e segurança tem sido um compromisso político assumido pelo Ministério da Saúde no Brasil.

Os capítulos dessa coletânea apresentam evidências da aposta institucional no aprimoramento das práticas de gestão da política do sangue. A descrição da trajetória da política, o registro das experiências inovadoras em gestão e melhoria da qualidade, os avanços evidenciados nas ações de vigilância sanitária e o investimento em processos de educação permanente em práticas de planejamento em saúde de natureza estratégica explicitam o compromisso político do Ministério da Saúde com a garantia da oferta de serviços e produtos relacionados ao sangue, como parte integrante das redes de atenção à saúde a todos os brasileiros.

É uma decisão que guarda coerência com o preceito constitucional da garantia da saúde como direito de todos e dever do Estado e traz enormes desafios, especialmente, no que diz respeito à redução das desigualdades regionais no acesso da população a esses produtos e serviços e à própria compreensão das Hemorredes como partes essenciais e intrínsecas das redes de atenção do Sistema Único de Saúde.

A utilização de distintas abordagens metodológicas em relação aos processos de planejamento das Hemorredes, a exemplo da gestão da qualidade e do enfoque estratégico-situacional, indica uma certa heterodoxia, que é muito bem-vinda, dada a complexidade dos distintos contextos de implementação do Sistema Único de Saúde (SUS) nas regiões brasileiras e, também, da 
dupla perspectiva do sangue ao interior do sistema de saúde: "produto/bem" e "serviço".

Se as intervenções fundamentadas na gestão da qualidade concorrem para o alcance da excelência dos processos relacionados ao "produto/bem", o planejamento estratégico ao envolver diversas representações institucionais na explicação dos problemas priorizados, contribui para a produção de acordos que sustentarão a viabilidade das operações dirigidas ao fortalecimento das Hemorredes estaduais e sua efetiva incorporação ao conjunto de serviços de saúde que compõem o SUS.

Há que se destacar que a opção pedagógica, compartilhada entre o Ministério da Saúde e o Instituto de Saúde Coletiva da Universidade Federal da Bahia, de oferecer cursos em Planejamento e Gestão de Sistemas e Serviços de Saúde ("Planeja Sangue") sob a forma de oficinas para apoiar a construção de planos diretores estaduais é coerente com a aposta na aprendizagem significativa, processo no qual "cursistas", "facilitadores", "moderadores" e "docentes" compartilham experiências de modo reflexivo e produzem conhecimento a partir dessa interação. Abordagem pedagógica que é parte do próprio processo de produção do documento "plano", que não se encerra no instante de sua finalização, pois se torna referência para a ação cotidiana dos profissionais e gestores implicados com a implementação dos planos diretores.

Por fim, vale lembrar a noção do planejamento como prática social, historicamente determinada, produzida por sujeitos implicados com a situação que pretendem modificar. Dados os desafios da gestão da política do sangue, mais relevantes se tornam as iniciativas de qualificação dos trabalhadores fundamentadas em abordagens autoreflexivas e problematizadoras para a construção de ações transformadoras em defesa da saúde como direito social e dever do Estado.

Ana Luíza Queiroz Vilasbôas ${ }^{1}$

1 Graduada em Medicina, mestre em Saúde Comunitária e doutora em Saúde Pública na área de Política e Planejamento em Saúde. Professora adjunta do Instituto de Saúde Coletiva da Universidade Federal da Bahia (ISC/UFBA). Chefe do Departamento de Saúde Coletiva I e vice-diretora do ISC/UFBA. 


\section{Apresentação}

Desde 2014 foram iniciadas as atividades do Projeto Planeja Sangue, registrado como cursos em Planejamento e Gestão de Sistema e Serviços de Saúde, o qual foi concebido por iniciativa da Coordenação Geral de Sangue e Hemoderivados do Ministério da Saúde (CGSH/MS) com cooperação técnica do Instituto de Saúde Coletiva da Universidade Federal da Bahia (ISC/UFBA).

O Projeto Planeja Sangue tem sido implementado em um contexto cujas práticas de Planejamento são incipientes nos serviços e sistema de saúde. A fim de apoiar as Hemorredes estaduais para a consolidação do processo de planejamento e concepção de Planos Diretores Estaduais de Sangue e Hemoderivados, os cursos em Planejamento e Gestão em Saúde têm sido ofertados desde 2015. No entanto, anterior a sua oferta foram realizados encontros durante o ano de 2014 e início de 2015 que geraram reflexões sobre política, planejamento e gestão em saúde estimulando as equipes de coordenação e elaboração do Projeto Planeja Sangue para a produção textual e bibliográfica sobre tais temas com o desafio de provocar nos leitores reflexões e inspirações de novas práticas nos Serviços de Hemoterapia e Hematologia que integram o Sistema Único de Saúde.

Esta obra, organizada em sete capítulos, inclui temas que trazem à discussão elementos conceituais e metodológicos sobre Política, Planejamento e Gestão em Saúde, além da abordagem sobre a Avaliação e a Vigilância e Qualidade dos serviços hemoterápicos. Nesta, o(a) leitor(a) também vai conhecer a proposta metodológica e os primeiros registros sobre o processo de implementação dos cursos em Planejamento e Gestão em Saúde. 
O capítulo de abertura do livro, intitulado "Planejamento em saúde: concepções, 'tentativas' e desafios para a prática”, apresenta os aspectos teóricos e históricos que circunscrevem as ações de planejamento no Sistema Único de Saúde (SUS). Aponta iniciativas e produtos para o planejamento em saúde e aborda a importância dos atores, bem como o papel e os desafios das instituições para a institucionalização do planejamento no sistema e nos serviços de saúde.

O segundo capítulo "Política de Sangue no Brasil: desafios e iniciativas para a sua integração na rede de atenção à saúde" resgata, inicialmente, a compreensão sobre política de saúde destacando o seu ciclo de desenvolvimento e com o intuito de recuperar aspectos sobre o modo de organização e de implementação da política de sangue no Brasil. Apresenta evolução histórica das propostas e ações voltadas para a hematologia e hemoterapia com destaque às proposições legais e resolutivas que instituíram e vêm instituindo a organização e o desenvolvimento de práticas na área. Os autores destacam alguns desafios para a Política de Sangue e para o fortalecimento da Hemorrede e, finalizam, exemplificando iniciativas e ações estratégicas recentes para o fortalecimento da gestão e da integração das práticas em hematologia e hemoterapia na rede de atenção à saúde.

O terceiro capítulo que trata da "Gestão da qualidade e avaliação dos serviços de hematologia e hemoterapia na perspectiva do Programa Nacional de Qualificação da Hemorrede", destaca o funcionamento das organizações e o cumprimento da sua missão como desafio de qualquer sistema de gestão, inclusive para os serviços de hemoterapia e hematologia, dadas as particularidades do seu principal produto: sangue e componentes. Os autores trazem à discussão a gestão da qualidade como importante tecnologia gerencial, e, portanto, com papel central nos sistemas de gestão, sendo na atualidade, inclusive, requisito sanitário essencial. Este capítulo ainda apresenta as contribuições do Programa Nacional de Qualificação da Hemorrede (PNQH) e sua versão estadual, o Programa Estadual de Qualificação da Hemorrede (PEQH) para o desenvolvimento de práticas de gestão eficazes, geradoras de produtos seguros e de qualidade.

No capítulo sobre "A vigilância sanitária e a qualidade na atenção hemoterápica” os autores destacam que a Saúde Pública no Brasil foi impulsionada pela Lei $n^{\circ} 8.080 / 1990$, trazendo a prioridade de formulação e execução de 
uma nova política de sangue para o país e a inclusão das ações de vigilância sanitária no âmbito dos serviços de saúde. Este capítulo enfatiza a função da vigilância sanitária de regular, normatizar, controlar e fiscalizar áreas e atividades críticas inerentes ao ciclo do sangue e seus processos de apoio, bem como, seu objetivo de reduzir riscos relativos à atividade hemoterápica para a população. Os autores também elencam alguns dos mais relevantes atos normativos sanitários na área de sangue a serem considerados no processo de planejamento da Hemorrede e estruturação de serviços de hematologia e hemoterapia.

Os dois capítulos seguintes deste livro enfatizam as escolhas metodológicas empregadas nos cursos em Planejamento e Gestão em Saúde e as experiências vivenciadas a partir do Projeto Planeja Sangue.

No quinto capítulo "Estratégias metodológicas adotadas para os cursos em Planejamento e Gestão em Saúde" estão abordadas as escolhas metodológicas utilizadas no Planeja Sangue em 2015. Neste, constam a produção do Guia para Estudos, como material didático e orientador das atividades propostas, sua estrutura e elementos constituintes, bem como, o desenho adotado para os cursos, ressaltando-se a proposta mista de aprendizagem na qual estão articulados momentos presenciais e momentos à distância. Apresenta a metodologia da problematização como recurso selecionado para dar sustentação ao desafio que envolve o projeto, o conteúdo teórico utilizado como base para o desenvolvimento das competências esperadas dos cursistas, bem como a programação detalhada de cada momento. Ao final, as autoras apresentam um documento orientador para subsidiar a elaboração de propostas preliminares de Plano Diretor das Hemorredes Estaduais.

O sexto capítulo "Notas sobre a implementação dos cursos em Planejamento e Gestão em Saúde e caracterização das Hemorredes estaduais" apresenta uma síntese da experiência da implementação do Planeja Sangue em 2015, abordando a origem do projeto, realizado a partir de cooperação técnica entre o Instituto de Saúde Coletiva e a Coordenação Geral de Sangue e Hemoderivados; também, a estrutura operacional dos cursos, as respectivas escolhas metodológicas, além de dados de caracterização das Hemorredes dos estados da Bahia, Roraima, Mato Grosso, Pernambuco e Paraíba, participantes do projeto em 2015. As autoras concluem o capítulo com algumas considerações acerca das fortalezas observadas no desenvolvimento, as mais 
relevantes oportunidades de melhoria e as perspectivas futuras para o Projeto Planeja Sangue.

Finalmente, o sétimo capítulo "Cursos em Planejamento e Gestão em Saúde: uma proposta de educação permanente em saúde?" propõe aos leitores uma reflexão sobre os "cursos em planejamento e gestão em saúde", apresentados como um dos caminhos para o fortalecimento das Hemorredes. As autoras apresentam elementos conceituais e metodológicos que definem os processos de Educação Permanente em Saúde; destacam a realidade e o cotidiano das práticas como ponto de partida para as mudanças e as competências esperadas a serem desenvolvidas ao longo do processo conforme proposição dos cursos.

Assim, este livro pretende contribuir com a discussão e reflexão sobre Política, Planejamento e Gestão em Saúde, com destaque à experiência do Planeja Sangue como proposta de inovação para o fortalecimento das Hemorredes estaduais no Sistema Único de Saúde (SUS). Convidamos todos(as) à leitura!

Mariluce Karla Bomfim de Souza e colaboradores. 


\title{
Planejamento em saúde: concepções, "tentativas" e desafios para a prática
}

\author{
Ana Angélica Ribeiro de Meneses e Rocha \\ Mariluce Karla Bomfim de Souza
}

\begin{abstract}
Alice: 'Poderia me dizer, por favor, qual o caminho para sair daqui?'

Gato: 'Isso depende muito do lugar para onde você quer ir.' Alice: 'Não me importa muito onde.'

Gato: 'Nesse caso, não importa por qual caminho você vá!' (CARROLL, 2005)
\end{abstract}

\section{Introdução}

Este capítulo aponta aspectos teóricos e históricos que circunscreve as ações de planejamento no Sistema Único de Saúde (SUS), como elemento da gestão. Aborda o papel dos principais atores que fazem parte da arena de disputas que circunscreve a gestão do sistema, as iniciativas pontuais de planejamento em saúde e seus produtos em idas e vindas sucessivas, ao sabor das conjunturas políticas e de cenários variados por todo país. São questões centrais no processo de construção do conhecimento, definição e difusão de metodologias para equipes de planejamento e gestão do SUS.

Embora se aponte avanços no SUS que ajudaram a solucionar problemas no acesso à atenção à saúde e na democratização da gestão (THE LANCET, 2011), sua condução vem exigindo dos seus componentes sempre uma cons- 
trução que envolve diversos contextos, redefinições de funções, atribuições e relações. Esse movimento dialético de construção e reconstrução, de mudanças entre os entes federados que compõem o SUS na forma de pensar, organizar, relacionar e cumprir as funções desenhadas, dentre as quais se situa a construção dos instrumentos de gestão.

Fazendo contraponto do fragmento da obra de Lewis Carroll, ao contrário da improvisação, o planejamento requer um conjunto de ações que devem ser pensadas antecipadamente a fim de direcionar o alcance do(s) objetivo(s) ou meta(s). Segundo Vilasbôas (2004, p. 4) consiste em "desenhar, executar e acompanhar um conjunto de propostas de ação orientado por um propósito com vistas à intervenção sobre um determinado recorte da realidade ou situação". Portanto, o planejamento é "compromisso com a ação". (PAIM, 2006, p. 769)

O planejamento é um caminho de escolha do gestor para a condução das organizações e instituições públicas e privadas. Nesse sentido, o planejamento pode ser entendido como um processo de transformação de uma situação para outra, considerando-se a finalidade, utilizando-se de instrumentos ou meios de trabalho (técnicas e saberes) e atividades (trabalho propriamente dito), e sob determinadas relações sociais inerentes a cada organização. (PAIM, 2006)

Mintzberg (2004), autor que muito discute sobre a gestão e o processo de decisão nas organizações, define o planejamento como um "procedimento formal" para a produção de resultado articulado, que deve ser visto como "esforço de formalizar os processos pelos quais as decisões são tomadas e integradas nas organizações”.

No entanto, o planejamento enquanto prática social - e também técnica, política, econômica e ideológica (PAIM, 2006) - pode se apresentar de "modo estruturado", através de políticas ou propostas de ação e atividades formuladas - planos, programas e projetos, ou de "modo não estruturado" (MATUS, 1996) ou como pensamento estratégico. (TESTA, 1995)

O arcabouço jurídico legal e normativo do SUS coloca o planejamento como responsabilidade gestora e, portanto, direcionadora do processo de gestão que deve compatibilizar as necessidades de saúde com os recursos disponíveis. Desde o ano 1990, a Lei n 8.142 estabelecia responsabilidades gestoras na elaboração do planejamento, bem como seu modo ascendente de 
fazê-lo, e determinava o plano de saúde como requisito para o recebimento de recursos. (BRASIL, 1990)

Toda a década de 1990 foi marcada pelo estímulo ao processo de descentralização, através da publicação de sucessivas normas operacionais, que implicou na

[...] redefinição das funções e responsabilidades de cada nível de governo com relação à condução político-administrativa do sistema de saúde em seu respectivo território (nacional, estadual, municipal), com a transferência, concomitante, de recursos financeiros, humanos e materiais para o controle das instâncias governamentais correspondentes. (TEIXEIRA, 2011, p. 6)

Além do que, a incorporação de metodologias, tecnologias e formulações teóricas influenciaram o desenho macroorganizativo do sistema.

A discussão dos aspectos teóricos e históricos, das concepções e iniciativas subsidia a construção de um projeto de cooperação técnica, capacitação e produção envolvendo a gestão do sangue e hemoderivados (Hemorrede) no Brasil, resultado de parceria entre o Ministério da Saúde e Universidade Federal da Bahia.

\section{A produção teórica e as "tentativas" para institucionalização do planejamento no Brasil}

A existência do Sistema Único de Saúde se deu posteriormente ao desenvolvimento das ideias mais profícuas sobre o planejamento na América Latina e no Brasil, essa situação paradoxal, segundo Rocha (2011), caracteriza-se por uma fase de riqueza teórica com poucas práticas seguida de grande demanda de aplicação prática e pouca absorção das teorias, daí a autora afirma que o planejamento em saúde é uma "questão, eminentemente, prática". O que se encontra, contudo, é uma situação paradoxal. Por um lado, o planejamento, enquanto produto social da ciência política latino-americana provocou movimentos no campo científico e ideológico através de proposições e metodologias potentes; mas, ao mesmo tempo, parece existir uma força contrária ao processo de institucionalização do planejamento, o que leva os seus produ- 
tos a cumprir um papel puramente ritualístico contribuindo para construir "o SUS no papel". (ROCHA, 2008) ${ }^{1}$

Spinelli e Testa (2005) apontam o Brasil como o país que mais produziu reflexões sobre planejamento em saúde nestes últimos 30 anos, em termos de textos publicados. Paim e Teixeira (2006) em balanço do estado da arte em planejamento e gestão assinalam essa área como a que no âmbito da Saúde Coletiva, expressa com mais clareza a dupla dimensão (saber e prática); e, alertam para o fato de que o conhecimento produzido responde a problemas e desafios colocados pelos sujeitos em sua ação política em determinados contextos históricos e que resultam em uma produção de relatos e experiências centradas nos sujeitos das práticas.

Dentre as várias concepções correntes sobre planejamento e gestão podem ser citadas: planejamento como instrumento de gestão, como prática de um processo social ou como ideologia, entre crenças e concepções versus um fazer, ou até numa visão marxista, como forma sublimada de luta de classes. (PAIM, 2002c, p. 27)

Neste sentido, Schraiber (1999, p. 230) aponta que, apesar da rica e bem completa plêiade de proposições de planejamento em saúde na América Latina, chama atenção pelo alto teor prescritivo e com orientações bastante apuradas do agir (em planejamento). O entendimento corrente da ação de planejar confunde-se com a produção de uma peça propositiva (o plano), que contém um projeto - de ação futura, uma proposta para articular outras ações, uma futura organização - formas de gerenciamento do trabalho produtor dos serviços - como uma proposta de condução da gestão de forma racionalizadora. Assim, fica o planejamento com a finalidade de instruir, de construir uma forma planejada de realizar o trabalho em saúde, e cumpre à gestão processar as "instruções" sobre as intervenções em saúde. O planejamento e a gestão, enquanto trabalho em saúde, realizam uma ação estratégica como forma de apoiar as resoluções concretas e particulares que o cotidiano dos serviços demanda.

Testa (1995) critica a tendência funcionalista que define a política como objetivo e a estratégia como o instrumento para alcançá-lo, pela dicotomia en-

1 Reflexões construídas a partir de um o processo etnográfico em quatro anos de gestão estadual, sob forma de estudo de caso da SES/Sergipe realizada pela coautora desse capítulo, Ana Angélica Ribeiro de Meneses e Rocha, sob orientação de Leny Trad cujo produto é uma tese de doutoramento, de 2008. 
tre o "fim" e o "meio". Para o autor, a política pode surgir como estratégia, tal como esta é o instrumento da política, em um diálogo circular, tornando-se um movimento recursivo que não tem princípio nem fim. Outra concepção compreende o uso do planejamento como um "[...] espaço metodológico e tecnicamente compreendido entre o processo de formulação de políticas de saúde e a administração de organizações ou serviços de saúde”. (PAIM, 2002b, p. 149)

Para Uribe Rivera e Artmann (2003) e Uribe Rivera (2003), com base na integração da abordagem do agir comunicativo de Habermas e do planejamento estratégico situacional, o planejamento é visto como um conjunto de práticas que permitam uma gestão por compromissos, um modelo de gestão negociado, de ajustamento mútuo e comunicativo. Nessas bases, o planejamento é uma ferramenta organizacional, um meio de desenhar e acompanhar a execução de proposições destinadas a operacionalizar decisões institucionais, uma ferramenta para condução da ação, porém mediada/subordinada à cultura das organizações como Vilasbôas (2006, p. 18) aponta:

O planejamento tem sido designado como um processo social, um método, uma técnica, uma ferramenta ou tecnologia de gestão, uma mediação entre as diretrizes políticas de uma organização e a subjetividade de seus trabalhadores [...] como um processo de caráter social que tem uma função orientadora no desenvolvimento da humanidade [...] uma prática sócio histórica concreta, parte indivisível da realidade social, que não se restringe à sua natureza instrumental, mediadas por valores, crenças e práticas [...].

Entende-se que as várias concepções ${ }^{2}$ trazem em si a questão de um método e de um sistema organizacional para implementação do propósito desenhado, uma formulação, estruturada ou não, para resolver uma determinada situação. Essa razão instrumental, segundo Campos (2000, p. 724) colocou o planejamento dos anos 1990 em meio a um dilema fundamental: Como fugir do papel controlador, advindo da razão instrumental, sem perder a própria instrumentalidade, não deixando de ter valor de uso?

2 Essas concepções se apóiam em Giordani (1979); Matus (1993); Merhy (1995); Schraiber e colaboradores (1999); Paim (2002c); Campos (2003) e Uribe Rivera e Artmann (2003). 
Diversas racionalidades alimentam as práticas institucionais, e, nesse sentido, pode se considerar que a "planificação enquanto processo social, não se reduz a um método propriamente, mas propicia um cálculo, um raciocínio, um pensamento, um diálogo, enfim, a produção de fatos políticos e sociais". Consequentemente não se encerra num método ou em tecnologias para a ação humana. (PAIM, 2002a, p. 427-428) A emergência, difusão e incorporação do planejamento em saúde na América Latina e no Brasil revelam um processo sócio-científico que procurou superar a visão puramente econômica para um movimento ético-político cuja cadeia de sínteses resulta do desenvolvimento dialético, da passagem do objetivo para o subjetivo, da necessidade para a liberdade. (JESUS, 2006, p. 12)

A Figura 1 a seguir mostra uma linha do tempo na qual se dispõe o desenvolvimento teórico-metodológico das diversas correntes de pensamento no âmbito do planejamento em saúde na América Latina, complementado, pari passu, às iniciativas desencadeadas no processo de construção do SUS.

Figura 1 - Linha do tempo sobre desenvolvimento teórico-conceitual do planejamento em saúde

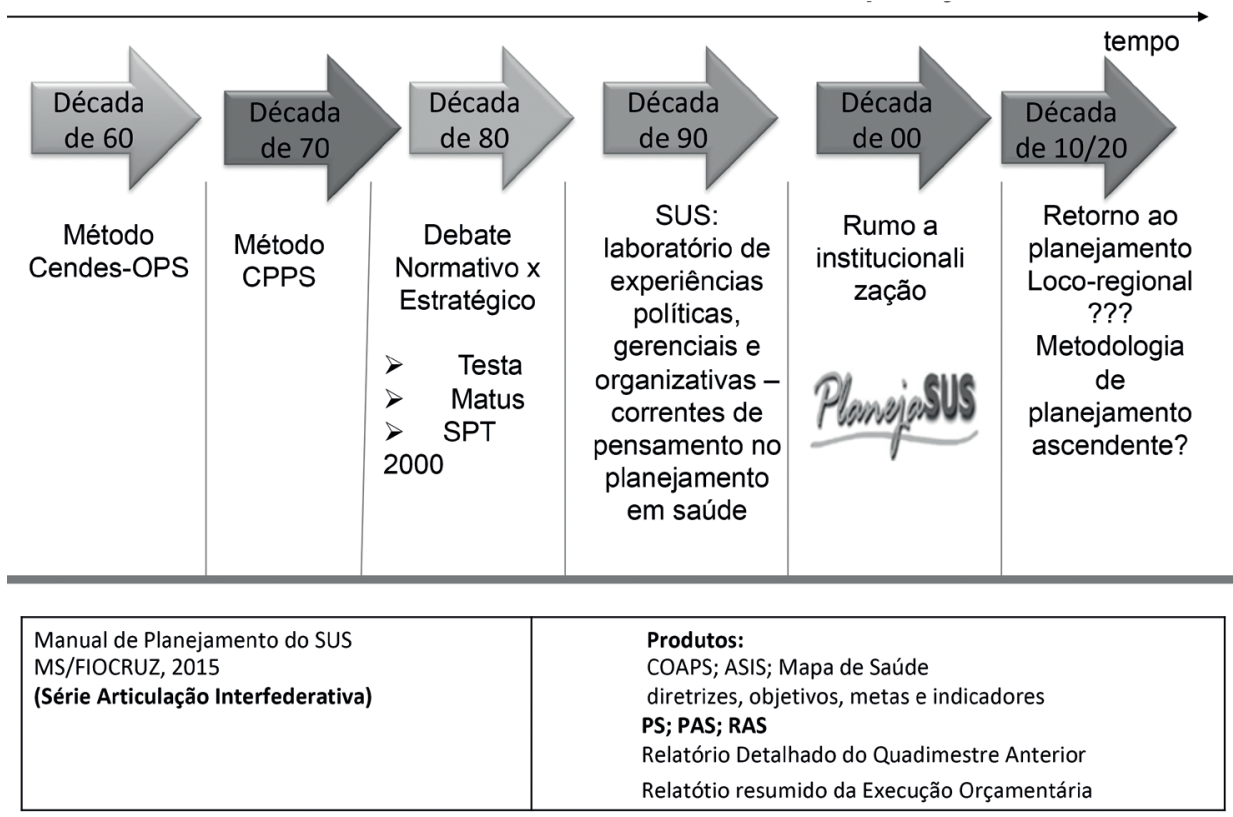

Fonte: adaptada de Teixeira e Rocha (2009). 
Para Luz (2013, p. 83-84) essa produção forma uma história mais ou menos explícita de como o Estado conduz os problemas das condições sanitárias da população, na qual o planejamento sempre aparece, senão como prática, mas ao menos como retórica na linguagem oficial. Cada década e a cada elaboração teórico metodológica aparece produções que as caracterizam como apontam vários autores.

Todas essas formulações se transformam em políticas específicas e implantadas nos espaços de atenção do sistema. Para Lotufo (2003, p. 17) a consecução de projetos intrainstitucionais tende a deflagrar processos que “[...] são espaços de incorporação de propostas de reforma político gerencial e administrativa que implica na adoção de métodos, técnicas e instrumentos de gestão oriundos de diversas correntes de pensamento" e, ressalta ainda que "[...] são introduzidos de forma desordenada, caótica, fragmentada, pontual, sem uma opção institucional explícita - um mix de métodos onde cada um aprende de um jeito e tenta aplicá-los à realidade". Torna-se, então, crucial entender entre políticas induzidas pelo Ministério da Saúde (MS), as funções institucionais em transformação e a forma como essas iniciativas são traduzidas pelos operadores.

Do método Centro de Estudos do Desenvolvimento/Organização Pan-Americana da Saúde (Cendes/OPS) é incorporado a lógica da programação na elaboração de programas, de normas técnicos, critérios de seleção de prioridades, da adequação da oferta e demanda nos espaços local e regional como acontece na construção das programações pactuadas; a proposta pelo Centro Pan-Americano de Planejamento de Saúde (CCPS) traz bases para o reconhecimento do conflito social como ponto de partida para a formulação de políticas sociais e incorpora a análise de viabilidade ao processo de planejamento.

O pensamento de Mario Testa não apresenta uma proposta metodológica estruturada e ordenada, mas incorpora o mapeamento de atores e posições nos diversos âmbitos de poder, importante para análise da dinâmica das organizações.

A formulação de Carlos Matus se constitui uma proposta metodológica denominado de Planejamento Estratégico Situacional (PES) que segundo Uribe Rivera (2003) contribui para pensar, pragmaticamente, o planejamento como gerência descentralizada de problemas abordados criativa e interativa- 
mente. Para Matus, planejar significa pensar antes de atuar, com método, de maneira sistemática; é uma ferramenta para pensar e criar o futuro (HUERTAS, 1994) e planifica quem governa, em um momento presente, através de um cálculo situacional de problemas e oportunidades, sendo inseparável da gestão e é necessariamente política. Dessa forma, o PES corrobora com a ideia que a formulação de políticas dá-se em diversos níveis de governo e âmbitos de gestão e em diversos níveis de abrangência: geral, particular e singular, havendo, assim, uma exigência de formulação de políticas que dêm conta dos problemas de saúde a cada nível de atenção e a cada esfera de governo.

Com a implantação do SUS como aponta o quadro, se abre uma profícua produção do que Teixeira (2006) denomina propostas de mudanças da forma de organizar a assistência. A autora, enfocando as diferenças e confluências, os contextos de origem e fundamentos filosóficos e teóricos, além de conteúdos e micropráticas apontam três modelos correntes:

- "Em defesa da vida", produzido pelo Laboratório de Planejamento (Lapa), originado em Campinas (SP), com a produção de Campos, Merhy e Cecílio que são incorporadas nos espaços de gestão como o Método da Roda e Caixa de Ferramentas, respectivamente. Outras formulações, também, são incorporadas nos espaços de atenção como o acolhimento, criação de vínculos, contratos e o conceito de autonomia, em espaços de micropoderes. São formulações que buscam a organização da demanda e racionalização com a mudança na concepção da população sobre suas necessidades e releitura das necessidades;

- Ações programáticas oriundas da experiência do Centro de Saúde Samuel Pessoa no Butantan (SP) que na década 1970/1980 utiliza a programação como tecnologia, centrada na reorganização do processo de trabalho e no viés ético e de construção de um projeto assistencial comum com trabalho em equipe (Schraiber, Mendes Gonçalves, Ayres, Peduzzi);

- Formulação e implementação de políticas como a promoção da saúde - como a proposta das cidades saudáveis, da Vigilância à Saúde e Saúde da Família. No caso da Vigilância à Saúde e organização dos territórios (Mendes, Teixeira, Vilasbôas, Paim) resultante da 
experiência do Distrito de Pau da Lima, Salvador (BA) junto com a Cooperação Italiana, Organização Pan-americana de Saúde (OPAS). Essa formulação considera o território como espaço vivo - apoiado no pensamento de Milton Santos, geógrafo baiano - nos seus diversos aspectos - administrativo, sanitário, epidemiológico - como um mosaico cultural e político. Procura superar a estrutura piramidal da rede de ofertas tendo a unidade básica de saúde e sua equipe como a grande ordenadora do cuidado nos espaços urbanos e rurais desse país em busca da integralidade e equidade do sistema. Por último, se tem a formulação da construção das Redes de Atenção à Saúde (RAS) proposta por Mendes (2011) posta na arena de disputas teóricas metodológicas do SUS, em curso em vários estados do Brasil sob a égide do Conselho Nacional de Secretários de Saúde (Conass), Secretarias Estaduais de Saúde (SES) e municípios.

\section{A importância dos atores no processo de planejamento em sqúde}

Para Matus (1993, 1996), o ator social pode ser uma pessoa ou coletivo cuja atuação pode transformar uma determinada situação, sendo fundamental, portanto, que tenha um projeto de intervenção, capacidade de mobilizar recursos necessários e o mínimo de organização para a execução do plano. Desse modo, o envolvimento de atores de distintos setores sociais se faz necessário para a elaboração de um planejamento baseado no processo participativo, o qual contemplará diferentes e diversas demandas, propostas e estratégias de intervenção e solução aos problemas priorizados.

É evidente que o processo de planejamento que envolve distintos atores também pode gerar conflitos, cooperação e consensos, sendo o uso da negociação essencial para isso. De acordo com Uribe Rivera e Artmann (1999), a negociação na perspectiva de lidar com conflitos para gerar a cooperação e o consenso é um recurso ideativo, criativo, interdisciplinar e de geração de múltiplas opções de ganho mútuo. O uso da negociação possibilita legitimidade e viabilidade política ao plano, pela participação e implicação dos atores na discussão. Nesse sentido, o planejamento caracteriza-se como ação política e a instituição responsável pela ação, é um sujeito social cujas "característi- 
cas estão enraizadas em sua própria história e lhe dão potência para realizar tarefas que, por sua vez, são construtores da história". (URIBE RIVERA; ARTMANN, 1999, p. 23) Essa construção ou consolidação é um aspecto abordado por Testa como a "constituição dos sujeitos sociais (coletivos)", uma instituição que precisa superar seus limites e assumir novos projetos como sujeito coletivo. (ROCHA, 2008, p. 30)

No caso do SUS são identificados atores coletivos que, por força de todo arcabouço jurídico, legal e normativo tem a obrigação de planejar: o Ministério da Saúde, e as secretarias estaduais/municipais de Sáude. Aporta-se a estes, atores como universidades, centros de pesquisa, assessorias públicas e privadas, consultores (ROCHA, 2011, p. 9) que fornecem um "saber fazer" nos momentos de construção dos produtos de planejamento ou instrumentos de gestão.

$\mathrm{Na}$ perspectiva do planejamento estratégico, o ator que planeja está dentro da realidade, coexiste com os demais que também planejam, e é importante aqui, ressaltar o sentido matusiano de ator social, referido por Artmann (1993, p. 13, grifo nosso):

O ator social é uma organização e no seu extremo, uma personalidade que cumpre os seguintes requisitos: tem um projeto, ainda que incoerente; controla algum recurso relevante para o jogo situacional, tem capacidade para acumular e desacumular força e, portanto, tem capacidade para produzir fatos no jogo social; participa de algum jogo parcial ou no grande jogo social; tem organização estável que lhe permite atuar com o peso de um coletivo coerente ou, no caso de uma personalidade, tem uma presença no sistema que lhe permite conquistar com suas ideias um coletivo social. Matus distingue esta categoria de outras que se referem a agrupações humanas, como agente, extrato social ou multidão.

No que tange a esfera estadual, em estudo de caso sobre planejamento e gestão na esfera estadual, Rocha (2008) ressalta que no cenário da Norma Operacional Básica do Sistema Único de Saúde (Nobsus)/96, Norma Operacional da Assistência à Saúde (NOAS) e do Pacto pela Saúde, os próprios secretários estaduais reconheciam que suas instituições viviam "situações difíceis", que alguns não hesitavam em caracterizar como crítica. Segundo relatórios de uma série de eventos promovidos pelo Ministério da Saúde (MS) e do Conselho 
Nacional dos Secretários Estaduais de Saúde (CONSELHO NACIONAL DE SECRETÁRIOS DE SAÚDE, 2007) no qual são citados velhos e novos problemas, no que diz respeito à capacidade gestora do sistema, podem ser destacados dois blocos de questões: o primeiro grupo de problema diz respeito às questões de definição de papéis e responsabilidades nas três esferas de governo e às dificuldades das relações, que refletem tensões e disputas entre as instâncias executivas e o aparato de controle social; o outro grupo de problemas que afetam as funções de gestão é composto por: a gestão não profissionalizada, aliada à alta rotatividade e ao despreparo dos dirigentes, a fragilidade das estruturas institucionais para análise e avaliação, os modelo de planejamento assistemáti$\mathrm{co}^{3}$ e a inadequação dos instrumentos de acompanhamento e avaliação.

Com base nos desafios apontados pode-se deduzir que a redefinição do papel dos gestores estaduais se constitui uma das tarefas mais importantes para a consolidação do SUS. Com efeito, parece que a solução de muitos desses problemas relacionados passa, necessariamente, por uma atuação eficaz da condução do sistema estadual, porém as SES entram em uma "crise de identidade", entre o papel histórico de prestadores de saúde que devem deixar de ser e o novo papel de gestores intermediários que devem assumir para os avanços exigidos na construção do SUS. (LOTUFO, 2003; ROCHA, 2008; SALDANHA, 2003)

A "crise de identidade das SES" foi estudada por Saldanha (2003), no sentido de entender por que essas instituições têm dificuldade de superar o papel desenhado ao longo de sua criação histórica. A autora utiliza o esquema explicativo de Hinings e Grenwood, segundo o qual os membros de uma instituição completam o desenho do organograma formal, desprezando ou preenchendo as estruturas através de um processo diário de interações emergentes e não formalmente descritas.

Essa ação é mediada por crenças e valores, ideias e significados distribuídos na instituição. As articulações entre as estruturas e o sistema de gestão formam o que os autores chamam de arquétipo, ou seja, uma série de estruturas e sistemas formais e informais cuja coerência é assegurada por associa-

3 O termo assistemático parece ser referido à forma pontual e desconectada como os instrumentos legais de gestão são produzidos, porém não é o mesmo que improvisação. Para Matus (1993, p. 55), o planejamento, como expressão tecnológica, pode assumir um formato estruturado definindo ao ser regulamentado por procedimentos práticos normatizados, ou um formato não estruturado (cálculo estratégico) sem requisitos de formalidade. (VILASBÔAS, 2006) 
ções de ideias, valores e crenças ou esquemas explicativos. De acordo com a capacidade de traduzir seus interesses em arranjos organizacionais, decorrentes de diferentes graus de poder, os grupos dominantes defendem esquemas explicativos e estruturas prevalentes, resultando em espaços de adaptação, alteração ou disputas. No caso das Secretaria de Estado de Saúde (SES), elas se vêm mantendo em um arquétipo de prestadora de serviços criando dificuldades institucionais, uma incapacidade ou resistência em mudar os seus processos internos, quando ainda agem de forma conflitante, e a tendência da SES é ver os municípios como concorrentes, num processo de competição negativa, o que não favorece as suas atividades de gestão.

O que foi percebido como o novo papel das secretarias estaduais de saúde está, em princípio, bem delineado pelo conjunto daquilo que se vem chamando de macrofunções das SES, a partir da tese de doutorado de Lavras (2003), que descreve aspectos centrais a respeito do processo de trabalho desenvolvidos ou que deveriam ser desenvolvidos nessas instituições, conforme quadro a seguir.

Quadro 1 - Atribuições, macrofunções e macroprocessos de trabalho das SES

\begin{tabular}{|c|c|c|}
\hline Atribuições & Macrofunções & Macroprocessos de trabalho \\
\hline $\begin{array}{l}\text { - Planejar e formular estratégias, } \\
\text { planos, programas e projetos } \\
\text { em saúde. } \\
\text { - Normatizar, regulamentar, } \\
\text { acompanhar e avaliar o sistema } \\
\text { estadual de saúde. } \\
\text { - Contribuir com o } \\
\text { desenvolvimento de Recurso } \\
\text { Humano (RH) em saúde. } \\
\text { - Promover o desenvolvimento } \\
\text { científico e tecnológico em } \\
\text { saúde. } \\
\text { No âmbito específico do SUS: } \\
\text { - Cooperar tecnicamente com os } \\
\text { municípios; } \\
\text { - Promover articulação regional; } \\
\text { - Gerenciar e executar } \\
\text { ações e serviços de saúde } \\
\text { supramunicipal ou suplementar; } \\
\text { - Participar do financiamento; } \\
\text { - Participar do provimento da } \\
\text { infraestrutura. }\end{array}$ & $\begin{array}{l}\text { - Formulação de políticas, planos, } \\
\text { - programas e projetos em saúde; } \\
\text { - Desenvolvimento de ações e } \\
\text { serviços de saúde; } \\
\text { - Regulação do Sistema Estadual } \\
\text { de Saúde; } \\
\text { - Financiamento e administração } \\
\text { de recursos; } \\
\text { - Gerenciamento institucional. }\end{array}$ & $\begin{array}{l}\text { - Planejamento e gestão interna da } \\
\text { SES; } \\
\text { - Desenvolvimento da assistência à } \\
\text { saúde no SUS; } \\
\text { - Desenvolvimento de projetos e } \\
\text { atividades de vigilância sanitária e } \\
\text { meio ambiente; } \\
\text { - Desenvolvimento de projetos } \\
\text { e atividades de vigilância } \\
\text { epidemiológica; } \\
\text { - Controle, avaliação e auditoria do } \\
\text { Sistema Estadual de Saúde; } \\
\text { - Programação em saúde; } \\
\text { - Gestão da informação em saúde; } \\
\text { - Desenvolvimento da Comunicação } \\
\text { Social em saúde; } \\
\text { - Gestão e Recursos Humanos em } \\
\text { saúde; } \\
\text { - Administração geral; } \\
\text { - Administração financeira; } \\
\text { - Desenvolvimento de projetos } \\
\text { estratégicos de natureza diversa. }\end{array}$ \\
\hline
\end{tabular}

Fonte: Lavras (2003, p. 66). 
Outra formulação diz respeito as Funções Essenciais da Saúde Pública (FESP) entendidas como atribuições indispensáveis a serem exercidas pelos órgãos gestores da saúde a fim de permitirem melhorar o desempenho das práticas de saúde por meio do fortalecimento das suas capacidades institucionais e identificadas como cruciais para a prática da saúde pública nos países. (CONSELHO NACIONAL DE SECRETÁRIOS DE SAÚDE, 2007)

Quadro 2 - Descrição das funções especiais de saúde pública

\begin{tabular}{|c|l|}
\hline Função Essencial & Descrição \\
\hline$N^{0} 1$ & Monitoramento, análise e avaliação da situação de saúde da população \\
\hline$N^{0} 2$ & Vigilância, investigação e controle dos riscos e danos na saúde pública \\
\hline$N^{0} 3$ & Promoção da saúde \\
\hline$N^{0} 4$ & Participação dos cidadãos na saúde \\
\hline$N^{0} 5$ & $\begin{array}{l}\text { Desenvolvimento de políticas e capacidade institucional de planificação e gestão em saúde } \\
\text { pública }\end{array}$ \\
\hline$N^{0} 6$ & Fortalecimento da capacidade institucional de regulação e fiscalização em saúde pública \\
\hline$N^{0} 7$ & Avaliação e promoção ao acesso equitativo da população aos serviços de saúde necessários \\
\hline$N^{0} 8$ & Desenvolvimento de recursos humanos e capacitação em saúde pública \\
\hline$N^{0} 9$ & Garantia a melhoria de qualidade dos serviços de saúde individuais e coletivos \\
\hline$N^{0} 10$ & $\begin{array}{l}\text { Investigação essencial para o desenvolvimento e implementação de soluç̃̃es inovadoras em } \\
\text { saúde pública }\end{array}$ \\
\hline$N^{0} 11$ & Redução do impacto de emergências e desastres em saúde \\
\hline
\end{tabular}

Fonte: Conselho Nacional de Secretários de Saúde [2007).

Essas concepções contribuem com a definição do papel e atribuições da gestão estadual do SUS, porém, trazem duas questões: as condições das SES como instituições e os processos de planejamento e gestão necessários para assumir os novos papéis. As SES apresentam uma estrutura básica (organograma) complexa, mecanismos sofisticados de operação e múltiplos mecanismos de coordenação e decisão, uma rede articulada de forma orgânica, um espaço de exercício de tipos distintos de poder: técnico, administrativo e político. Ao se afastarem da função de prestadora de serviço, as SES se aproximam da figura de uma instituição responsável pela criação do conhecimento, ou seja, de apresentar produtos que as institui como lócus de uma "inteligência sanitária", com o compromisso de avaliar os serviços prestados e os necessários para a população. Entre os dois papéis ou na indefinição 
institucional, a obra citada, de Rocha (2008), ressalta alguns dos pontos que foram perseguidos desde a concepção do projeto de criação de uma agenda estadual:

- Normatização de um método de trabalho de planejamento como forma de ampliar as acumulações de conhecimentos e práticas sobre o processo saúde e doença - método baseado na participação e construção coletiva;

- Identificação e discussão das diversas racionalidades presentes no governo e sua determinação na capacidade de alcançar propósitos de mudanças - responsabilização no enfrentamento dos problemas com base nas necessidades da população e do sistema de saúde;

- Ampliação do estoque de poder, através do conhecimento e racionalidades acumulados (TESTA, 2004 apud ROCHA, 2008), deslocado da esfera central para a esfera regional - ampliando a representatividade nos fóruns de discussão com a agregação de todos os envolvidos nos problemas;

- Criação de compromissos regionais com um novo valor de uso e um novo valor social para o espaço regional - ampliar a responsabilização;

- Fortalecimento dos atores regionais, a partir da criação de um projeto comum e defesa da agenda regional - ações de pertinência e emponderamento dos operadores nos territórios.

No âmbito municipal, estudo desenvolvido por Souza e Teixeira (2013) apresenta uma proposta de instrumento para autoavaliação da gestão do SUS no âmbito municipal - Funções da Gestão Municipal (FGM) do SUS ${ }^{4}$ - a partir da revisão e redefinição do conteúdo do instrumento de autoavaliação

4 São funções da gestão municipal: FGM/SUS n 1: Análise da situação/estado de saúde do município da população do município ou avaliação da situação de saúde do município; FGM/ SUS ${ }^{\circ} 2$ 2: Promoção, educação e comunicação em saúde; FGM/SUS n ${ }^{\circ}$ 3: Coordenação e execução das ações da vigilância em saúde para a identificação precoce e o controle de doenças/ agravos, riscos e danos à saúde; FGM/SUS n ${ }^{\circ}$ 4: Emergências em saúde pública e proteção e promoção da saúde de grupos com riscos e necessidades especiais; FGM/SUS nº 5: Promoção 
das Funções Essenciais da Saúde Pública (CONSELHO NACIONAL DE SECRETÁRIOS DE SAÚDE, 2007; ORGANIZACIÓN PANAMERICANA DE LA SALUD, 2002), à luz dos princípios e diretrizes do Pacto de Gestão (BRASIL, 2006a) e da reflexão de Noronha, Lima e Machado (2005) sobre as funções e competências das instâncias gestoras do SUS. O conjunto das 15 funções com as respectivas perguntas foi validado através de consulta a especialistas (gestores e pesquisadores) mediante a técnica de "conferência de consenso". (SOUZA; SILVA; HARTZ, 2005)

Com destaque à FGM/SUS nº 6: Desenvolvimento de políticas e capacidade institucional de planejamento e programação em saúde, esta foi definida como capacidade de condução do processo de formulação de objetivos estratégicos, metas, propostas de ação e respostas coletivas às necessidades sociais, com execução e intervenção sobre determinado problema, requerendo para tal estudos e propostas metodológicas coerentes com a análise da situação de saúde, o desenho da situação desejável que se pretende alcançar, a definição dos cenários prováveis nos quais se estará atuando, a formulação dos objetivos em função dos problemas priorizados, o desenho das estratégias - "definição das linhas de ação" -, a análise de coerência (interna e externa) dessas proposições, a factibilidade e viabilidade das intervenções e a programação, acompanhamento e avaliação dos planos e dos programas de ação mediante a definição do uso de indicadores para determinar o alcance do processo de implementação das ações a serem realizadas, bem como o orçamento previsto para a execução destas no âmbito do SUS municipal. (CONSELHO NACIONAL DE SECRETÁRIOS DE SAÚDE, 2007; TEIXEIRA, 2001)

A descrição desta função remete a necessária habilidade, perícia e capacidade técnica, administrativa e política do gestor para o desenvolvimento

e garantia da oferta/prestação direta e acesso universal e equitativo às ações e aos serviços de saúde de qualidade; FGM/SUS n ${ }^{\circ}$ 6: Desenvolvimento de políticas e capacidade institucional de planejamento e programação em saúde; FGM/SUS nº 7: Acompanhamento (coordenação e execução) e avaliação dos serviços e ações da atenção básica; FGM/SUS nº 8: Gestão pública do sistema de saúde e gerência dos serviços de saúde; FGM/SUS nº 9: Coordenação, negociação, regulação, controle, avaliação e auditoria de ações, bens e serviços e do sistema de saúde; FGM/SUS n ${ }^{\circ}$ 10: Gestão do trabalho e formação e desenvolvimento de recursos humanos/pessoas para o SUS; FGM/SUS $n^{\circ} 11$ : Pesquisa científica, inovação e incorporação tecnológica em saúde; FGM/SUS n ${ }^{\circ}$ 12: Financiamento em saúde; FGM/SUS ${ }^{\circ} 13$ : Processo de descentralização e fortalecimento da municipalização; FGM/SUS no 14: Participação e controle social em saúde; FGM/SUS n ${ }^{\circ} 15$ : Cooperação intermunicipal para o fortalecimento do processo de regionalização. (SOUZA; TEIXEIRA, 2013) 
do processo de planejamento. Se utilizado, tal instrumento de autoavaliação poderia ser uma ferramenta útil para a identificação de eventuais fragilidades no processo de gestão do sistema de saúde, podendo contribuir para institucionalização de práticas de planejamento e fortalecimento da autonomia daqueles na busca de soluções aos problemas que enfrentam no cotidiano do processo de construção do SUS.

Cabe aqui uma reflexão como a esfera federal do Governo assume o papel indutor de política colocando-se na posição de "núcleo ideológico" agente de mudanças, muitas vezes a partir de prescrição de agentes internacionais. (PAIM, 2002c, p. 32) Assim foi quando procurou identificar os principais problemas e auxiliar na transformação da situação, com vista às necessidades de descentralização e gestão, deu início, em junho de 2001, a um projeto de fortalecimento e apoio ao desenvolvimento da gestão estadual do SUS, sob a responsabilidade da Secretaria de Políticas de Saúde do Ministério da Saúde. O projeto teria entre seus objetivos

[...] ordenar, aprofundar teoricamente e sistematizar conceitos e idéias à respeito do desenvolvimento da política de saúde no Brasil e, em particular, dos processos de mudança em curso no âmbito institucional das Secretarias de Estado da Saúde". (LAVRAS, 2003, p. 13)

Após a NOAS, outras "tentativas" ministeriais foram induzidas aos gestores estaduais e municipais, como a proposta de um Sistema de Planejamento do Sistema Único de Saúde apresentada pelo Pacto de Gestão, que trouxe o planejamento como diretriz e o considera, enquanto processo a ser desenvolvido de forma articulada, integrada e solidária entre as três esferas de gestão.

A necessidade de organização de um sistema de planejamento do Sistema Único de Saúde ficou explicitada durante o processo de formulação do Plano Nacional de Saúde (PNS) 2004-2007, conduzido pela Subsecretaria de Planejamento e Orçamento da Secretaria Executiva do Ministério da Saúde mais especificamente por ocasião da discussão da gestão, monitoramento e avaliação do plano, por um grupo consultivo ad hoc, mobilizado pela Secretaria Técnica da Rede Interagencial de Informação para a Saúde (Ripsa). 
Assim, a fragilidade exposta no processo foi transformada em proposta de intervenção, de caráter coletivo, com a realização de oficinas para construção das bases organizativas e conceituais de forma coletiva com as secretarias estaduais e municipais de saúde, com representações do Conselho Nacional dos Secretários Estaduais de Saúde (Conass); do Conselho Nacional de Secretários Municipais (Conasems) além dos órgãos e entidades do próprio Ministério da Saúde, da Organização Pan-americana de Saúde (OPAS) e do Ministério do Planejamento, Orçamento e Gestão (MPOG). Os produtos das Oficinas, apresentadas sob a forma de propostas e subsídios às discussões e definições, aliadas a contribuições de pesquisadores e especialistas da área da Saúde Coletiva foram publicadas e difundidas em todo país. (BRASIL, 2009)

As experiências de conformação do Pacto pela Saúde (BRASIL, 2006a) representaram uma tentativa de avanços normativos do SUS, passando da visão de considerar estados e municípios como meros prestadores de serviço, à assunção do seu papel como gestor na condição de ente federado. Entre os principais objetivos do pacto se insere a necessidade de implementar, difundir a cultura de planejamento e de formular metodologias e modelos de instrumentos básicos do processo de planejamento, através da criação de um sistema de planejamento integrado, solidário, ascendente.

A Portaria $\mathrm{n}^{\circ} 3.085$ de $1^{\circ}$ de dezembro de 2006, que regulamenta o sistema de planejamento do SUS, determina que são os instrumentos básicos resultantes do processo de planejamento nas três esferas de gestão do SUS: o plano de saúde, a programação anula de saúde e o relatório anual de gestão, compatíveis com os respectivos Planos Plurianuais (PPA), a Lei de Diretrizes Orçamentárias (LDO) e a Lei Orçamentária Anual (LOA), conforme dispositivos constitucionais acerca destes instrumentos. (BRASIL, 2006b) Outras iniciativas podem ser citadas: realização de pesquisa nacional sobre atividade de planejamento nas três esferas administrativas visando a consolidação de informações que permitissem o conhecimento da estrutura disponível e da sua inserção no processo de gestão do SUS; descentralização de recursos financeiros e um processo de capacitação com cursos de curta duração ministrados em todas as unidades federadas.

Nesse contexto, o Instituto de Saúde Coletiva da Universidade Federal da Bahia (ISC/UFBA) conduz o projeto de capacitação do PlanejaSUS realizando cursos de curta duração em 27 estados brasileiros abrangendo profissionais 
das três esferas de governo envolvendo mais de 1.300 pessoas; também titulou especialistas em estados das regiões: Norte (Tocantins, Amapá), Sudoeste (Minas Gerais), Nordeste (Rio Grande do Norte, Paraíba, Pernambuco, Alagoas, Sergipe, Bahia) e Centro Oeste (Mato Grosso do Sul, Distrito Federal). O projeto que contemplaria os demais estados da federação ficou a cargo de outra Instituição de Ensino Superior (IES) e não se concretizou. Foi realizada a segunda pesquisa nacional e estudo de casos múltiplos para averiguar o alcance do PlanejaSUS, mas o projeto de construção do planejamento do sistema deixa de ser do interesse do Ministério da Saúde (MS), os resultados não são publicados, o movimento se esvazia nos anos subsequentes ficando um vácuo na condução do planejamento do sistema. Posteriormente, o ISC/ UFBA oferta cursos de Planejamento e Gestão de Sistema e Serviços de Saúde voltados para o fortalecimento das Hemorredes Estaduais.

O Decreto $n^{\circ} 7.508$ de 28 de junho de 2011 corrobora com as características do processo de planejamento da saúde, ascendente e integrado, do nível local até o federal, ouvidos os respectivos Conselhos de Saúde. Em dezembro de 2015 o MS publica o Manual de Planejamento criando outros instrumentos além do Plano de Saúde, Programação Anual de Saúde e Relatório Anual de Gestão sob a égide de colaboração com a Fiocruz. (BRASIL, 2011) A ênfase dos processos de planejamento avança para o espaço regional e o coloca como elemento central da pactuacão e responsabilização. Embora, a descentralização tenha se constituído ao lado da regionalização como diretriz e princípio organizativo do SUS, respectivamente, os movimentos para sua institucionalização se deram em momentos diferentes, pós-anos 2000, estimulada pela Norma Operacional da Assistência à Saúde (NOAS 2001/02), ganhando impulso com o Pacto de Gestão, em 2006, e, recentemente, com o Decreto $n^{\circ} 7.508$ de 2011.

Se a NOAS considerou a regionalização como principal "estratégia” para a descentralização do sistema e organização dos serviços de saúde, e destacou, dentre outras coisas, a concepção, a implantação e o monitoramento do Plano Diretor de Regionalização e do Plano Diretor de Investimento como instrumentos de planejamento (BRASIL, 2001, 2002), o Pacto pela Gestão, enquanto dimensão do Pacto pela Saúde, enfatiza, dentre outras diretrizes, a regionalização e o planejamento. (BRASIL, 2006a) O pacto apresenta a regionalização como processo de organização das ações e serviços de saúde numa determi- 
nada região, visando a universalidade do acesso, a equidade, a integralidade e resolutividade, voltada a construção de uma rede regionalizada de atenção à saúde. No entanto, diante da diversidade locorregional e operativa, propõe o planejamento regional e a instituição de mecanismos de cogestão para promover a organização das regiões sanitárias. (BRASIL, 2006a)

O Decreto $\mathrm{n}^{\circ} 7.508$ reafirma a regionalização enquanto princípio organizativo para o SUS com atenção em rede, destacando a região de saúde como espaço geográfico constituído por municípios agrupados com o fim de integrar a organização, bem como o planejamento e a execução de suas ações e serviços de saúde. Com ênfase também no planejamento regional, o documento afirma a sua importância para a ampliação do acesso e da oferta de ações em saúde e indica a constituição do Contrato Organizativo da Ação Pública de Saúde (COAP). (BRASIL, 2011) Tal contrato caracterizaria um acordo de colaboração entre os entes para a organização da rede de atenção, de modo que deveria integrar os planos de saúde dos entes que constituíssem tal rede; “deveria” porque até o primeiro semestre de 2015, quatro anos após a publicação do decreto, efetivamente nenhum COAP está firmado, embora alguns estados como o Mato Grosso do Sul e o Ceará tivessem "tentado" aderir a tal contrato.

Embora os documentos mais recentes apontem para a necessidade de integração e a articulação interfederativa dos entes na região, este se constitui como importante desafio, segundo Vieira (2009), além da inadiável institucionalização do planejamento. Ademais, o crescente subfinanciamento (SOARES; SANTOS, 2014), a ausência de cultura de planejamento e de cooperação solidária entre os entes federativos, a baixa governança regional e a dificuldade de acesso tanto pela falta de serviços, quanto pelas distâncias regionais (LEITE; LIMA; VASCONCELOS, 2012) integram a lista de desafios para a operacionalização do SUS que assegure a atenção integral e universal. (FREIRE, 2015)

Freire (2015) em seu projeto de dissertação de mestrado sobre o processo de planejamento em uma região de saúde de um estado do Norte do país levantou a partir de bases online (2000-2014), estudos e experiências sobre planejamento e gestão em diversos estados brasileiros (ASSUNÇÃO, 2013; BOTTI et al., 2013; CARNEIRO; FORSTER; FERREIRA, 2014; JESUS; TEIXEIRA, 2014; LACERDA et al., 2012; LIMA; LOPES, 2007; LOTUFO; MIRANDA, 2007; ROCHA, 2008; SARTI et al., 2012; SORIA GALVARRO et al., 2012; TEIXEIRA, 
2010; URIBE RIVERA, 2006; VIANNA et al., 2007) apontando como principais resultados o avanço do planejamento como ferramenta integradora diante da pluralidade e multicentricidade da saúde e os desafios relativos a implementação e manutenção de uma cultura de planejamento ascendente na gestão e de políticas públicas integradoras, ao subfinanciamento das ações e as desigualdades locorregionais. (FREIRE, 2015)

Assim como a regionalização precisa ser, sobretudo, um processo político que lida com a diversidade do próprio SUS e coerente com as diversidades das regiões do Brasil, o planejamento de igual forma é também complexo, necessitando análise, compreensão e engajamento político e institucional. No espaço organizativo regional, uma proposta de formalizar um enfoque de planejamento criativo e solidário tem como aposta o estabelecimento de novas relações internas no espaço regional de governança, a partir da comunicação/ articulação entre os atores sociais, prevista no projeto de intervenção, o qual se articula com elementos do campo teórico para favorecer a delimitação e apropriação desse espaço pelos atores regionais. (LIMA et al., 2012)

\section{O papel e os desafios de instituições: considerações finais}

Parte-se do pressuposto que o planejamento é uma ação social que se estabelece através de um cálculo sistemático apresentando como requisito a "existência de corpos ideológicos, teóricos e metodológicos que apoiam o cálculo que precede e preside a ação” procurando imprimir coerência e racionalidades particulares à ação; consequentemente, a sistematicidade diferencia o planejamento da improvisação. (MATUS, 1993, p. 55)

Em contexto de tomada de decisão negociada, como acontece no Sistema Único de Saúde, é necessário que se analise, explique e aprecie a realidade, a partir da visão de vários interessados e que estão imersos na situação concreta que precisam transformar. (ROCHA, 2008) Para isso, é necessário compreendê-los a partir dos aspectos políticos, econômicos e ideológicos-culturais da ação do homem na sociedade. (ARTMANN, 1993) Essa função exige novos aspectos institucionais, outra organicidade, a criação de uma rede de compromissos e responsabilidades com objetivos institucionais redefinidos. (TESTA, 2002, p. 17) 
Na pertinência de que o ambiente pressiona a instituição por outros processos de trabalho se cria um novo valor de uso e um novo valor social. É uma ação que se constrói como viável, sendo iniciada como um projeto, uma motivação e para um futuro. Ou seja, o "motivo para" (diferente das razões históricas originais que a sustentam) e um "motivo porque" (as raízes da motivação para formular em definitivo esse projeto particular). (SCHUTZ, 1993 apud TESTA, 2002, p. 22)

Neste sentido, a instituição responsável pela ação é um sujeito social cujas “[...] características estão enraizadas em sua própria história e lhe dão potência para realizar tarefas que, por sua vez, são construtores da história”. (SCHUTZ, 1993 apud TESTA, 2002, p. 23) Essa construção ou consolidação é um aspecto abordado por Testa como a "constituição dos sujeitos sociais (coletivos)", ou seja, uma instituição que precisa superar seus limites e assumir novos projetos como sujeito coletivo. O planejamento exige acumulação técnica, estoque de conhecimento, liderança na condução da gestão, dependendo do que é disponível dentro da instituição, mesmo em situações ou cenários desfavoráveis, em situação de escassez, existem iniciativas de planejamento correntes no cotidiano da organização que podem ser assistemáticas ou utilizadas para vencer resistências, diminuir a fragmentação institucional e tentar criar uma agenda ou propósito comum. (ROCHA, 2008; VILASBÔAS, 2006)

No caso concreto de planejamento da Hemorrede, objeto dessa obra, foi articulado um projeto usando a experiência acumulada entre atores construindo um projeto comum: no âmbito nacional pela Coordenação Geral de Sangue e Hemoderivados do Ministério da Saúde: como Instituição de Ensino, o ISC/UFBA apoiado na acumulação na Saúde Coletiva. Destaca-se a produção de diversos capítulos de livros, artigos, dissertações e teses que articulam Planejamento \& Gestão; alianças entre instituições das esferas federais, estaduais e municipais, em projetos de cooperação técnica e capacitação - PlanejaSUS, formação de especialistas da região norte e mestrado profissional para profissionais da Hemorrede de todo país. O objetivo foi agrupar atores envolvidos na produção de sangue e hemoderivados e do cuidado de portadores de doenças hematológicas na esfera estadual, em momentos de capacitação e momentos de articulação com o objetivo de construir o esboço do Plano Diretor do Sangue dos Estados do Brasil. A acumulação institucional dos operadores foi capaz de refinar uma proposta, o Planeja Sangue, que ar- 
ticula esferas de governo - federal, estadual e municipal -, diversos níveis de atenção - dos hemocentros coordenadores até as agencias transfusionais em alguns momentos -, setores de vigilância, planejamento e avaliação (da esfera estadual), prestadores públicos e privados e representantes da gestão social (conselheiros de saúde).

Estabelece-se aqui uma concordância com os autores que servem de referência: discutir planejamento é discutir política e, discutindo política, se discute ideologia, filosofia, ou pelo menos, concepções filosófico-conceituais que parecem está sempre em processo de superação (JESUS, 2006); e o planejamento, em suas distintas racionalidades, tem o papel de orientação da ação humana dirigida para o alcance de uma dada finalidade - uma ação social. (VILASBÔAS, 2006) Agrupar esses atores em momentos de aprendizagem e introspecção sobre a realidade vivenciada pode ser o início de um movimento de análise, proposição e tomada de decisão para consolidação da Hemorrede, um que tem a dupla função de ser produtora de insumos para a rede de atenção (sangue e hemoderivados) e como produtora de cuidado para populações afetadas por patologias muitas vezes negligenciadas.

\section{Referências}

ARTMANN, E. O planejamento estratégico situacional: a trilogia matusiana e uma proposta para o nível local de saúde (uma abordagem comunicativa). 1993. 228 f. Dissertação (Mestrado em Saúde Pública) - Fundação Oswaldo Cruz, Rio de Janeiro, 1993.

ASSUNÇÃO, M. A. P. de. Estudo sobre a implantação da gestão regional de saúde no Vale do Peixoto na Amazônia mato-grossense. 2013. 143 f. Dissertação (Mestrado em Saúde Coletiva) - Instituto de Saúde Coletiva, Universidade Federal da Bahia, Salvador, 2013

BOTTI, C. S. et al. Regionalização dos serviços de saúde em Mato Grosso: um estudo de caso da implantação do Consórcio Intermunicipal de Saúde da Região do Teles Pires, no período de 2000 a 2008. Epidemiologia e Serviços de Saúde, Brasília, DF, v. 22, n. 3, p. 491-500, jul./set. 2013.

BRASIL. Decreto 7.508, de 28 de junho de 2011. Regulamenta a Lei ${ }^{\circ} 8.080$, de 19 de setembro de 1990, para dispor sobre a organização do Sistema Único de Saúde - SUS, o planejamento da saúde, a assistência à saúde e 
a articulação interfederativa, e dá outras providências. Diário Oficial [da] República Federativa do Brasil, Brasília, DF, 29 jun. 2011.

BRASIL. Lei $\mathrm{n}^{\circ}$ 8.142, de 28 de dezembro de 1990. Dispõe sobre a participação da comunidade na gestão do Sistema Único de Saúde (SUS) e sobre as transferências intergovernamentais de recursos financeiros na área da saúde e dá outras providências. Diário Oficial [da] República Federativa do Brasil, Poder Legislativo, Brasília, DF, 31 dez. 1990. Seção 1, p. 25694.

BRASIL. Ministério da Saúde. Manual de planejamento no SUS. Brasília, DF, 2015. (Série articulação interfederativa, v. 4).

BRASIL. Ministério da Saúde. Portaria ${ }^{\circ}$ 95, de 26 de janeiro de 2001. Norma Operacional da Assistência à Saúde - NOAS-SUS 01/01. Diário Oficial [da] República Federativa do Brasil, Brasília, DF, 29 jan. 2001. Seção 1, p. 23.

BRASIL. Ministério da Saúde. Portaria n ${ }^{\circ}$ 373, de 27 de fevereiro de 2002. Norma Operacional da Assistência à Saúde - NOAS-SUS 01/02. Diário Oficial [da] República Federativa do Brasil, Brasília, DF, 28 fev. 2002. Seção 1, p. 52.

BRASIL. Ministério da Saúde. Portaria n ${ }^{\circ}$ 399, de 22 de fevereiro de 2006. Divulga o Pacto pela Saúde 2006 - Consolidação do SUS e aprova as Diretrizes Operacionais do Referido Pacto. Diário Oficial [da] República Federativa do Brasil, Brasília, DF, 23 fev. 2006a. Seção 1, p. 43.

BRASIL. Ministério da Saúde. Portaria n 2.135, de 25 de setembro de 2013. Estabelece diretrizes para o processo de planejamento no âmbito do Sistema Único de Saúde (SUS). Diário Oficial [da] República Federativa do Brasil, Brasília, DF, 26 set. 2013.

BRASIL. Ministério da Saúde. Portaria n ${ }^{\circ}$ 3.085, de 1 de dezembro de 2006. Regulamenta o Sistema de Planejamento do SUS. Diário Oficial [da] República Federativa do Brasil, Brasília, DF, 4 dez. 2006b. Seção 1, p. 39.

BRASIL. Ministério da Saúde. Portaria $n^{\circ} 4.279$, de 30 de dezembro de 2010. Estabelece diretrizes para a organização da Rede de Atenção à Saúde no âmbito do Sistema Único de Saúde (SUS). Diário Oficial [da] República Federativa do Brasil, Brasília, DF, 31 dez. 2010. Seção 1, p. 88.

BRASIL. Ministério da Saúde. Regionalização solidária e cooperativa: orientações para sua implementação no SUS. Brasília, DF, 2007. (Série B: textos básicos de saúde).

BRASIL. Ministério da Saúde. Sistema de planejamento do SUS (PlanejaSUS): uma construção coletiva - trajetória e orientações de operacionalização. Brasília, DF, 2009. (Série B: textos básicos de saúde). 
CAMPOS, R. O. Análise do planejamento como dispositivo mediador de mudanças institucionais com base em um estudo de caso. Cadernos de Saúde Pública, Rio de Janeiro, v. 16, n. 4, p. 1021-1030, out./dez. 2000.

CAMPOS, R. O. Planejamento em saúde: a armadilha da dicotomia públicoprivado. Revista de Administração Pública, Rio de Janeiro, v. 37, n. 2, p. 189200, mar./abr. 2003.

CARNEIRO, P. S.; FORSTER, A. C.; FERREIRA, J. B. B. A dinâmica de três colegiados de gestão regional: um olhar sobre a regionalização e pactuação. Saúde em Debate, Rio de Janeiro, v. 38, n. 100, p. 57-68, jan./mar. 2014.

CARROLL, L. Alice no país das maravilhas. Porto Alegre: LP\&M, 2005.

CONSELHO NACIONAL DE SECRETÁRIOS DE SAÚDE. A gestão de saúde nos estados: avaliação e fortalecimento das funções essenciais. Brasília, DF, 2007.

FREIRE, M. L. S. Planejamento em saúde em região de saúde do estado de Tocantins (2011-2015). 2015. 166 f. Dissertação (Mestrado em Saúde Coletiva) - Instituto de Saúde Coletiva, Universidade Federal da Bahia, Salvador, 2015.

GIORDANI, J. A. La planificacion como proceso social: um esquema de analisis. Cuadernos Sociedad Venezolana de Planificación, Caracas, n. 3, p. 147177, 1979.

HUERTAS, F. Entrevista com Matus. Caracas: F. Altandir, 1994.

JESUS, W. L. A. de. Re-significação do planejamento no campo da saúde coletiva: desafios teóricos e busca de novos caminhos. 2006. $236 \mathrm{f}$. Dissertação (Mestrado em Saúde Coletiva) - Universidade Estadual de Feira de Santana, Feira de Santana, 2006.

JESUS, W. L. A. de; TEIXEIRA, C. F. Planejamento governamental em saúde no estado da Bahia, Brasil: atores políticos, jogo social e aprendizado institucional. Ciência \& Saúde Coletiva, Rio de Janeiro, v. 19, n. 9, p. 38393848, 2014.

LACERDA, J. T. de et al. Avaliação da gestão para o planejamento em saúde em municípios catarinenses. Ciência \& Saúde Coletiva, Rio de Janeiro, v. 17, n. 4, p. 851-859, 2012.

LAVRAS, C. Secretarias de estado da saúde no Brasil: organizações em processo de mudança. 2003. 147 f. Tese (Doutorado em Saúde Coletiva) Universidade de Campinas, Campinas 2003. 
LEITE, V. R.; LIMA, K. C.; VASCONCELOS, C. M. de. Financiamento, gasto público e gestão dos recursos em saúde: o cenário de um estado brasileiro. Ciência \& Saúde Coletiva, Rio de Janeiro, v. 17, n. 7, p. 1849-1856, 2012.

LIMA, J. de C.; URIBE RIVERA, F. J. Gestão de sistemas regionais de saúde: um estudo de caso no Rio Grande do Sul, Brasil. Cadernos de Saúde Pública, Rio de Janeiro, v. 22, n. 10, p. 2179-2189, out. 2006.

LIMA, L. D. de et. al. Descentralização e regionalização: dinâmica e condicionantes da implantação do Pacto pela Saúde no Brasil. Ciência \& Saúde Coletiva, Rio de Janeiro, v. 17, n. 7, p. 1903-1914, 2012.

LOPES, C. M. N. Sistemas microrregionais de serviços de saúde no Ceará (19982006): implantação e resultados na utilização das internações hospitalares. 2007. 121 f. Dissertação (Mestrado em Saúde Pública) - Centro de Ciências da Saúde, Universidade Estadual do Ceará, Fortaleza, 2007.

LOTUFO, M. A gestão pública em saúde: análise da capacidade de governo da alta direção da SES - Mato Grosso em 2001. 2003. 133 f. Tese (Doutorado em Saúde Pública) - Instituto de Saúde Coletiva, Universidade Federal da Bahia, Salvador, 2003.

LOTUFO, M.; MIRANDA, A. S. de. Sistemas de direção e práticas de gestão governamental em secretarias estaduais de saúde. Revista de Administração Pública, Rio de Janeiro, v. 41, n. 6, p. 1143-1163, nov./dez. 2007.

LUZ, M. T. As instituições médicas do Brasil. 2. ed. Porto Alegre: Rede Unida, 2013. (Coleção Clássicos da Saúde Coletiva).

MATUS, C. Estratégias políticas: chimpanzé, Maquiavel e Gandhi. Tradução de Giselda Barroso. São Paulo: Fundap, 1996.

MATUS, C. Política, planejamento e governo. Brasília, DF: Ipea, 1993. Tomo 1.

MATUS, C. Los tres cinturones del gobierno. Caracas: Fondo Editorial Altadir, 1997.

MENDES, E. V. As redes de atenção à saúde. Brasília, DF: Organização PanAmericana da Saúde, 2011.

MERHY, E. E. Planejamento como tecnologia de gestão: tendências e debates sobre planejamento em saúde no Brasil. In: GALLO, E. (Org.). Razão e planejamento: reflexões sobre política, estratégia e liberdade. São Paulo: Hucitec; Rio de Janeiro: Abrasco, 1995. p. 117-149.

MINTZBERG, H. Ascensão e queda do planejamento estratégico. São Paulo: Bookman, 2004. 
MINTZBERG, H. Criando organizações eficazes: estruturas em cinco configurações. São Paulo: Atlas, 1995.

NORONHA, J. C.; LIMA, L. D. de; MACHADO, C. V. A gestão do Sistema Único de Saúde: características e tendências. In: CONFERÊNCIA NACIONAL DE CIÊNCIA, TECNOLOGIA E INOVAÇÃO EM SAÚDE, 2., 2004, Brasília, DF. Anais... Brasília, DF: Ministério da Saúde, 2005. p. 45-94.

ORGANIZACIÓN PANAMERICANA DE LA SALUD. La salud pública en las Américas: nuevos conceptos, análisis del desempeño y bases para la acción. Washington, 2002.

OUVERNEY, A. M. Regionalização do SUS: uma análise da estratégia de integração intermunicipal. Administração em Diálogo, São Paulo, n. 7, p. 91106, 2005.

PAIM, J. S. Aspectos críticos da institucionalização da planificação em organizações públicas de saúde. In: PAIM, J. S. Saúde, política e reforma sanitária. Salvador: Instituto de Saúde Coletiva, 2002a. p. 407-429.

PAIM, J. S. Burocracia e aparato estatal: implicações para a planificação e implementação de políticas de saúde. In: PAIM, J. S. Saúde, política e reforma sanitária. Salvador: Instituto de Saúde Coletiva, 2002b. p. 149-162.

PAIM, J. S. A crise do planejamento autoritário em saúde. In: PAIM, J. S. Saúde, política e reforma sanitária. Salvador: Instituto de Saúde Coletiva, 2002c. p. 27-38.

PAIM, J. S. Planejamento para não especialistas. In: CAMPOS, G. W. de S. et al. (Org.). Tratado de saúde coletiva. São Paulo: Hucitec; Rio de Janeiro: Ed. Fiocruz, 2006. p. 767-782.

PAIM, J. S.; TEIXEIRA, C. F. Política, planejamento e gestão em saúde: balanço do estado da arte. Revista de Saúde Pública, São Paulo, v. 40, ago. 2006. Número especial.

ROCHA, A. A. R. de M. e. O planejamento no cotidiano de uma instituição hipercomplexa: o caso da SES/Sergipe. 2008. 156 f. Tese (Doutorado em Saúde Pública) - Instituto de Saúde Coletiva, Universidade Federal da Bahia, Salvador, 2008.

ROCHA, J. S. Y. Da Cendes-Opas ao PlanejaSUS: teoria e prática do planejamento em saúde no Brasil. In: IBAÑEZ, N.; ELIAS, P. E. M.; SEIXAS, P. H. D. (Org.). Política e gestão pública em saúde. São Paulo: Hucitec: Cealag, 2011. cap. 11, p. 261-284. 
SALDANHA, S. A mudança organizacional na Secretaria de Estado da Saúde de Santa Catarina. 2003. 123 f. Dissertação (Mestrado em Saúde Coletiva) Instituto de Saúde Coletiva, Universidade Federal da Bahia, Salvador, 2003.

SANTOS, L. Sistema Único de Saúde: os desafios da gestão interfederativa. Campinas: Saberes, 2013.

SARTI, T. D. et al. Avaliação das ações de planejamento em saúde empreendidas por equipes de saúde da família. Cadernos de Saúde Pública, Rio de Janeiro, v. 28, n. 3, p. 537-548, mar. 2012.

SCHRAIBER, L. B. et al. Planejamento, gestão e avaliação: identificando problemas. Ciência \& Saúde Coletiva, Rio de Janeiro, v. 4, n. 2, p. 221-242, 1999.

SILVA, J. M. da. Planejamento governamental em saúde, no âmbito federal, entre 1985 e 2014. 2015. 223 f. Tese (Doutorado em Saúde Pública) - Instituto de Saúde Coletiva, Universidade Federal da Bahia, Salvador, 2015.

SOARES, A.; SANTOS, N. R. dos. Financiamento do Sistema Único de Saúde nos governos FHC, Lula e Dilma. Saúde em Debate, Rio de Janeiro, v. 38, n. 100, p. 18-25, jan./mar. 2014.

SORIA GALVARRO, M. del P. Q. et al. Desigualdades regionais na saúde no estado de Minas Gerais. Revista de Administração Hospitalar e Inovação em Saúde, Belo Horizonte, v. 8, n. 8, p. 12-27, jan./jun. 2012.

SOUZA, L. E. P. F. de; SILVA, L. M. V. da; HARTZ, Z. M. de A. Conferência de consenso sobre a imagem-objetivo da descentralização da atenção à saúde no Brasil. In: HARTZ, Z. M. de A.; SILVA, L. M. V. da (Org.). Avaliação em saúde: dos modelos teóricos à prática na avaliação de programas e sistemas de saúde. Salvador: Edufba; Rio de Janeiro: Ed. Fiocruz, 2005. p. 65-102.

SOUZA, M. K. B.; TEIXEIRA, C. F. Autoavaliação da gestão municipal do SUS: processo de construção do instrumento. In: CONGRESSO BRASILEIRO DE POLÍTICA, PLANEJAMENTO E GESTÃO EM SAÚDE, 2., 2013, Belo Horizonte. Anais... Belo Horizonte: Abrasco, 2013.

SPINELLI, H.; TESTA, M. Del diagrama de Venn al nudo borromeo: recorrido de la planificación en América Latina. Salud Colectiva, Buenos Aires, v. 1, n. 3, p. 323-335, sept./dic. 2005. Disponível em: <http://www.scielo.org.ar/pdf/sc/ vln3/vln3a05.pdf >. Acesso em: 10 dez. 2015.

TEIXEIRA, C. F. Enfoques teóricos-metodológicos do planejamento em saúde. In: TEIXEIRA, C. F. (Org.). Planejamento em saúde: conceitos, métodos e experiências. Salvador: Edufba, 2010. p. 17-32. 
TEIXEIRA, C. F. A mudança do modelo de atenção à saúde e o SUS: desatando nós e criando laços. In: TEIXEIRA, C. F.; SOLLA, J. P. Modelo de atenção à saúde: promoção, vigilância e saúde da família. Salvador: Edufba, 2006. p. 19-58.

TEIXEIRA, C. F. Planejamento municipal em saúde. Salvador: Instituto de Saúde Coletiva da Universidade Federal da Bahia, 2001.

TEIXEIRA, C. F. Os princípios do Sistema Único de Saúde. Salvador, 2011. Texto de apoio elaborado para subsidiar o debate nas Conferências Municipal e Estadual de Saúde. Disponível em: <https://www.almg.gov.br/export/sites/ default/acompanhe/eventos/hotsites/2016/encontro_internacional_saude/ documentos/textos_referencia/07_principios_sistema_unico_saude.pdf $>$. Acesso em: 30 jan. 2016.

TEIXEIRA, C. F.; ROCHA, M. Cadernos de exercícios do PlanejaSUS: material didático. 2009.

TESTA, M. Análisis de instituciones hipercomplejas. In: MERHY, E. E.; ONOCKO, R. Agir em saúde: um desafio para o público. 2. ed. São Paulo: Hucitec, 2002. p. 17-70.

TESTA, M. Pensamento estratégico e lógica de programação. São Paulo: Hucitec; Rio de Janeiro: Abrasco, 1995.

TESTA, M. Pensar en salud. 3. ed. Buenos Aires: Lugar Editorial, 2004.

TESTA, M. Saber en salud: la construción del conocimiento. Buenos Aires: Lugar Editorial, 1997.

THE LANCET. Londres: Elsevier, May 2011. Série especial Health in Brazil. Disponível em: $<$ http://www.thelancet.com/series/health-in-brazil $>$. Acesso em: 14 jul. 2011.

URIBE RIVERA, F. J. Análise estratégica em saúde e gestão pela escuta. Rio de Janeiro: Ed. Fiocruz, 2003.

URIBE RIVERA, F. J.; ARTMANN, E. Planejamento e gestão em saúde: flexibilidade metodológica e agir comunicativo. Ciência \& Saúde Coletiva, Rio de Janeiro, v. 4, n. 2, p. 355-365, 1999.

URIBE RIVERA, F. J.; ARTMANN, E. Planejamento e gestão em saúde: flexibilidade metodológica e agir comunicativo. In: URIBE RIVERA, F. J. Análise estratégica em saúde e gestão pela escuta. Rio de Janeiro: Ed. Fiocruz, 2003. p. 17-35. 
VIANA, A. L. D. et al. Sistema de saúde universal e território: desafios de uma política regional para a Amazônia Legal. Cadernos de Saúde Pública, Rio de Janeiro, n. 23, p. S117-S131, 2007. Suplemento 2.

VIEIRA, F. S. Avanços e desafios do planejamento no Sistema Único de Saúde. Ciência \& Saúde Coletiva, Rio de Janeiro, v. 14, p. 1565-1577, 2009. Suplemento 1 .

VILASBÔAS, A. L. Q. Planejamento e programação das ações de vigilância em saúde no nível local do Sistema Único de Saúde. Rio de Janeiro, 2004. Texto de circulação interna para o curso Proformar.

VILASBÔAS, A. L. Q. Práticas de planejamento e implementação de políticas de saúde no âmbito municipal. 2006. 166 f. Tese (Doutorado em Saúde Públca) Instituto de Saúde Coletiva, Universidade Federal da Bahia, Salvador, 2006. 


\title{
Política de Sangue no Brasil: desafios e iniciativas para a sua integração na rede de atenção à saúde
}

\author{
Mariluce Karla Bomfim de Souza \\ Glauciene Analha Leister \\ Júnia Guimarães Mourão Cioffi \\ Cláudio Medeiros Santos \\ Helder Teixeira Melo
}

\section{Resgatando a compreensão sobre política de saúde}

A discussão sobre uma política de saúde requer o resgate dos seus conceitos básicos para entendê-la. A palavra política está relacionada a polis que quer dizer "cidade ou comunidade organizada e composta por cidadãos (politikos)". O termo política pode ser considerado sob diferentes pontos de vista, por exemplo, enquanto "prática restrita aos que atuam no âmbito das instituições políticas" ou "o que perpassa as relações sociais e diz respeito a todo e qualquer indivíduo”. (PINTO; VIEIRA-DA-SILVA; BAPTISTA, 2014, p. 69, grifo do autor)

A política como expressão da atuação dos estados remete às concepções de políticas públicas e políticas sociais, sendo a primeira entendida como ações do Estado voltadas para o interesse público/coletivo e influenciada pela economia, regime social, visão dos governantes e atuação dos grupos so- 
ciais, e a segunda, enquanto políticas que os governos desenvolvem voltadas para o bem-estar e a proteção social. (FLEURY; OUVERNEY, 2012)

A política de saúde pode ser entendida como política pública e também política social, e, portanto, como resposta social a problemas e necessidades de saúde. Desse modo, pode ser caracterizada pela ação ou omissão de uma organização (Estado), enquanto resposta social, diante dos problemas e necessidades de saúde e seus determinantes (sociais, ambientais e culturais), bem como em relação à produção, distribuição e regulação de bens, serviços e ambientes que afetam a saúde dos indivíduos e da coletividade. (PAIM, 2003)

A política de saúde se encontra na interface entre o Estado, a sociedade e o mercado, de modo que se caracteriza por distintos interesses e por múltiplas determinações. Portanto, segundo Fleury e Ouverney (2012) para entendê-la deve-se considerar os seus objetivos e finalidades, as estratégias, as técnicas e planos de ação para implementação da política, os efeitos produzidos nas relações sociais, os espaços que orientam o processo decisório, os diferentes projetos sociais, os marcos institucionais que referenciam e sustentam a política e os valores e referenciais éticos que tal política influencia sobre a vida social.

Embora, desde 1974, Gary Brewer afirmasse que as políticas sofriam determinações que modificavam seu curso, muitos analistas de políticas, inclusive ele, propuseram etapas ou estágios para a compreensão do desenvolvimento de uma política. Nos anos 1990, Howlett e Ramesh sistematizaram em cinco etapas o processo da política pública. Portanto, o ciclo se inicia com a entrada na agenda, sendo a incorporação de problemas na "agenda de governos" o ponto de partida para a elaboração de propostas de políticas públicas e de ação governamental; a formulação da política contemplando as intenções, ações e alternativas para a solução dos problemas; a tomada de decisão caracterizada pelas escolhas políticas (ação ou omissão) para o desenvolvimento das intervenções; a etapa de implementação diretamente relacionada à etapa de formulação, visto que a provável e não rara divisão institucionalizada entre quem elabora e quem implementa denuncia as dificuldades de operacionalização/efetivação da política; e finalmente, o processo de monitoramento dos resultados que define a etapa de avaliação da política.

Este capítulo não pretende fazer a análise de uma política de saúde, mas recuperar alguns aspectos sobre o modo de organização e de "fazer" da polí- 
tica de sangue no Brasil, apontando seus desafios e iniciativas, tendo em vista a perspectiva de sua integração nas redes de atenção à saúde.

\section{Evolução histórica das propostas e ações voltadas para a hematologia e hemoterapia no Brasil}

O desenvolvimento da hemoterapia no Brasil teve início a partir da década de 1940, duas décadas após a revolução científica marcada pela pesquisa do Dr. Karl Landsteiner sobre efeitos aglutinantes e grupos sanguíneos. A possibilidade de exames pré-transfusionais para verificação da compatibilidade sanguínea entre doador e receptor romperam o empirismo da transfusão de sangue, estabelecendo um período científico neste campo. (JUNQUEIRA; ROSENBLIT; HAMERSCHLAK, 2005)

A descoberta dos antígenos de superfície das hemácias que estabelecem os grupos sanguíneos $\mathrm{ABO}$, além do emprego de anticoagulantes, e o aperfeiçoamento de equipamentos de coleta e de transfusão de sangue, trouxeram a oportunidade do surgimento de um novo tipo de estabelecimento de saúde, o Banco de Sangue, que teria a função da estocagem do sangue doado e compatibilização imuno-hematológica entre receptor e sangue doado.

Tais adventos promoveram, a partir da década de 1930, o surgimento dos primeiros bancos de sangue no mundo, sendo o primeiro no Brasil inaugurado em 1941, no Hospital Fernandes Figueira, atualmente pertencente à Fundação Oswaldo Cruz. Em seguida, houve a criação do Banco de Sangue da prefeitura do Distrito Federal, em 1945.

Entretanto, cabe ressaltar que o desenvolvimento e o pioneirismo da hemoterapia brasileira não foram acompanhados por regulamentação estatal, trazendo consequências técnicas e políticas para o setor de saúde. (SARAIVA, 2005) De acordo com Melo (2015) até o ano de 1964, a ausência do poder público e o atraso da regulamentação do setor foram prejudiciais ao desenvolvimento da hemoterapia. Esse período "pré-regulamentar", ressalta Saraiva (2005), levou à expansão dos bancos de sangue privados e à comercialização dos produtos hemoterápicos, implicando sobre os processos de doação de sangue, que era então, remunerada, com o sangue comercializado livremente. Na verdade, foram praticamente nulos os esforços de controle da atividade hemoterápica no Brasil até 1964. (SANTOS; MORAES; COELHO, 1991) 
Nesta época, debatia-se acerca da doação voluntária e altruísta em contraponto à doação remunerada, com fins de lucro. Não havia, ainda, uma consciência acerca da necessidade de políticas efetivas para a atenção hematológica e hemoterápica. Como recurso terapêutico cada vez mais difundido, o sangue passou a despertar os interesses do mercado. (PONTES apud SANTOS; MORAES; COELHO, 1991)

Contíguo à realização do primeiro evento científico relacionado ao tema em 1949 à criação, no mesmo ano, da Associação dos Doadores Voluntários de Sangue no Rio de Janeiro e da Fundação da Sociedade Brasileira de Hematologia e Hemoterapia, em 1950, o governo federal sancionou a Lei ${ }^{\circ} 1.075$, de 27 de março de 1950, que Santos, Moraes e Coelho (1991) ressaltam ser a primeira lei no Brasil sobre a doação voluntária de sangue; e, a primeira citação legal sobre a temática de sangue no Brasil. (MELO, 2015) Guerra (2005) ressalta que esta lei teve por objetivo valorizar a doação voluntária de sangue em um período em que era comum a escassez de doadores. Por força deste ato normativo, a doação voluntária de sangue passou a representar ato nobre e relevante para a sociedade e para o Brasil quando realizada em banco de sangue estatal. (BRASIL, 1950) Passada mais de uma década, surgiu outra normativa relacionada à doação nos termos do Decreto ${ }^{\circ} 53.988 / 1964$, que instituiu o dia nacional do doador voluntário de sangue.

Ainda que pioneiros no ordenamento jurídico da hemoterapia, a lei e o decreto supracitados não representaram formulação política mais expressiva ou orientação técnica (MELO, 2015) que trouxessem impacto para a área. Entre a publicação da Lei ${ }^{\circ} 1.075$, em 1950, e a primeira metade da década de 1960 não houve avanços normativos maiores na esfera federal, sobre a hematologia e a hemoterapia.

Em 1960, o tema avançou com a publicação da Lei n ${ }^{\circ}$ 4.701, de 28 de junho de 1965 (BRASIL, 1965), que inicialmente trouxe uma proposição legal oriunda de um grupo de trabalho idealizado pelo Poder Executivo Federal, por ação da Comissão Nacional de Hemoterapia (CNH), que havia sido constituída por meio do Decreto ${ }^{\circ} 54.494 / 1964$. A CNH tinha como objetivo estudar e propor a legislação disciplinadora da hemoterapia no Brasil, estabelecendo as bases para uma Política Nacional de Sangue e a estruturação de um órgão gestor para o gerenciamento nacional da política de sangue. (MELO, 2015) 
Ainda no final desta década, em 1969, foi proposto o modelo hemoterápico brasileiro através do relatório do Dr. Piérre Cazal (OPAS) que propunha a implantação de uma Política Nacional de Sangue através de um sistema de hemocentros descentralizados. (CAZAL, 1969; SANTOS; MOARES; COELHO, 1991)

Em 1980, foi publicada a Portaria Interministerial $\mathrm{n}^{\circ} 7$ - Ministério da Saúde/ Ministério da Previdência e Assistência Social (MS/MPAS) - que estabeleceu o Programa Nacional de Sangue e Hemoderivados (Pró-Sangue), importante avanço da área. Sampaio (2013) destaca que o Pró-Sangue foi de fundamental importância para o avanço da área de sangue no país, no sentido de estruturar e expandir para o interior do país uma rede de serviços de hemoterapia (hemorrede), com o objetivo de alcançar a cobertura hemoterápica em todo o país, utilizando, para isso, a doação voluntária de sangue, a qualificação de recursos humanos e a padronização dos procedimentos técnicos.

Na mesma década do surgimento do Pró-Sangue no Brasil, e desde 1983 com a implantação das Ações Integradas de Saúde (AIS), ${ }^{1}$ os hemocentros seguiram com o programa de extensão da rede hemoterápica apoiados pelas Secretarias Estaduais de saúde e pelo Ministério da Saúde. (BARCA, 2013)

Desde a concepção dos hemocentros públicos, a atenção às pessoas com coagulopatias hereditárias, ${ }^{2}$ principalmente as hemofilias, se caracterizava como uma de suas diretrizes. As pessoas compareciam diariamente aos serviços de hemoterapia para o tratamento hemoterápico, pela necessidade de transfusão para realizar as terapias de reposição de fatores. Nesta época, o tratamento de reposição aos hemofílicos era realizado principalmente com o Plasma Fresco Congelado e Crioprecipitado e, esporadicamente, concentrados de fator de coagulação liofilizado.

Ainda na década de 1980, alguns eventos e descobertas impulsionaram o direcionamento do interesse das autoridades para a melhoria da Política

1 As AIS, instituídas de acordo com as orientações e pressupostos do plano Conselho Consultivo de Administração Previdenciária (Conasp), constituíam uma "estratégia de integração programática entre as organizações de saúde de nível federal, estadual e municipal” (CASTRO; VIANA, 1992 apud PUGIN; NASCIMENTO, 1996, p. 13), e que incluía também os diversos prestadores de serviços nas três esferas.

2 As coagulopatias hereditárias, decorrentes da deficiência de um ou mais fatores da coagulação sanguínea, são caracterizadas pela ocorrência de distúrbios hemorrágicos cuja gravidade varia de forma espontânea e/ou traumática. (BRASIL, 2012) 
de Sangue e da Política de Atenção aos Hemofílicos, como o agravante dos novos casos da Síndrome de Imunodeficiência Adquirida (AIDS) no país, marcada em 1981 principalmente pelo conhecimento da via transfusional como importante fonte de transmissão, com a constatação de que $2 \%$ dos casos de AIDS eram transmitidos por transfusão e que $50 \%$ dos hemofílicos apresentavam-se contaminados pelo HIV. (RIBEIRO, 2007) Na ocasião, já se considerava que o atendimento às pessoas com coagulopatias deveria ser multidisciplinar, com abordagens fisioterápicas, ortopédicas, odontológicas, psicológicas, dentre outras.

A preocupação com a transfusão de HIV/AIDS foi expressa por meio de ato legislativo - Lei $n^{\circ} 7.649 / 1988$, publicado no mesmo ano da promulgação da Constituição Federal Brasileira (CF/88) e da garantia da saúde enquanto direito mediante o SUS. A referida lei estabeleceu o cadastramento obrigatório dos doadores de sangue e a realização de exames laboratoriais no sangue coletado, a fim de prevenir o desenvolvimento e proliferação de doenças. (MELO, 2015) O temor com a propagação de doenças por meio do agente curativo da hemoterapia, em especial para os pacientes que faziam transfusões frequentes e regulares dos hemocomponentes, fez com que o tema das infecções transmissíveis por transfusão ampliasse significativamente o controle sanitário e a regulamentação do setor.

Ainda, quanto a atenção pessoas com coagulopatias, devido às suas características, complexidades e complicações, os hemocentros, ao longo do tempo, buscaram se estruturar para ofertar o cuidado multidisciplinar e integral no próprio Serviço de Hematologia e Hemoterapia (SHH), ora se aproximando e ora se distanciando dos demais equipamentos de saúde disponíveis no SUS.

Quanto à atenção às pessoas com hemoglobinopatias, cabe ressaltar que foi absorvida pelos hemocentros no final da década de 1980. Pessoas com doença genética hematológica, com várias intercorrências clínicas e alta morbidade e mortalidade, não conseguiam atendimento especializado na rede do SUS e passaram a ter os mesmos cuidados disponibilizados para os pacientes com coagulopatias dentro dos hemocentros. (CIOFFI; MURAO, 2007)

Estimulada pelos movimentos sociais, em 1996 foi publicada, pelo Ministério da Saúde, a Portaria GM/MS n 951, de 10 de maio de 1996, que instituiu grupo de trabalho para elaborar o Programa Nacional de Doença Falciforme. 
(BRASIL, 1996) A primeira política pública direcionada para Doença Falciforme foi em 2001, através da Portaria GM/MS nº 822, de 6 de junho de 2001, quando foi instituído o Programa Nacional de Triagem Neonatal, ${ }^{3}$ para detecção de quatro doenças congênitas no período neonatal, incluindo as Hemoglobinopatias. (MÁXIMO, 2009) Este programa foi elaborado com base em programas estaduais que já em andamento, com resultados que evidenciavam a importância de uma política voltada para esta população com doença de alta morbidade e mortalidade.

A Organização Mundial da Saúde (OMS) orienta os países membros que seus respectivos Ministérios da Saúde devem proporcionar uma liderança eficaz e governança no desenvolvimento de um sistema nacional de sangue totalmente integrado ao sistema de saúde. A organização considera que a atenção hemoterápica, em um país, deve prover de forma responsável a segurança transfusional e a disponibilidade de sangue e derivados, considerando esta pauta como problema de saúde pública. (ORGANIZAÇÃO MUNDIAL DA SAÚDE, 2014 apud MELO, 2015)

O marco governamental que demonstra esse compromisso e as responsabilidades, dos agentes públicos envolvidos com a segurança e disponibilidade dos produtos hemoterápicos, expressou-se na Lei n ${ }^{\circ} 10.205$, de 21 de março de 2001 que regulamentou o artigo 199 da CF88, abordando sobre a coleta, processamento, estocagem e distribuição de sangue e hemoderivados e estabeleceu o ordenamento institucional para a execução de tais atividades. (BRASIL, 2001b)

Esta lei dispôs sobre a Política Nacional de Sangue, Componentes e Hemoderivados e determinou a garantia da autossuficiência e harmonização das ações do poder público em todos os níveis de governo, dentre outras coisas. O capítulo que trata da direção e gestão, refere que a execução da política nacional caberá ao Sistema Nacional de Sangue, Componentes e Derivados (Sinasan), que atuará observando vários postulados, e acrescenta, em seu artigo 17, que aos estados, Distrito Federal e Municípios, por meio de suas secretarias de saúde ou equivalentes, caberão a coordenação da execução das

3 O Programa de Triagem Neonatal (PNTN), com triagem para a identificação das hemoglobinopatias (Fase 2) foi instituído através da Portaria $n^{\circ} 822 / 2001$. Entretanto, vale destacar que a triagem neonatal já havia sido criada, desde 15 de janeiro de 1992, com testes para detecção precoce de fenilcetonúria e hipotireoidismo congênito (Fase 1). (CANÇADO; JESUS, 2007) 
ações correspondentes do Sinasan no seu âmbito de atuação, em articulação com o Ministério da Saúde. (BRASIL, 2001b)

O artigo 10 da Lei $n^{\circ}$ 10.205/2001 confere observância dos princípios e diretrizes do SUS à Hematologia e Hemoterapia, inclusive no que se refere à busca da equidade, da integralidade do cuidado, da acessibilidade às ações e serviços, da descentralização político-administrativa, da capacidade de resolubilidade dos serviços e da organização dos serviços a fim de evitar a duplicidade de meios para fins idênticos, dentre outros, como disposto na Lei $\mathrm{n}^{\circ} 8.080$, de 19 de setembro de 1990. (BRASIL, 1990)

Também, no ano de 2001, foram publicados o Decreto n 3990/2001 e a Resolução da Diretoria Colegiada $n^{\circ} 151$. O decreto, dentre outras determinações, tratou das competências dos entes federativos na implementação da Política de Sangue e Hemoderivados, com atribuições diversas, com ênfase na regionalização, na garantia do acesso da população de sua área de abrangência à assistência hemoterápica, na garantia da assistência à saúde dos portadores de doenças hematológicas, conforme pactuações do Estado, por meio de referências e contrarreferências, bem como outras atribuições voltadas para vigilância, planejamento, gestão de pessoas, gestão da informação e financiamento para a melhoria da qualidade do sangue. (BRASIL, 2001a)

A Resolução de Diretoria Colegiada (RDC) no 151 Anvisa/MS apresentava o modelo de conformação técnica e administrativa da Hemorrede brasileira, a ser estruturada em cada unidade federativa, sendo constituída pelos seguintes serviços: um Hemocentro Coordenador (HC), situado na capital do estado; Hemocentros Regionais (HR) e Núcleos de Hemoterapia (NH) estrategicamente distribuídos na extensão territorial de cada estado; Unidades de Coleta e Transfusão (UCT), Unidades de Coleta (UC) e Central de Triagem Laboratorial de Doadores (CTLD), opcionais e a depender da capacidade técnica e operacional da cada estado; e, as Agências Transfusionais (AT), de menor densidade tecnológica. (AGÊNCIA NACIONAL DE VIGILÂNCIA SANITÁRIA, 2001)

Ao longo do tempo, várias normatizações foram dando estruturação jurídica para o desenvolvimento das ações e serviços da Hemorrede no Brasil. No que se refere à atenção às pessoas com coagulopatias, cabe destacar o ato normativo publicado, RDC n ${ }^{\circ} 10$ de 23 de janeiro de 2004, pela Anvisa, resolução que limitou o uso de Plasma Fresco Congelado (PFC) às pessoas com coagulopatias adquiridas, contraindicando o seu uso para os casos de Hemofília, 
exceto quando se comprovasse o risco de vida e a falta de hemoderivados. (AGÊNCIA NACIONAL DE VIGILÂNCIA SANITÁRIA, 2004)

A determinação do uso de hemoderivados para as pessoas com coagulopatias, a aquisição permanente de concentrado de fatores de coagulação pelo Ministério da Saúde e a possibilidade do fracionamento de PFC excedente para produção de hemoderivados foram importantes marcos que promoveram a melhoria da qualidade de vida às pessoas com Hemofilia e que, ao mesmo tempo, evidenciaram a necessidade dos serviços disponibilizarem atenção integral, ofertando, dessa forma, cuidado para além do tratamento medicamentoso exigindo, portanto, o envolvimento e a articulação dos diversos pontos das Redes de Atenção do SUS. Diferentemente da Atenção às pessoas com Doença Falciforme, não há uma Política de Atenção Integral às pessoas com coagulopatias, mas sim publicações de protocolos ${ }^{4}$ que orientam o tratamento dos pacientes hemofílicos, o que aponta a necessidade de orientações/diretrizes para a organização dos serviços em rede.

$\mathrm{Na}$ atenção às pessoas com hemoglobinopatias, destaca-se a Portaria Ministerial $n^{\circ} 1.391$, de 16 de agosto, publicada em 2005, que estabelece no âmbito do SUS, as diretrizes para a Política Nacional de Atenção Integral às Pessoas com Doença Falciforme e outras Hemoglobinopatias, com o objetivo de mudar a história natural da doença no Brasil a partir da redução da morbimortalidade e melhoria da qualidade de vida. (BRASIL, 2005) O inciso II do artigo primeiro desta portaria, ao estabelecer a promoção da garantia da integralidade da atenção por equipe multidisciplinar e as interfaces entre as diferentes áreas técnicas do Ministério da Saúde para a articulação das demais ações que extrapolam a competência da Hemorrede, direciona as ações dos gestores às premissas do Pacto pela Saúde (BRASIL, 2005) de integração das ações de promoção à saúde e das ações da Atenção Básica, média e alta complexidade/densidade tecnológica.

$\mathrm{Na}$ Atenção Hemoterápica foram diversos os avanços alcançados para a melhoria da qualidade dos hemocomponentes ao longo dos anos. De acordo com o Relatório Anual de Vigilância Sanitária, de 2015, 92,23\% dos 888 serviços de hemoterapia avaliados em 2014 se encontravam em situação con-

4 Em 2014 foram publicadas as portarias $n^{\circ} 364$ e a n 478 com protocolos para uso de indução de imunotolerância para pacientes com hemofilia A e inibidor e para uso de profilaxia primária para hemofilia grave, respectivamente. (BRASIL, 2014a, 2014b) 
siderada satisfatória, entre baixo e médio risco potencial. Entre 2012 a 2014, observou-se redução do risco sanitário pela diminuição dos percentuais de estabelecimentos classificados nas categorias de médio, médio alto e alto risco potencial, o que aponta evolução favorável da qualidade das ações e produtos hemoterápicos, resultado de investimentos técnicos e gerenciais realizados pelos diversos atores envolvidos no aperfeiçoamento da segurança transfusional. Destaca-se como importante estratégia que influenciou na melhoria da qualidade dos SHH, o Programa Nacional de Qualificação da Hemorrede (PNQH) e o Programa Estadual de Qualificação da Hemorrede (PEQH) que permitem a identificação de cenários nos SHH e têm sido considerados potentes estratégias para apontar oportunidades de melhorias técnicas e gerenciais na Hemorrede e para promover o aperfeiçoamento dos processos de trabalho na premissa da gestão da qualidade, com o intuito de possibilitar diagnóstico situacional da Hemorrede e orientar o desenvolvimento de ações visando ao aumento da segurança transfusional para todos os serviços do país. (BRASIL, 2016)

Apesar dos êxitos obtidos para Atenção Hematológica e Hemoterápica, ainda persistem entraves importantes em todo país, especialmente em regiões que historicamente sofrem iniquidades sociais, desde dificuldade de acessibilidade às ações e aos serviços de saúde até atendimento em tempo oportuno das necessidades identificadas.

\section{A Política de Sangue e o desafio para o fortalecimento da Hemorrede}

O modelo estabelecido para o Sistema Nacional de Sangue, Componentes e Derivados (Sinasan) em 2001, fazia a transição da perspectiva da governança e responsabilidade dos estados para o âmbito federal na hemoterapia. (HOGAN; GARGARELLA, 1997) Tal situação parece decorrer da percepção de que o Ministério da Saúde deveria assumir maior liderança no desenvolvimento da política de sangue e hemoderivados para todo o sistema do Brasil, frente as carências percebidas no setor.

Com ampliação da demanda por atendimento hematológico e hemoterápico aos serviços de abrangência SUS e também com a ampliação do escopo da atenção aos portadores de hemoglobinopatias e coagulopatias, as hemor- 
redes estaduais foram se estruturando de forma diferenciada, ajustando-se às conjunturas locais e estruturais. Constituiu-se como desafio à gestão da hematologia e hemoterapia nas três esferas de governo a condução da política nacional de sangue nas instâncias de pactuação interfederativa do SUS, bem como a inclusão de ações e proposições da Hemorrede em metas políticas nas agendas governamentais.

Atualmente, observam-se hemorredes estaduais com fragilidades importantes de articulação entre os seus SHH. Em 2001, na tentativa de padronização das Hemorredes, foi publicada a RDC151, de 21 de agosto de 2001. (AGÊNCIA NACIONAL DE VIGILÂNCIA SANITÁRIA, 2001) Esta RDC definiu os níveis de complexidade dos serviços de hemoterapia, mas não abordou a complexidade relacionada ao atendimento das pessoas com coagulopatias e hemoglobinopatias. Apesar de ser muito utilizada para o cadastramento dos serviços de hemoterapia, públicos e privados, municipais ou estaduais pelas Vigilâncias Sanitárias, é possível concluir a necessidade de atualizações para compatibilização da norma com as estruturas agora existentes, tanto para a hemoterapia, quanto para a hematologia.

Uma importante ferramenta à organização da Hemorrede e para o enfrentamento das dificuldades apontadas é a formulação dos planos diretores nacional e estaduais de sangue, componentes e derivados, previstos no Decreto $\mathrm{n}^{\circ}$ 3.990/2001, Art. $4^{\circ}$, inciso XIII. Tais planos são fundamentais para orientar estados, municípios e o Distrito Federal na execução de ações e estratégias no setor, permitindo a definição de parâmetros assistenciais, ou ainda, acompanhar e avaliar o cumprimento das metas políticas locais para a área do sangue, componentes e derivados.

Ao colocar o usuário do SUS como indivíduo que deve ser efetivamente considerado no desenho da atenção integral e tendo em vista que em muitas regiões do país os SHH não comportam toda a oferta de cuidado necessária, torna-se fundamental o estreitamento e a oficialização das negociações das ações com os demais gestores do SUS, bem como com os usuários do sistema, inclusive no que se refere às pactuações referentes ao redesenho de rede e até mesmo a ampliação de serviços. A Política de Sangue deve ser conhecida por todos os agentes do processo, inclusive por ser estratégica, permeando tanto a atenção hospitalar quanto a ambulatorial. Discussões habituais do sistema, como ampliação de leitos de terapia intensiva ou referenciamento de cirurgias 
para determinado município deve levar em conta a estrutura locorregional da hemorrede. Estes e outros motivos impulsionam a importância do papel da hemorrede na condução/pactuação regional das políticas do SUS, tanto nas que envolvem diretamente a hematologia e hemoterapia, quanto na necessidade das hemorredes ampliarem sua interlocução com os demais segmentos.

Segundo Cândido e Abreu (2000), citados por Bastos e Souza (2014, p. 16), uma hemorrede constitui-se como uma rede de serviço de saúde com característica intraorganizacional, constituída por departamentos e setores que mantêm trocas e interações entre si, com características de flexibilidade, horizontalização e descentralização. A organização da hemorrede prevê a otimização de recursos financeiros e equipes de trabalho qualificadas para o desenvolvimento das atividades e o compartilhamento dos problemas.

As hemorredes estaduais no Brasil se caracterizam pela forma diversa de gestão e organização dos serviços que a constituem, em muitos destes estados sua organização encontra-se descentralizada e regionalizada (BASTOS; SOUZA, 2014; SOUZA; VIANA, 2014), constituída por serviços do setor público e privado (SILVA; SOARES; IWAMOTO, 2009), e por uma rede interorganizacional representada por contratos com clínicas e hospitais da mesma região ou de outras próximas que consomem produtos da hemorrede. (GRAMKOW, 2002)

Considerando, portanto, a complexidade da hemorrede que deve estar organizada e sustentada nos princípios da Política do Sangue, haja vista a sua conformação diversa, destacam-se também a universalidade de sua abrangência, já que se almeja cobertura hemoterápica 100\% pública, a despeito do seu atendimento público e privado, bem como a transversalidade de sua atuação, pois o hemocomponente é considerado produto estratégico para outras ações de saúde, como urgência e emergência, procedimentos cirúrgicos, desde os mais simples até os mais complexos, como transplantes, etc.

Um importante tema relacionado ao fortalecimento da Política de Sangue, diz respeito ao financiamento das atividades hemoterápicas e da assistência hematológica. Vetado na Lei $\mathrm{n}^{\circ} 10.205 / 2001$, o tema permanece ausente da discussão normativa específica do setor, restringindo-se o financiamento da hemoterapia ao repasse de teto de transferência de recursos federais e ao ressarcimento de produção na Hemorrede, pelo modelo de tabela de procedimentos do SIA/SIH/SUS. 
A aprovação da Emenda Constitucional $n^{\circ} 29$, que determina valores de aporte pelas instâncias federal, estaduais e municipais, apresentou possibilidades para o financiamento do setor; e, as portarias $\mathrm{n}^{\circ} 1.737$ de 19 de agosto de 2004 e $^{\circ} 1.469$ de 10 de julho de 2006 trouxeram a possibilidade da Hemorrede obter ressarcimento dos serviços prestados fora do âmbito do SUS, com o direcionamento da ampliação da cobertura pelos serviços públicos; porém, ainda existe gargalo no financiamento da Hemoterapia no país. Tal questão deve ser abordada de forma especial nas discussões sobre planejamento do setor, e até mesmo do redesenho de um modelo mais apropriado ao financiamento dos altos custos da hemoterapia no Brasil e no mundo.

\section{(Re)conhecendo a rede de atenção à saúde e os desafios para a integração da política do sangue}

Após mais de duas décadas desde o surgimento do SUS e, considerados os avanços alcançados, muitos entraves e lacunas ainda existem para a sua consolidação nos termos da constituição. Dentre as lacunas ainda persistentes no SUS, destaca-se a intensa fragmentação das ações e serviços de saúde. (BRASIL, 2006a) Embora exista robusto arcabouço jurídico e normativo, que ampara a organização do sistema de saúde e instrumentaliza os gestores do SUS nas suas áreas de abrangência, muitas têm sido as dificuldades e os desafios para a operacionalização de uma atenção integral.

Assumir os princípios e diretrizes do SUS nas práticas de saúde pressupõe compreendê-los na sua complexidade e reconhecer que de fato é um desafio realizar gestão, assistência e pesquisa em conformidade com todas essas premissas, visto que há uma grande gama de variáveis que influenciam o alcance dos resultados, incluindo a dificuldade de acessibilidade às ações e aos serviços de saúde; entraves com relação ao financiamento; (des)articulação entre os pontos de atenção das Redes de Atenção à Saúde (RAS); problemas nos sistemas logísticos e de apoio, na governança dos serviços, dentre outros.

Nesse contexto e no que se refere à integração das políticas de saúde e de suas ações, há que destacar também o perfil demográfico e etário atual da população, que adquiriu padrão diferente do século passado, apresentando novos desafios para a organização do sistema e dos serviços de saúde. O nú- 
mero de idosos representa um contingente expressivo em termos absolutos e de crescente importância relativa no conjunto da sociedade brasileira, daí decorrendo uma série de novas exigências em termos de políticas públicas e organização do sistema e serviços de saúde. O contexto atual caracteriza-se pela persistência de antigos problemas de saúde pública e o surgimento de novas formas de adoecer e morrer por doenças transmissíveis emergentes e reemergentes, fatos estes que apontam para grandes desafios, especialmente para o setor saúde que demanda mudanças urgentes nas práticas e modos de gestão e organização do sistema de saúde.

Em geral, os problemas de saúde não se distribuem uniformemente e envolvem tecnologias diversas em sua complexidade e custo. Neste sentido, Noronha, Lima e Machado (2012) apontam para a necessidade de organizar uma rede de atenção à saúde no SUS, sendo necessário, para isso, a hierarquização e regionalização das ações e serviços de acordo com as necessidades. Para estes autores, a rede de atenção à saúde representa “[...] o conjunto de estabelecimentos, de diferentes funções e perfis de atendimento, que operam de modo ordenado e articulado no território, de modo a atender as necessidades de saúde de uma população". (NORONHA; LIMA; MACHADO, 2012, p. 369)

Em documento base sobre redes regionalizadas de atenção à saúde publicado pelo Ministério da Saúde, em 2008, constavam os desafios para a conformação e consolidação das redes de atenção, inclusive na proposta de redes regionalizadas. Dentre estes, estavam citados a insuficiência da base de financiamento da política de saúde; a assimetria na distribuição dos serviços; o acesso insuficiente aos serviços de atenção especializada e hospitalar; as limitações na capacidade institucional - recursos financeiros, humanos e técnicos - da maioria dos municípios; a baixa funcionalidade e racionalidade do processo de organização e gestão dos sistemas de saúde em âmbito regional; além da precariedade das relações de vínculo funcional, com elevada rotatividade de profissionais e abordagem reduzida do processo saúde doença cuidado. (BRASIL, 2008)

Para o enfrentamento das dificuldades nas práticas de saúde, estratégias vêm sendo debatidas e operacionalizadas nos serviços de saúde, incluindo ações macro e micropolíticas, bem como a utilização de ferramentas relacionadas às tecnologias duras, leve-duras e leves, que resultem na organização 
de serviços que produzam cuidado singularizado e que considerem as necessidades do usuário para o planejamento das suas ações. (MALTA; MERHY, 2010; MERHY, 1998)

No plano macropolítico, a organização dos serviços em Redes de Atenção à Saúde é uma das estratégias de superação da fragmentação da atenção e da gestão, com o intuito de aperfeiçoar o funcionamento político-institucional do SUS, visando assegurar ao usuário o conjunto de ações e serviços efetivos e eficientes que respondam às necessidades de saúde individuais em âmbitos local e regional. (BRASIL, 2010; HARTZ; CONTANDRIOPOULOS, 2004, p. 331; MENDES, 2010)

A fim de direcionar a conformação das redes de atenção à saúde, em 2010, o Ministério da Saúde publicou a Portaria GM n ${ }^{\circ} 4.279$, de 30 de dezembro de 2010, que considera a estruturação da rede como estratégia para superar a fragmentação da atenção e da gestão nas Regiões de Saúde e aperfeiçoar o funcionamento político-institucional do SUS, com vistas a assegurar ao usuário o conjunto de ações e serviços de que necessita, com efetividade e eficiência. Tal normativa apresenta os diversos atributos da rede, cabendo destacar a definição da população e território, a disposição de diversos estabelecimentos de saúde, os mecanismos de coordenação e integração assistencial, bem como, o sistema de governança, a gestão integrada dos sistemas de apoio administrativo, clínico, logístico e o financiamento. No que se refere às conceituações listadas no referido marco normativo, após destacar que os pontos de atenção de uma rede representam os espaços para oferta de determinados serviços produzidos de forma singular, a portaria delineia exemplos destes espaços destacando, entre outros, os serviços de hematologia e hemoterapia. (BRASIL, 2010)

Reforçando a importância do estabelecimento das redes de atenção e tendo em vista os desafios para sua operacionalização, em 2011, foi publicado o Decreto $n^{\circ} 7.508$, de 28 de junho de 2011, pelo Ministério da Saúde, que dentre outras disposições, enfatizou a estrutura de organização hierarquizada e regionalizada para a operacionalização do SUS, destacou a necessidade do planejamento e articulação interfederativa, e apontou alguns dispositivos como os contratos organizativos de ação pública, as alternativas de portas de entrada, o mapa da saúde, as comissões intergestoras regionais e os protocolos e diretrizes clínicas e terapêuticas. Nas suas disposições 
preliminares conceituou as redes de atenção à saúde como o “[...] conjunto de ações e serviços de saúde articulados em níveis de complexidade crescente, com a finalidade de garantir a integralidade da assistência à saúde”. (BRASIL, 2011)

Para além dos instrumentos normativos, a discussão de RAS também é colocada por muitos autores. Dentre eles, Mendes $(2010,2011)$ cita que as RAS se configuram como organizações poliárquicas de conjuntos de serviços de saúde, vinculados entre si por uma missão única, por objetivos comuns e por uma ação cooperativa e interdependente, que permitem ofertar atenção contínua e integral a determinada população, coordenada pela atenção primária à saúde/atenção básica prestada no tempo certo, no lugar certo, com o custo certo, com a qualidade certa e de forma humanizada, e com responsabilidades sanitárias e econômicas por esta população. Constituídas por três elementos: a população, a estrutura operacional e o modelo de atenção à saúde, as redes de atenção caracterizam-se pela sua complexidade e pelos desafios para sua operacionalização.

Nesse contexto, ao considerar a transversalidade da hematologia e hemoterapia com as diversas áreas da saúde e entendendo que suas práticas e produtos ora se caracterizam como sistema de apoio, ora como ponto de atenção (ver Figura 1) torna-se necessário potencializar as práticas de gestão integrativas em rede para superação das invisibilidades e vazios assistenciais da atenção hematológica e hemoterápica.

As diferenças e particularidades das diversas regiões do país revelam dificuldades variadas que vão desde os níveis estratégicos até os níveis táticos e operacionais, sendo desde problemas macroestruturais até dificuldades técnicas e internas inerentes aos processos de trabalho. Dentre as fragilidades para a integração da Política do Sangue na Rede de Atenção à Saúde, encontram-se deficiências na pactuação e implementação de políticas estaduais para hematologia e hemoterapia, modelo de financiamento insuficiente para as demandas inclusive reprimidas, deficiências em qualificação técnica e gerencial decorrentes de problemas diversos relacionados a força de trabalho e a governança, diversidade na natureza jurídica dos serviços, infraestrutura física e de equipamentos inadequada, dentre outros. 
Figura 1 - Os serviços de hematologia e hemoterapia na estrutura operacional das redes de atenção à saúde

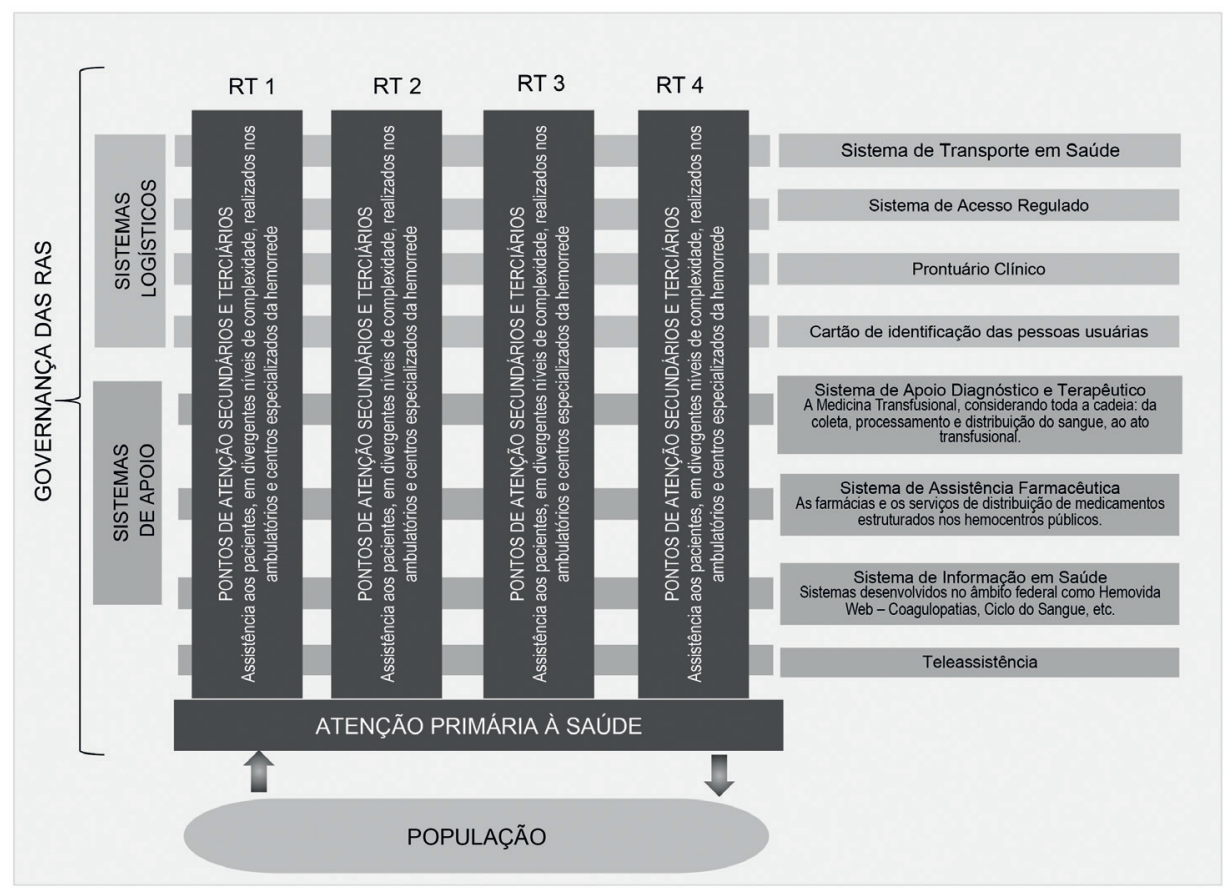

Fonte: elaborada pelos autores com base em Mendes [2011].

\section{Iniciativas e ações estratégicas recentes para o fortalecimento da integração da gestão e das práticas em hematologia e hemoterapia na Rede de Atenção à Saúde}

No sentido de fortalecer as práticas integrativas em rede, o "Planeja Sangue" é importante iniciativa da Coordenação-Geral de Sangue e Hemoderivados do Ministério da Saúde desenvolvido em parceria, desde 2014, com o Instituto de Saúde Coletiva da Universidade Federal da Bahia (ISC/UFBA), que dirige esforços para a incorporação de tecnologias de gestão e mudanças de práticas político-gerenciais no âmbito do sistema público de saúde. O referido projeto visa instrumentalizar os gestores e profissionais envolvidos para o desenvolvimento da capacidade técnica de planejar, assim como estimular o compromisso com a institucionalização local do planejamento em saúde, 
proporcionando, assim, apoio às hemorredes estaduais para a formulação e execução de Planos Diretores de Sangue e Hemoderivados e de planos estratégicos operacionais voltados à gestão dos serviços de hemoterapia; bem como, para a análise e aperfeiçoamento da política estadual para as pessoas com coagulopatias e hemoglobinopatias, de forma a possibilitar a compreensão de que o cuidado dessas pessoas perpassa por todos os níveis de atenção, abrangendo, desse modo, a gestão da política e a gestão dos serviços.

Além disso, propõe-se a estimular o processo de planejamento em saúde de modo articulado, solidário e integrado entre os diversos serviços que compõem o SUS, contemplando as necessidades regionais de cada estado e visando como principal produto o Plano Diretor de Hematologia e Hemoterapia, de maneira a ser pactuado nas instâncias locais do SUS de forma articulada às Redes de Atenção a Saúde e na perspectiva da inserção das necessidades das Hemorredes nas agendas políticas estaduais.

Outra iniciativa importante da gestão federal é o PNQH, como já citado anteriormente, que tem como objetivo aperfeiçoar as atividades dos $\mathrm{SHH}$ com foco na melhoria dos processos, a fim de promover o aumento da segurança transfusional por meio da colaboração mútua da Hemorrede. O programa visa promover a qualidade técnica e gerencial da atenção hematológica e hemoterápica em consonância com os princípios e diretrizes do SUS, no que se refere à constante busca da integralidade, da universalidade e da equidade na disponibilização dos serviços hematológicos e hemoterápicos. Como a abrangência do PNQH se destina principalmente aos hemocentros coordenadores, e considerando a complexidade que envolve a segurança transfusional, foi necessário ampliar o escopo de atuação do programa e implantar a etapa de estadualização, com o PEQH, implantação que foi iniciada em 2011. (BRASIL, 2016) O PEQH tem como objetivo implantar e implementar o programa de qualificação técnica e gerencial na hemorrede estadual/regional, promovendo, assim, o fortalecimento da articulação e da coordenação estadual entre os SHH, visando à conformação em rede dos SHH.

Assim, enquanto o Planeja Sangue promove o envolvimento dos diversos atores sociais da Secretaria Estadual de Saúde, das Vigilâncias, gestores e profissionais dos serviços de hematologia e hemoterapia e dos diversos pontos de atenção, dentre outros no processo de elaboração do Plano Diretor da Hemorrede estadual e, com isso se caracteriza como prática integrativa 
da Hemorrede com os pontos de atenção da RAS, o PEQH consolida-se como potente iniciativa para fortalecer a articulação dos serviços de hematologia e hemoterapia em rede. Dessa forma, embora com ênfase e abrangência diferentes, as estratégias citadas se complementam e se entrelaçam à medida que pretendem promover a disponibilização das ações e serviços aos usuários do SUS de forma articulada e a oferta da atenção hematológica e hemoterápica de modo integral.

Outra iniciativa ou ação estratégica da gestão federal indutora de articulação da Hemorrede com outros pontos de atenção da RAS é a elaboração e o fortalecimento de linhas de cuidado na atenção hematológica e hemoterápica, que tem como exemplo, a Linha de Cuidado às pessoas com Doença Falciforme. (BRASIL, 2015) A Linha de Cuidado é uma proposta de reorganização dos processos de trabalho, com base na organização de fluxos assistenciais capazes de garantir acesso às tecnologias necessárias. Estes fluxos têm o usuário como elemento central e estruturante de todo processo de produção da saúde e opera com base na integralidade e nas necessidades de saúde dos usuários. (FRANCO; MAGALHÃES JÚNIOR, 2004)

Malta e Merhy (2010) ressaltam que a organização do serviço com base em Linhas de Cuidado deve promover ao usuário um "caminhar na rede de serviços" de forma segura e sem obstáculos. Apontam ainda que a linha de produção de cuidado não deve se esgotar no Projeto Terapêutico, mas que deve continuar no acompanhamento deste usuário ao longo do tempo, a fim de garantir a integralidade do cuidado em todos os serviços acessados. Para tanto, os autores salientam a necessária responsabilização tanto da equipe, quanto dos gestores públicos, para que não ocorram a interrupção e a segmentação do cuidado.

A organização de Linhas de Cuidado estimula a utilização de tecnologias leves produtoras de singularizações no cuidado e considera, para o planejamento das ações em saúde, as necessidades do usuário como ponto de partida para a conformação da oferta da atenção em saúde. (MALTA; MERHY, 2010)

A estruturação de Linhas de Cuidado pode ser potente ferramenta de gestão especialmente na Atenção Hematológica, visto que conforme já colocado anteriormente, possibilita, ao ser devidamente pactuada com os atores necessários, a oferta de cuidados que não estão disponíveis nos SHH. Ainda, 
considerando a perspectiva do cuidado integral e que em muitas regiões do país a acessibilidade é um obstáculo que ocasiona várias implicações para o sucesso da adesão ao tratamento, a elaboração e a implementação de Linhas de Cuidado na Atenção Hematológica favorece a superação dos vazios assistenciais, visto, inclusive, que o atendimento próximo ao local de residência proporciona estabelecimento de vínculo entre o usuário e a equipe de saúde, promovendo uma abordagem mais integral. Na atenção às pessoas com Hemoglopinopatias, essa lógica de cuidado tem refletido na redução da morbimortalidade e no aumento da expectativa de vida para as pessoas com doença Falciforme. (BRASIL, 2006b, 2016)

Apesar da importância da gestão federal no fomento e na orientação das diretrizes para a organização de Linhas de Cuidado na Atenção Hematológica, cabe ressaltar que a conformação e a pactuação dos fluxos de cuidado ocorrem nas instâncias regionais, já que uma determinada região de saúde possui características diversas quanto à composição dos serviços em sua rede. Por esse motivo, o envolvimento dos devidos gestores de serviço e da Secretaria de Saúde do estado torna-se essencial para legitimar as negociações e os acordos dos fluxos estabelecidos. Nesse sentido, recomenda-se, ainda, a aprovação das Linhas de Cuidado nas Comissões Intergestores Regional (CIR) e nas Comissões Intergestores Bipartite (CIB) (BRASIL, 2011), com o intuito não apenas de definir os serviços envolvidos, mas também de pleitear investimentos para a melhoria da atenção.

Por fim, para além da elaboração e definição da Linha de Cuidado, a implementação é etapa importante deste ciclo de políticas públicas, pois é entendida como o "resultado de um processo interativo através do qual uma política, que se mantém em formulação durante um tempo considerável, se relaciona com o seu contexto e com as organizações responsáveis por sua implementação". (BAPTISTA; REZENDE, 2011, p. 150) Rua (1998) também coloca os riscos existentes na fase da implementação, pois pode ocorrer distanciamento entre a demanda que deu origem ao processo e seu atendimento efetivo. Além disso, ressalta que não existe vínculo direto entre a decisão política e a sua implementação.

Os desafios para implementação das Linhas de Cuidado também podem ser considerados os mesmos aos das RAS, já que operam na mesma lógica de integração de serviços, tais como a capacitação das equipes e dos gestores; 
a incipiente estrutura de gestão nas regiões de saúde; a governança e financiamento insuficiente das redes; as deficiências em sistemas de informação e comunicação; o nó crítico da regulação; e a insuficiência da oferta histórica de serviços do SUS em diversos componentes e nas várias regiões do país. (MAGALHÃES JÚNIOR, 2014)

Nesse sentido, considerando os desafios da implementação das Linhas de Cuidado, especialmente no atual cenário econômico do país e considerando as complexidades e peculiaridades da Atenção Hematológica, que ora exigem a concentração de cuidados nos serviços de hematologia e hemoterapia e ora necessitam articulação com outros pontos de atenção das RAS, pressupõem-se que os desafios são amplos desde as fases de elaboração e definição até a de implementação, o que aponta a necessidade do envolvimento permanente de profissionais, gestores e usuários e o alinhamento de múltiplas estratégias técnicas e de gestão visando à melhoria da oferta de cuidados a este público.

\section{Considerações finais}

Embora projetos, estratégias e iniciativas têm sido desenvolvidos visando à implementação de ações integrativas nos demais entes federativos, muitas dificuldades e desafios ainda persistem no cotidiano dos gestores, profissionais e usuários que buscam melhorias para a atenção hematológica e hemoterápica.

O compromisso para a superação das vulnerabilidades programáticas, sociais e individuais presentes na atenção hematológica e hemoterápica é coletivo e exige ainda grandes somas de investimentos material e humano, bem como impõem a necessidade tanto de ações e de resultados imediatos, quanto de longo prazo. Portanto, o reconhecimento e análise dos problemas, bem como, a priorização, o desenho e execução das ações é responsabilidade dos diferentes atores, não sendo o esforço restrito individualmente ao gestor, profissional ou usuário.

Resgatando a importância da inclusão e permanência da política na agenda de governo, bem como, o desenvolvimento das propostas e iniciativas/ ações voltadas para a hemoterapia e atenção hematológica e a necessidade de avaliação que deve contemplar o esforço para a integração das ações e serviços na rede de atenção, as discussões não se esgotam, ao contrário, este 
capítulo provoca reflexões e ousa estimular e motivar práticas transformadoras da realidade que promovam a superação da fragmentação da atenção aos usuários do SUS e dos desafios da gestão em saúde.

\section{Referências}

AGÊNCIA NACIONAL DE VIGILÂNCIA SANITÁRIA (Brasil). Resolução nº 10, de 23 de janeiro de 2004. Aprova as diretrizes para uso de Plasma Fresco Congelado - PFC e de Plasma Vírus Inativo. Diário Oficial [da] República Federativa do Brasil, Brasília, DF, 26 jan. 2004. Disponível em: <http://redsang. ial.sp.gov.br/site/docs_leis/rs/rs10.pdf>. Acesso em: 29 jan. 2016.

AGÊNCIA NACIONAL DE VIGILÂNCIA SANITÁRIA (Brasil). Resolução ${ }^{\circ}$ 151, de 21 de agosto de 2001. Aprova o Regulamento Técnico sobre Níveis de Complexidade dos Serviços de Hemoterapia. Diário Oficial [da] República Federativa do Brasil, Brasília, DF, 22 ago. 2001.

AVALIAÇÃO sanitária dos serviços de hemoterapia - 2014. Boletim Anual de Avaliação Sanitária em Serviços de Hemoterapia, Brasília, DF, n. 7, nov. 2015. Disponível em: <http://portal.anvisa.gov.br/documents/33840/2817158/ 7\%C2\%BA+Boletim+Anual+de+Avalia\%C3\%A7\%C3\%A3o+Sanit\%C3\%Alria +em+Servi\%C3\%A7os+de+Hemoterapia+2015/884eafal-baeb-47d9-9061e761lddle274>. Acesso em: 6 maio 2016.

BAPTISTA, T. W. de F.; REZENDE, M. de. A ideia de ciclo na análise de políticas públicas. In: MATTOS, R. A. de; BAPTISTA, T. W. de F. (Org.). Caminhos para análise das políticas de saúde. Porto Alegre: Rede Unida, 2011. p. 138-172. Disponível em: <http://historico.redeunida.org.br/editora/ biblioteca-digital/serie-interlocucoes-praticas-experiencias-e-pesquisasem-saude/caminhos-para-analise-das-politicas-de-saude-pdf $>$. Acesso em: 17 maio 2016.

BARCA, D. A. A. V. Política nacional de sangue, componentes e hemoderivados no Brasil. In: BRASIL. Ministério da Saúde. Técnico em hemoterapia: livro texto. Brasília, DF: 2013. p. 37-45. Disponível em: <http:// bvsms.saude.gov.br/bvs/publicacoes/tecnico_hemoterapia_livro_texto.pdf $>$. Acesso em: 28 mar. 2014.

BASTOS, M. S.; SOUZA, M. K. B. Perfil de agências transfusionais no estado do Pará: adequação à legislação hemoterápica. Salvador, 2014.

BRASIL. Decreto $n^{\circ} 3.990$, de 30 de outubro de 2001. Regulamenta o art. 26 da Lei $n^{\circ} 10.205$, de 21 de março de 2001, que dispõe sobre a coleta, processamento, estocagem, distribuição e aplicação do sangue, seus 
componentes e derivados, e estabelece o ordenamento institucional indispensável à execução adequada dessas atividades. Diário Oficial [da] República Federativa do Brasil, Poder Executivo, Brasília, DF, 31 out. 2001a. Seção 1, p. 1.

BRASIL. Decreto $\mathrm{n}^{\circ} 7.508$, de 28 de junho de 2011. Regulamenta a Lei $\mathrm{n}^{\circ}$ 8.080, de 19 de setembro de 1990, para dispor sobre a organização do Sistema Único de Saúde - SUS, o planejamento da saúde, a assistência à saúde e a articulação interfederativa, e dá outras providências. Diário Oficial [da] República Federativa do Brasil, Poder Executivo, Brasília, DF, 29 jun. 2011. Seção 1, p. 1.

BRASIL. Lei ${ }^{\circ}$ 1.075, de 27 de março de 1950. Dispõe sôbre doação voluntária de sangue. Coleção de Leis da República Federativa do Brasil, Brasília, DF, v. 3, p. 142, abr. 1950.

BRASIL. Lei ${ }^{\circ}$ 4.701, de 28 de junho de 1965. Dispõe sobre o exercício da atividade hemoterápica no Brasil e dá outras providências. Diário Oficial [da] República Federativa do Brasil, Poder Legislativo, Brasília, DF, 9 jul. 1965. Seção 1, p. 6450. Disponível em: <http://www.planalto.gov.br/ccivil_03/leis/ L4701.htm>. Acesso em: 10 nov. 2015.

BRASIL. Lei n ${ }^{\circ} 8.080$, de 19 de setembro de 1990. Dispõe sobre as condições para a promoção, proteção e recuperação da saúde, a organização e o funcionamento dos serviços correspondentes e dá outras providências. Diário Oficial [da] República Federativa do Brasil, Poder Legislativo, Brasília, DF, 20 set. 1990. Seção 1, p. 18055.

BRASIL. Lei 10.205, de 21 de março de 2001. Regulamenta o § $4^{\circ}$ do art. 199 da Constituição Federal, relativo à coleta, processamento, estocagem, distribuição e aplicação do sangue, seus componentes e derivados, estabelece o ordenamento institucional indispensável à execução adequada dessas atividades, e dá outras providências. Diário Oficial [da] República Federativa do Brasil, Poder Legislativo, Brasília, DF, 22 mar. 2001b. Seção 1, p. 1. Disponível em: <http://www.planalto.gov.br/ccivil_03/leis/leis_2001/ 110205.htm>. Acesso em: 10 nov. 2015.

BRASIL. Ministério da Saúde. Portaria n ${ }^{\circ}$ 364, de 6 de maio de 2014. Aprova o Protocolo de Uso de Profilaxia Primária para Hemofilia Grave._Diário Oficial [da] República Federativa do Brasil, Brasília, DF, 7 maio 2014a. Seção 1, p. 46.

BRASIL. Ministério da Saúde. Portaria n ${ }^{\circ}$ 399, de 22 de fevereiro de 2006. Divulga o Pacto pela Saúde 2006 - Consolidação do SUS e aprova as Diretrizes Operacionais do Referido Pacto. Diário Oficial [da] República Federativa do Brasil, Brasília, DF, 23 fev. 2006a. Seção 1, p. 43. Disponível em: 
<http://bvsms.saude.gov.br/bvs/saudelegis/gm/2006/prt0399_22_02_2006. html>. Acesso em: 20 jan. 2016.

BRASIL. Ministério da Saúde. Portaria ${ }^{\circ}$ 478, de 16 de junho de 2014. Aprova o Protocolo de Uso de Indução de Imunotolerância para Pacientes com Hemofilia A e Inibidor. Diário Oficial [da] República Federativa do Brasil, Brasília, DF, 17 jun. 2014b. Seção 1, p. 70.

BRASIL. Ministério da Saúde. Portaria $n^{\circ}$ 822, de 6 de junho de 2001. Institui, no âmbito do Sistema Único de Saúde, o Programa Nacional de Triagem Neonatal. Diário Oficial [da] República Federativa do Brasil, Brasília, DF, 7 jun. 2001c. Seção 1, p. 33. Disponível em: <http://bvsms.saude.gov.br/bvs/ saudelegis/gm/2001/prt0822_06_06_2001.html>. Acesso em: 6 maio 2016.

BRASIL. Ministério da Saúde. Portaria n 951, de 10 de maio de 1996. Institui grupo de trabalho com a finalidade de elaborar o Programa Nacional de Anemia Falciforme. Diário Oficial [da] República Federativa do Brasil, Brasília, DF, 13 maio 1996.

BRASIL. Ministério da Saúde. Portaria n ${ }^{\circ}$ 1.391, de 16 de agosto de 2005. Institui no âmbito do Sistema Único de Saúde, as diretrizes para a Política Nacional de Atenção Integral às Pessoas com Doença Falciforme e outras Hemoglobinopatias. Diário Oficial [da] República Federativa do Brasil, Brasília, DF, 18 ago. 2005. Seção 1, p. 40. Disponível em: <http://bvsms.saude.gov. br/bvs/saudelegis/gm/2005/prt1391_16_08_2005.html>. Acesso em: 20 jan. 2016.

BRASIL. Ministério da Saúde. Portaria ${ }^{\circ} 4.279$, de 30 de dezembro de 2010. Estabelece diretrizes para a organização da Rede de Atenção à Saúde no âmbito do Sistema Único de Saúde (SUS). Diário Oficial [da] República Federativa do Brasil, Brasília, DF, 31 dez. 2010. Seção 1, p. 88. Disponível em: <http://bvsms.saude.gov.br/bvs/saudelegis/gm/2010/prt4279_30_12_2010. html>. Acesso em: 1 dez. 2014.

BRASIL. Ministério da Saúde. Secretaria de Atenção à Saúde. Departamento de Atenção Especializada e Temática. Doença falciforme: diretrizes básicas da linha de cuidado. Brasília, DF, 2015. 82 p.

BRASIL. Ministério da Saúde. Secretaria de Atenção à Saúde. Departamento de Atenção Especializada e Temática. Guia para implementar avaliações nos serviços de hematologia e hemoterapia na perspectiva do Programa Nacional de qualificação da hemorrede. Brasília, DF, 2016. Disponível em: <http://bvsms. saude.gov.br/bvs/publicacoes/guia_implementar_avaliacoes_servicos_ hematologia.pdf $>$. Acesso em: 13 maio 2016. 
BRASIL. Ministério da Saúde. Secretaria de Atenção à Saúde. Departamento de Atenção Especializada. Manual de anemia falciforme para agentes comunitários de saúde. Brasília, DF, 2006b. (Série A: normas e manuais técnicos). Disponível em: <http://bvsms.saude.gov.br/bvs/publicacoes/ manual_anemia_falciforme_agentes_comunitario.pdf $>$. Acesso em: 17 maio 2016.

BRASIL. Ministério da Saúde. Secretaria de Atenção à Saúde. Departamento de Atenção Especializada. Perfil das coagulopatias hereditárias no Brasil: 2009-2010. 2. ed. Brasília, DF, 2012.

BRASIL. Ministério da Saúde. Secretaria de Atenção à Saúde. Diretoria de Articulação de Redes de Atenção à Saúde. Redes regionalizadas de atenção à saúde: contexto, premissas, diretrizes gerais, agenda tripartite para discussão e proposta de metodologia para apoio à implementação. Brasília, DF, 2008.

CANÇADO, R. D.; JESUS, J. A. A doença falciforme no Brasil. Revista Brasileira de Hematologia e Hemoterapia, [São Paulo], v. 29, n. 3, p. 203-206, 2007.

CÂNDIDO, G. A.; ABREU, A. F de. Os conceitos de redes e as relações interorganizacionais: um estudo exploratório. In: BASTOS, M. S.; SOUZA, M. K. B. Perfil de agências transfusionais no estado do Pará: adequação à legislação hemoterápica. Salvador, 2014.

CAZAL, P. Relatório sobre a organização da hemoterapia no Brasil. [S.l.]: Organização Mundial da Saúde, 1969.

CIOFFI, J. G. M.; MURAO, M. Produção de serviços: o ciclo do sangue e os ambulatórios. In: FUNDAÇÃO CENTRO DE HEMATOLOGIA E HEMOTERAPIA DE MINAS GERAIS. Fundação Hemominas: 1985-2007. Belo Horizonte, 2007. cap. 9, p. 91-156.

FLEURY, S.; OUVERNEY, A. M. Política de saúde: uma política social. In: GIOVANELLA, L. et al. (Org.). Políticas e sistema de saúde no Brasil. 2. ed. rev. e ampl. Rio de Janeiro: Ed. Fiocruz, 2012. cap. 1, p. 25-57.

FRANCO, T. B.; MAGALHÃES JÚNIOR, H. M. A integralidade na assistência à saúde e a organização das linhas de cuidado. In: MERHY, E. E. et al. $O$ trabalho em saúde: olhando e experienciando o SUS no cotidiano. São Paulo: Hucitec, 2004.

GRAMKOW, A. Redes e parcerias organizacionais: a experiência da maricultura catarinense. 2002. 158 f. Dissertação (Mestrado em Administração) Universidade Federal de Santa Catarina, Florianópolis, 2002. 
GUERRA, C. C. C. Fim da doação remunerada de sangue no Brasil faz 25 anos. Revista Brasileira de Hematologia e Hemoterapia, [São Paulo], n. 27, n. 1, p. 1-4, jan./mar. 2005.

HARTZ, Z. M. de A.; CONTANDRIOPOULOS, A.-P. Integralidade da atenção e integração de serviços de saúde: desafios para avaliar a implantação de um "sistema sem muros". Cadernos de Saúde Pública, Rio de Janeiro, v. 20, p. 331336, 2004. Suplemento 2.

HOGAN, V.; GARGARELLA, G. Revisão do Sistema Nacional de Sangue. Brasília, DF, 1997. Relatório destinado ao Ministério da Saúde.

JUNQUEIRA, P. C.; ROSENBLIT, J.; HAMERSCHLAK, N. História da hemoterapia no Brasil. Revista Brasileira de Hematologia e Hemoterapia, [São Paulo], v. 27, n. 3, p. 201-207, 2005.

LANDSTEINER, K. Zur Kenntnis der anti fermentativen, lytischen und agglutinierenden Wirkungen des Blutserums und der Lymphe. Zentralbl Bakteriol, [S.1.], n. 27, p. 357- 362, 1900.

MAGALHÃES JÚNIOR, H. M. Redes de atenção à saúde: rumo à integralidade. Revista Divulgação em Saúde para Debate, Rio de Janeiro, n. 52, p. 15-37, out. 2014. Disponível em: <http://cebes.org.br/site/wp-content/uploads/2014/12/ Divulgacao-52.pdf $>$. Acesso em: 18 maio 2016.

MALTA, D. C.; MERHY, E. E. O percurso da linha do cuidado sob a perspectiva das doenças crônicas não transmissíveis. Interface: comunicação, saúde e educação, Botucatu, v. 14, n 34, p. 593-605, jul./set. 2010.

MÁXIMO, C. A política de atenção integral à pessoa com doença falciforme no estado do Rio de Janeiro e os desafios da descentralização. 2009. $104 \mathrm{f}$. Dissertação (Mestrado em Saúde Publica) - Escola Nacional de Saúde Pública, Fundação Oswaldo Cruz, Rio de Janeiro, 2009. Disponível em: <https://www.arca.fiocruz.br/bitstream/icict/5267/2/1168.pdf>. Acesso em: 7 jan. 2016.

MELO, H. T. Mapeamento do ordenamento jurídico da política nacional de sangue e da regulamentação técnica na área do sangue e derivados. 2015. 102 f. Dissertação (Mestrado em Medicina) - Faculdade de Medicina de Ribeirão Preto, Universidade de São Paulo, Ribeirão Preto, 2015. Disponível em: $<$ http://www.teses.usp.br/teses/disponiveis/17/17155/tde-22062015-215957/ pt-br.php>. Acesso em: 26 jan. 2016.

MENDES, E. V. As redes de atenção à saúde. 2. ed. Brasília, DF: Organização Pan-Americana da Saúde, 2011. 
MENDES, E. V. As redes de atenção à saúde. Ciência \& Saúde Coletiva, Rio de Janeiro, v. 15, n. 5, p. 2297-2305, 2010.

MERHY, E. E. A perda da dimensão cuidadora na produção da saúde: uma discussão do modelo assistencial e da intervenção no seu modo de trabalhar a assistência. In: CAMPOS, C. R. et al. (Org.). Sistema Único de Saúde em Belo Horizonte: reescrevendo o público. Belo Horizonte: Xamã, 1998. p. 103-120.

NORONHA, J. C.; LIMA, L. D.; MACHADO, C. V. O Sistema Único de Saúde SUS. In: GIOVANELLA, L. et al. (Org.). Políticas e sistema de saúde no Brasil. 2. ed. rev. e ampl. Rio de Janeiro: Ed. Fiocruz: Cebes, 2012. cap. 12, p. 365-393.

PAIM, J. S. Políticas de saúde no Brasil. In: ROUQUAYROL, M. Z.; ALMEIDA FILHO, N. de. Epidemiologia \& saúde. 6. ed. Rio de Janeiro: Medsi, 2003. p. 587-603.

PINTO, I. C. M.; VIEIRA-DA-SILVA, L. M.; BAPTISTA, T. V. F. Ciclo de uma política pública de saúde: problematização, construção da agenda, institucionalização, formulação, implementação e avaliação. In: PAIM, J. S.; ALMEIDA FILHO, N. de. Saúde coletiva: teoria e prática. Rio de Janeiro: MedBook, 2014. cap. 6, p. 69-81.

PUGIN, S. R.; NASCIMENTO, V. B. do. Principais marcos das mudanças institucionais no setor saúde (1974-1996). 1996. (Série didática, n. 1). Disponível em: <http://www.cedec.org.br/files_pdf/DIDATIl.pdf $>$. Acesso em: 7 jan. 2016.

RIBEIRO, C. M. F. A hemoterapia no Brasil até 1980 e a criação dos hemocentros públicos nacionais. In: FUNDAÇÃO CENTRO DE HEMATOLOGIA E HEMOTERAPIA DE MINAS GERAIS. Fundação Hemominas: 1985-2007. Belo Horizonte, 2007. cap. 2, p. 25-36.

RUA, M. G. Análise de políticas públicas: conceitos básicos. In: RUA, M. das G.; CARVALHO, M. I. V. de. O estudo da política: tópicos selecionados. Brasília, DF: Paralelo 15, 1998. Disponível em: <http://franciscoqueiroz.com.br/portal/ phocadownload/gestao/rua\%20maria\%20_\%20analisedepoliticaspublicas. pdf $>$. Acesso em: 23 jan. 2016.

SAMPAIO, D. D. A. Cenário político, social e cultural da hemoterapia no Brasil. In: BRASIL. Ministério da Saúde. Técnico em hemoterapia: livro texto. Brasília, DF: 2013. p. 7-18. Disponível em: <http://bvsms.saude.gov.br/bvs/ publicacoes/tecnico_hemoterapia_livro_texto.pdf $>$. Acesso em: 28 mar. 2014.

SANTOS, L. A. de C.; MORAES, C.; COELHO, V. S. P. A hemoterapia no Brasil de 64 a 80. Physis: Revista de Saúde Coletiva, Rio de Janeiro, v. 1, n. 1, p. 161$182,1991$. 
SARAIVA, J. C. P. A história da hemoterapia no Brasil. Revista Brasileira de Hematologia e Hemoterapia, [São Paulo], v. 27, n. 3, p. 153-158, 2005.

SILVA, K. F. N.; SOARES, S.; IWAMOTO, H. H. A prática transfusional e a formação dos profissionais de saúde. Revista Brasileira de Hematologia e Hemoterapia, [São Paulo], v. 31, n. 6, p. 421-462, dez. 2009.

SOUZA, L. E. P. F.; VIANA, A. L. D’A. Gestão do SUS: descentralização, regionalização e participação social. In: PAIM, J. S.; ALMEIDA FILHO, N. de. Saúde coletiva: teoria e prática. Rio de Janeiro: MedBook, 2014. p. 261-269. 


\title{
Gestão da qualidade e avaliação dos serviços de hematologia e hemoterapia na perspectiva no Programa Nacional de Qualificação da Hemorrede
}

\author{
Jane Terezinha Martins \\ Glauciene Analha Leister \\ Cláudio Medeiros Santos
}

\section{Introdução}

O papel fundamental da gestão é levar as organizações ou serviços a cumprir a sua missão. Na expressão de Magretta e Stone (2002) "criação de valor" é o elemento fundamental, a missão da gestão. Valor, no sentido apresentado pelas autoras, significa capacidade de atender às reais necessidades daqueles que são os destinatários, os usuários, os consumidores dos serviços e produtos oferecidos pela organização. Quer seja valor econômico, aplicado no contexto das organizações privadas, quer seja valor social ou bem-estar social, aplicado para as organizações públicas, sem fins lucrativos.

Com posicionamento semelhante, Mintzberg (2010, p. 61) destaca que a suprema finalidade da gestão é "garantir que a unidade sirva ao seu propósito básico”, realizando para isso, ações eficazes. 
Em suas conclusões sobre a natureza da gestão Mintzberg (2010, p. 23) propõe que gestão não é ciência, muito menos profissão. Gestão é uma prática, aprendida principalmente com a experiência e enraizada no contexto.

Para o autor, a gestão eficaz, compreendida como uma prática, está associada a aplicação de três elementos essenciais: a arte, vista como discernimento criativo, visão, intuição, ideias; a habilidade prática, que guarda estreita relação com a experiência, com a capacidade de fazer conexões, de compreender e resolver problemas; e finalmente, a ciência, entendida como a aplicação de métodos, uso sistemático da análise. Como estes elementos interagem sempre nos limites de um dado contexto, pode-se afirmar que não existe a melhor maneira de fazer gestão. (MINTZBERG, 2010)

Na gestão de serviços públicos de saúde, em particular, na gestão dos serviços públicos de hematologia e hemoterapia os desafios se ampliam. São serviços localizados em diferentes regiões, contextos e culturas, com estrutura jurídica e organizacional variada; uns ligados a Administração Direta Estadual, outros ligados as universidades e outros mais estruturados nos modelos ${ }^{1}$ de autarquias, fundações e organizações sociais. Os seus gestores, nestes variados contextos, empregando suas habilidades, suas ciências e suas artes, lançam mão de instrumentos, métodos, práticas e modelos, buscando, ao fim e ao cabo, fazer com que estas organizações cumpram a sua missão de disponibilizar sangue e componentes na quantidade compatível com as necessidades e demandas e com a qualidade adequada para maior segurança e efetividade dos procedimentos de atenção à saúde, particularmente os transfusionais.

Em busca destas ações eficazes de gestão, uma das tecnologias gerenciais empregadas frequentemente nos serviços de hematologia e hemoterapia é a gestão da qualidade. Nestes serviços, a qualidade do produto final é consequência de uma complexa rede de atividades e processos, que vão desde a adequada seleção do doador até a disponibilização e transporte do produto para os Centros de Atenção a Saúde, onde serão utilizados. Não obstante os avanços das práticas de produção e modernização da gestão dos serviços, esta qualidade pode ver-se comprometida em algumas das etapas da cadeia,

1 Veja definições e características de cada modelo organizativo em Conselho Nacional de Secretários de Saúde (1995). 
podendo, por conseguinte, ampliar o potencial de riscos e danos à saúde do cliente final. Devido a isso os serviços hemoterápicos devem incorporar em suas atividades conceitos de qualidade e boas práticas de produção. (LEDESMA RODRÍGUEZ; FRANCO CAMA, 2007)

Para Berwik (1991), citado por Malik e Schiesari (1998, p. 27), a gestão da qualidade nos serviços de saúde está fundamentada em alguns princípios, dentre eles o de que "[...] o trabalho produtivo é realizado através de processos [e] [...] a principal fonte de falhas de qualidade são os problemas nos processos", devendo, por isso, o controle de qualidade ter que se concentrar nestes conjuntos de atividades. Na sua lista de princípios, Berwik (1991 apud MALIK; SCHIESARI, 1998, p. 27) assevera que a “[...] administração da qualidade emprega três atividades básicas, estreitamente inter-relacionadas: planejamento da qualidade, controle da qualidade e melhoria da qualidade".

Para Donabedian (1990), a qualidade da atenção à saúde é definida como o "grau em que os meios mais desejáveis" são empregados para a melhoria na saúde. Sangue e componentes seguros e com padrões adequados de qualidade podem se entendidos como um "meio desejável" apresentado no conceito desse autor. Destaca ele que nenhuma avaliação da qualidade seria possível sem a existência e a combinação de critérios e padrões. Os critérios seriam os elementos da estrutura, processo e resultados e os padrões declarações quantitativas mais específicas que permitam avaliar frequência e magnitude.

Antes que qualquer um destes três elementos (estrutura, processo e resultados) seja utilizado para avaliação da qualidade, é necessário que as relações (causa e efeito) entre eles sejam conhecidas e estabelecidas, o que implica tanto conhecimentos das ciências organizacionais como também das ciências clínicas ou médicas. (DONABEDIAN, 1988)

Aplicando a tríade apresentada por Donabedian (1990) no âmbito dos Serviços de Hemoterapia, tem-se na "estrutura" todos os recursos materiais, humanos, de infraestrutura e tecnologias empregadas na produção de hemocomponentes, incluindo, na parte de recursos humanos, tanto as características quantitativas como as relacionadas a competência e formação profissional. Na dimensão dos "processos", encontra-se o modo como as atividades são executadas, encadeadas e organizadas de forma a gerar os produtos. Por 
fim, os produtos gerados (sangue e componentes) compõem a dimensão dos "resultados", incluindo também aqui os efeitos ou a modificação dos estados de saúde gerados após a prática transfusional.

$\mathrm{Na}$ atualidade, a gestão da qualidade nos serviços de hemoterapia foi incorporada a legislação sanitária sendo sua aplicação, não mais uma escolha do gestor, mas uma exigência legal. A Portaria GM n ${ }^{\circ} 158$ do Ministério da Saúde, de 4 de fevereiro de 2016, que redefine o regulamento técnico de procedimentos hemoterápicos, estabelece no capítulo II - Da Garantia da Qualidade, os princípios gerais do sistema da qualidade que deve ser mantido pelo serviço. Neste capítulo II, o artigo 240 estabelece:

Art. 240. O serviço de hemoterapia disporá de políticas e ações que assegurem a qualidade dos produtos e serviços garantindo que os procedimentos e processos ocorram sob condições controladas. § $1^{\circ}$ São, entre outras, as ações de que trata o 'caput': I - métodos e ferramentas de melhoria contínua; II - processos de proposição de ações preventivas e corretivas; e III - tratamento das reclamações e sugestões dos usuários. § $2^{\circ} \mathrm{O}$ desempenho dos processos será acompanhado por meio de indicadores e definição de metas. (BRASIL, 2016a)

A gestão de serviços e, em particular a gestão da qualidade, guarda uma relação muito próxima com a prática da Avaliação. Vieira-da-Silva (2014) chega a afirmar que a avaliação é um dos componentes do processo de gestão e pode ser realizada objetivando, por exemplo, determinar se um dado programa (ou mesmo um dado serviço) está produzindo os resultados que deveria. A avaliação contribui para a melhoria do processo decisório e deve ser vista pela gestão como um instrumento para o enfrentamento e a resolução de problemas nos serviços ou programas de saúde. (TANAKA; MELO, 2008)

Nesta mesma linha de pensamento Malik e Shiesari $(1998$, p. 9) afirmam que:

A avaliação tenta trazer respostas a perguntas a respeito dos resultados esperados de um programa, ação ou serviço. O objeto pode ser o impacto ou até os processos. Ambos os focos guardam estreitas semelhanças com o desenvolvimento do pensamento 
da qualidade, cujo marco inicial deu-se via inspeções do produto final, até chegar à avaliação da qualidade dos processos (ou sua administração) antes que o produto final saia da fábrica. O fundamental, quando se fala em avaliação, é ter claro que ela serve para definir se algo é ou não bom, digno de ser prosseguido ou deve ser interrompido. Para isso, devem-se explicitar os critérios utilizados, a que necessidades ou interesses esses critérios respondem e quem pode ser favorecido ou prejudicado em presença desses resultados.

O Serviço de Hematologia e Hemoterapia está oferecendo Sangue e Componentes segundo os padrões de qualidade estabelecidos pelas normas sanitárias, pelas boas práticas de produção ou pelos padrões de qualidade desejados? A gestão está atuando adequadamente? Os processos produtivos estão ajustados? Onde estão os problemas? O que pode ser melhorado? O que está ótimo? São todas perguntas de gestão que a prática sistemática da avaliação pode responder.

Nesse contexto, o Programa Nacional de Qualificação da Hemorrede (PNQH) é considerado importante ferramenta para a identificação de cenários nos Serviços de Hematologia e Hemoterapia (SHH) e, consequentemente, potente estratégia para apontar oportunidades de melhorias técnicas e gerenciais na Hemorrede e para promover o aperfeiçoamento dos processos de trabalho na premissa da gestão da qualidade. Assim, com o intuito de possibilitar diagnóstico situacional da Hemorrede e orientar o desenvolvimento de ações visando ao aumento da segurança transfusional para todos os serviços do país, em 2008, o PNQH foi criado com os seguintes objetivos (BRASIL, 2016b):

- Promover a qualificação técnica e gerencial da Hemorrede Pública Nacional;

- Identificar áreas críticas/estratégicas para priorizar investimento de recursos na Hemorrede;

- Implantar e implementar o processo de melhoria contínua nos SHH, por meio da avaliação permanente dos processos de trabalho; 
- Apoiar a elaboração e monitorar a evolução de Planos de Ação (PA) dos SHH, para as não conformidades e/ou recomendações apontadas no relatório de visita;

- Promover a cooperação e a integração entre SHH públicos do país;

- Prestar consultorias técnicas e realizar capacitações conforme necessidades apontadas nas visitas;

- Motivar mudanças internas nos SHH, como a implantação e/ou implementação do sistema de gestão da qualidade, a certificação e/ ou acreditação da unidade, capacitação dos profissionais, enfim a busca pela excelência da qualidade dos serviços e produtos hemoterápicos e hematológicos.

Em 2015, um estudo de avaliabilidade do PNQH, aplicado no Hemocentro do Ceará (SOBREIRA, 2015), desenvolveu o Modelo Lógico do Programa, analisando os modelos: causal, operacional e lógico teórico. No modelo causal, identificou o problema que o programa pretende resolver ou minimizar. Já no modelo lógico operacional identificou a estrutura, os processos, e o objetivos de produção, finalizando no modelo lógico teórico, a identificação dos objetivos e finalidades da intervenção. O estudo concluiu que o programa contribui para impulsionar mudanças e melhorias nos SHH (Figura 1).

Considerando a complexidade dos objetivos definidos, para o alcance dos mesmos e para a operacionalização do programa foi sistematizada ampla gama de ações, inclusive com o consenso da Comissão de Assessoramento Técnico (CAT) do PNQH e de gestores da Hemorrede. Assim, considerando como referência, os padrões de boas práticas de produção e das normas vigentes, estabeleceu-se que seriam realizadas visitas de avaliação formativas e processuais, com o intuito de promover o aperfeiçoamento dos processos de trabalho nos Serviços de Hematologia e Hemoterapia, buscando se distanciar da tônica de auditoria.

"Avaliar para conhecer, conhecer para ajudar, ajudar para melhorar" foi o lema adotado, traduzindo, portanto, a essência do programa, de além de promover o levantamento de informações para a gestão dos SHH, desenvolver uma rede de relacionamentos técnicos e gerenciais capaz de induzir mudan- 


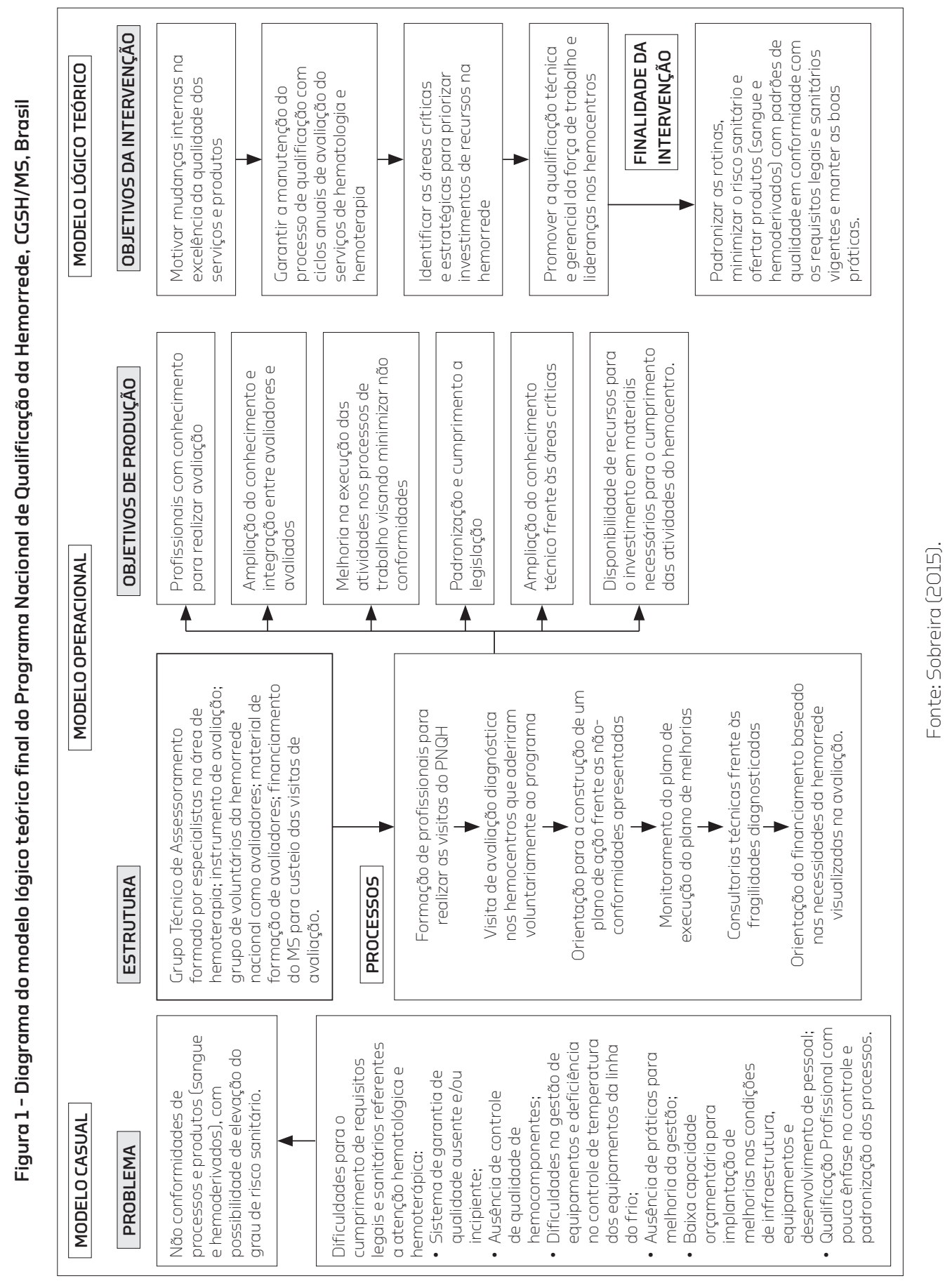


ças locais de melhoria na qualidade dos produtos e serviços hematológicos e hemoterápicos.

Com a concepção citada acima, acordou-se a conformação das avaliações em ciclos de visita e revisita, em que no primeiro momento seria realizado o diagnóstico situacional do SHH visitado e na revisita seriam analisadas as implementações das ações de melhorias apontadas na visita. Dessa forma, esse ciclo estaria contemplado nas seguintes etapas: planejamento da visita de avaliação do SHH, avaliação nos SHH pela equipe de avaliadores, planejamento das ações de melhoria, execução das ações de melhoria pelos SHH visitados, reavaliação dos resultados alcançados pelas ações de melhoria (revisita) e renovação dos planos de ações, conforme ilustrado na Figura 2.

Figura 2 - Ciclo de melhorias do Programa Nacional de Qualificação da Hemorrede

\section{COMPREENDENDO O CICLO DO PNQH}

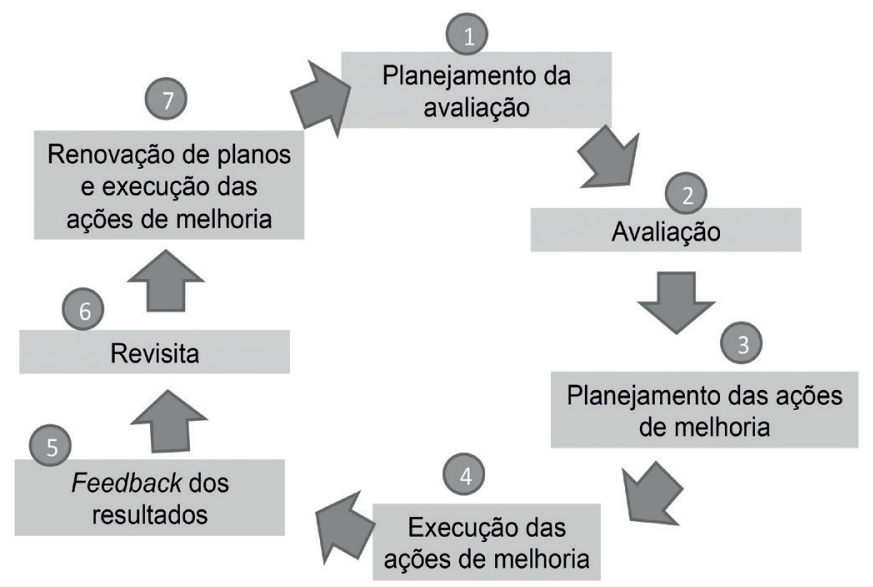

Fonte: adaptada de Brasil (2016).

Além da definição do ciclo apontado acima, identificou-se a necessidade da utilização de um instrumento para nortear os avaliadores durante as visitas, para padronizar as informações obtidas, para propiciar avaliação 
de todos os setores do SHH e para possibilitar análise técnica e gerencial de cada setor. Para elaboração do referido roteiro, realizou-se força tarefa com a participação de treze profissionais, contando com especialistas dos SHH e da CGSH e com a representação de diferentes formações profissionais: médicos, enfermeiros, farmacêuticos bioquímicos e biomédicos. Para o desenvolvimento do roteiro foram utilizados os instrumentos (checklist) da Fundação Centro de Hematologia e Hemoterapia de Minas Gerais, do Centro de Hemoterapia e Hematologia do Rio de Janeiro, do Centro de Hematologia e Hemoterapia de Santa Catarina e do Centro de Hematologia e Hemoterapia Hemocentro de Campinas/Universidade Estadual de Campinas (Unicamp), buscando contemplar todas as atividades técnicas, administrativas e gerenciais de um SHH, abrangendo tanto a Atenção Hemoterápica, quanto a Hematológica, com ênfase em coagulopatias e, posteriormente, em hemoglobinopatias.

A primeira versão do roteiro utilizado nas visitas de avaliação era composta por 23 planilhas e 540 requisitos. Ao longo do tempo e com a experiência desenvolvida pela utilização do roteiro do programa, atualmente o instrumento de avaliação contém 27 planilhas, com 336 requisitos.

Para análise dos requisitos contidos no instrumento, foram definidos os seguintes parâmetros de pontuação: totalmente conforme (C), parcialmente conforme (PC), não conforme (NC) e não se aplica (NA). O instrumento também contemplou campos para o registro de observações e recomendações, como é possível visualizar na Figura 2. Cabe ressaltar que no PNQH foi instituído o parâmetro de pontuação PC (parcialmente conforme), característica diferencial dos demais instrumentos de avaliação utilizados por outras instituições e que embute significados de estímulos aos SHH, pois promove que os serviços que possuem alguma evidência e/ou prática parcial de atendimento do requisito busquem seu cumprimento total.

A seguir, a Figura 3 ilustra como estão organizados os requisitos e os parâmetros de pontuação utilizados no instrumento de avaliação. 
Figura 3 - Requisitos e parâmetros de pontuação utilizados no instrumento de avaliação do PNQH

\begin{tabular}{|c|c|c|c|c|c|c|}
\hline \multicolumn{7}{|c|}{ Nome da instituição: } \\
\hline \multicolumn{7}{|c|}{ Responsável pela área: } \\
\hline \multicolumn{7}{|c|}{ Data da avaliação: } \\
\hline $\mathrm{N}^{\circ}$ & Requisitos & $\mathrm{C}$ & $\mathrm{PC}$ & NC & NA & Observações \\
\hline 1 & 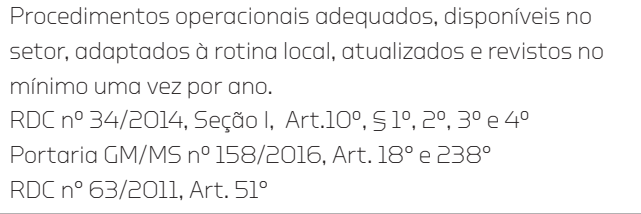 & & & & & \\
\hline ट & 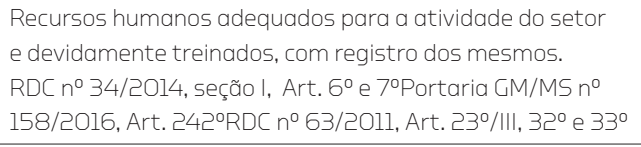 & & & & & \\
\hline 3 & $\begin{array}{l}\text { Área e condições de trabalho adequadas. } \\
\text { RDC n 34/2014, seção I, Art. } 8^{\circ} \\
\text { RDC n 50/ट00ट } \\
\text { Portaria GM/MS n 158/2016, Art. } 255^{\circ}\end{array}$ & & & & & \\
\hline 4 & $\begin{array}{l}\text { Técnica, reagentes e controles utilizados adequados } \\
\text { (citar a técnica utilizada).RDC n 34/2014, Seção VI, Art. } \\
\text { 7200 Portaria GM/MS n 158/2016, anexo VII }\end{array}$ & & & & & \\
\hline 5 & 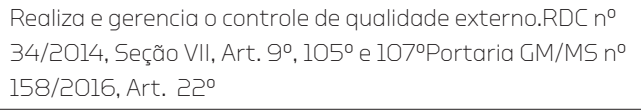 & & & & & \\
\hline 6 & $\begin{array}{l}\text { Realiza controle de qualidade interno, incluindo validação } \\
\text { dos procedimentos.RDC nº 34/2014, Seção VII. Art. 9. } \\
105^{\circ} \text { e } 107^{\circ} \text { Portaria GM/MS n 158/2016, Art. } 22^{\circ}\end{array}$ & & & & & \\
\hline \multicolumn{2}{|c|}{ Total } & O & 0 & 0 & 0 & \\
\hline
\end{tabular}

Fonte: adaptada de Brasil (2016).

Cabe salientar que a avaliação da variação do percentual de conformidade dos SHH deve ser realizada criticamente, a partir de análise interna do instrumento de avaliação e dos relatórios de qualificação do $\mathrm{PNQH}$, atentando-se para a obtenção dos seguintes resultados:

- Avaliação geral dos SHH por região;

- Avaliação dos SHH por setores;

- Comparativo da evolução de conformidade geral por serviço, por região e entre ciclos das visitas e revisitas técnicas. 
Para a compilação dos resultados, a análise de conformidade dos requisitos avaliados é realizada em cada planilha do roteiro de avaliação, sendo calculado ao final da avaliação o percentual de conformidade, de parcial conformidade e de não conformidade, item por item, de cada área/planilha. A partir desse cálculo setorial, realiza-se o consolidado geral do serviço, que expressa o cenário da avaliação de conformidade, como é possível observar na Figura 4, que permite a visualização gráfica dos percentuais de conformidade, parcial conformidade e não conformidade por setor.

Figura 4 - Distribuição percentual dos critérios de conformidade do $\mathrm{SHH}$, por setor e por ano da visita

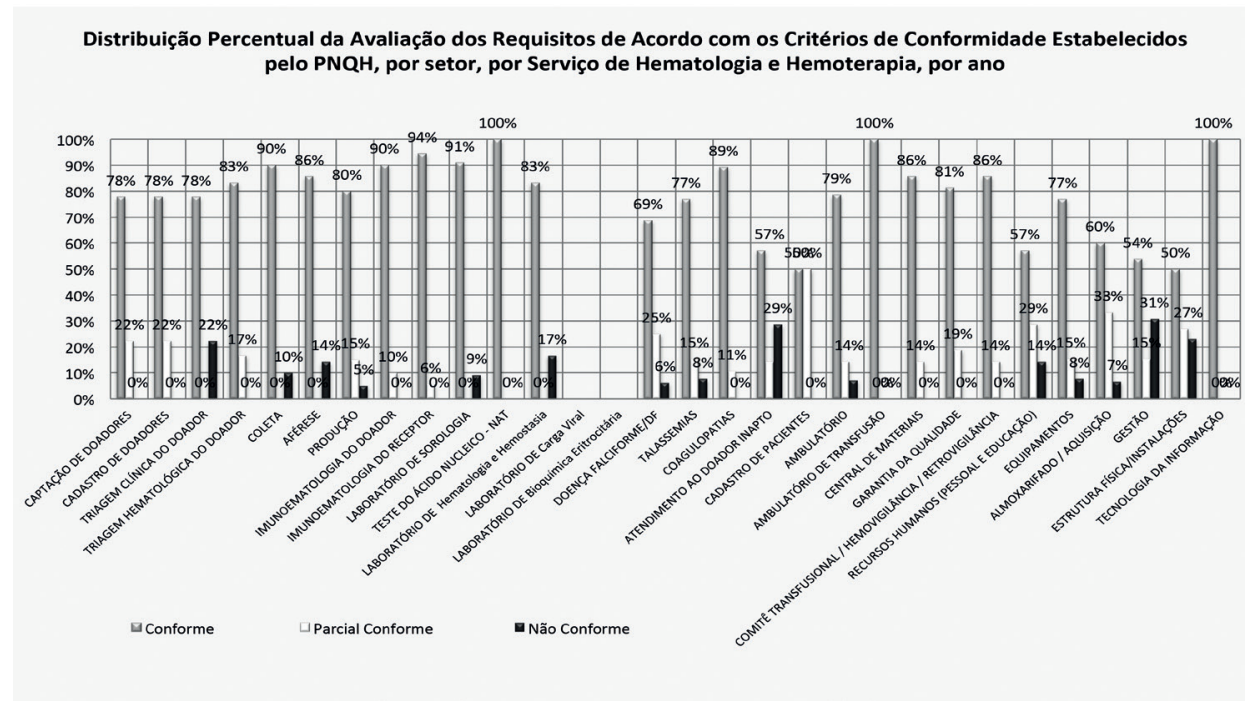

Fonte: adaptada de Brasil (2016).

Outras conformações gráficas são possíveis de se obter com os dados levantados após compilação das informações das visitas de avaliação, dentre as quais é possível visualizar a distribuição percentual dos critérios de conformidade por região do país (Figura 5), o que permite a análise e o direcionamento de ações e de investimentos a serviços com maior necessidade de melhorias. 
Figura 5 - Distribuição percentual gráfica dos critérios de conformidade por região entre 2008 a 2015

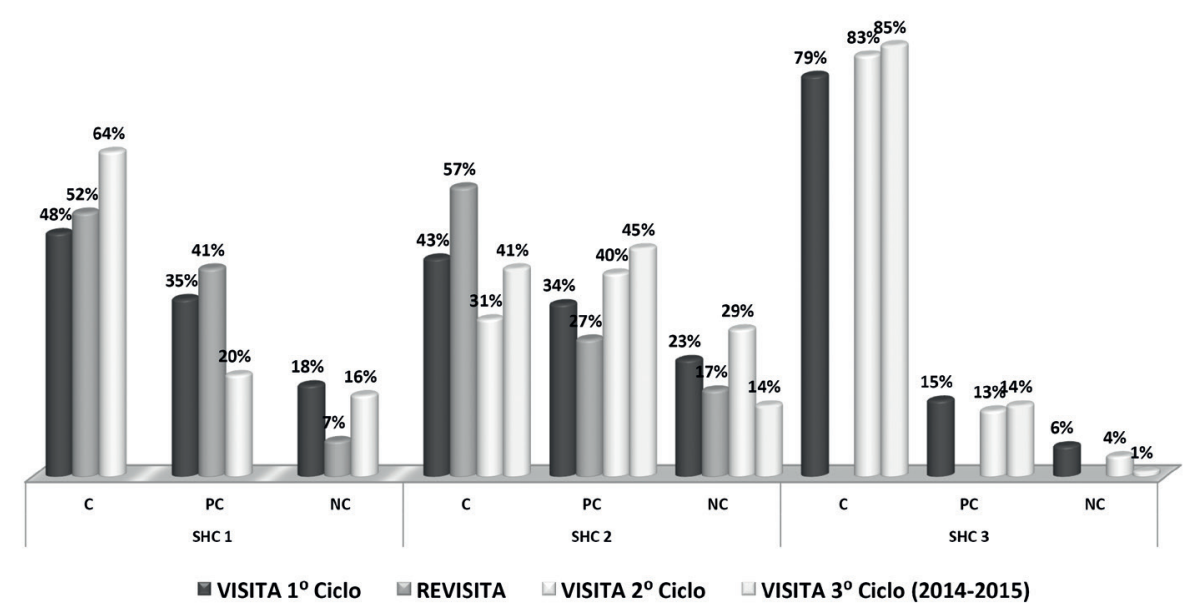

Fonte: adaptada de Brasil (2016).

A partir dos dados consolidados e analisados, com base nas não conformidades encontradas nas visitas, o PNQH orienta a elaboração do plano de ação (PA) para que o SHH visitado implemente estratégias para a correção da não conformidade ou implantação de melhorias. O compartilhamento de experiências, de boas práticas e de recomendações não ocorre apenas na consolidação final das informações, pois é possível cooperação técnica aos SHH durante as visitas. Além disso, o apoio aos SHH também ocorre por meio de consultorias, que podem ser direcionadas para eventuais dificuldades que surgirem durante a elaboração e/ou execução do PA ou destinadas a alguma fragilidade específica de algum setor ou processo de trabalho, conforme necessidade do serviço.

Dessa forma, conclui-se que os principais produtos esperados das visitas de avaliação do PNQH são o diagnóstico situacional da Hemorrede e a consolidação dos dados e evidências por meio dos relatórios gerados a partir das visitas. A análise e a interpretação adequada das informações levantadas é etapa fundamental para subsidiar as ações de melhoria e o aperfeiçoamento da qualidade dos produtos e serviços ofertados aos usuários do SUS.

Apesar da qualidade do roteiro oferecer subsídios para avaliação técnica e gerencial adequada, entendeu-se como fundamental importância para o de- 
senvolvimento da visita a formação de avaliadores, o que levou a identificação de 27 profissionais que atendessem o perfil desejado e que participassem, em seus serviços, de auditorias internas e/ou supervisão técnica, a fim de compor a equipe de avaliadores do programa. Com o intuito de instrumentalizar, padronizar a postura desses colaboradores para a compreensão dos objetivos do programa foram elaboradas Diretrizes para a conduta dos avaliadores do PNQH, compostas por itens que expressassem os objetivos do programa e que orientassem os profissionais quanto as suas atuações durante as visitas.

Com a experiência do primeiro ciclo de visitas, identificou-se a necessidade de formação de maior número de avaliadores para tornar mais efetiva a implementação do Programa, o que levou o PNQH a formar, ao longo do tempo, 375 colaboradores que atuam de forma voluntária, estabelecendo redes de parceria na Hemorrede e perseguindo o objetivo coletivo de promover o aperfeiçoamento da Atenção Hematológica e Hemoterápica aos usuários do SUS.

Com a sistemática de atuação contextualizada acima, o Programa se destina à Hemorrede dos 26 estados e do Distrito Federal, rede esta composta, em cada estado, pelos seguintes serviços: Hemocentros Coordenadores (HC), Hemocentros Regionais (HR), Hemonúcleos (HN), Unidades de Coleta e Transfusão (UCT), Unidades de Coleta (UC), Agências Transfusionais (AT) e da Assistência Hemoterápica (AH). Cabendo ressaltar a peculiaridade do estado de São Paulo, que devido ao grande quantitativo de bolsas coletadas e transfundidas no estado, possui seis hemocentros regionais com característica de serviço coordenador, que em seus âmbitos de atuação, também apoiam as ações do PNQH.

O PNQH priorizou suas ações para os HC, porém, considerando a estrutura da hemorrede nacional, que atualmente conta com aproximadamente 2029 SHH, sendo, dentre eles, mais de 50\% AT (AGÊNCIA NACIONAL DE VIGILÂNCIA SANITÁRIA, 2015); a complexidade que envolve a segurança transfusional; e reconhecendo que cada parte isolada do processo pode influenciar na qualidade do produto final ofertado, entendeu-se que se tornava imprescindível a inserção do Sistema de Gestão da Qualidade também nas AT, previsto em regulamentação, contemplando, portanto, a descrição dos procedimentos, a realização de registros, o tratamento de não conformidades (NC), a inspeção de reagentes e de materiais, o gerenciamento e o monitoramento de indicadores e, principalmente, o adequado armazenamento, manuseio e apli- 
cação dos hemocomponentes. Assim, em 2011 foi criado o Programa Estadual de Qualificação da Hemorrede (PEQH), o que exigiu adaptações no instrumento de avaliação para atender as características principalmente das AT e ampliação da formação de avaliadores regionais. Cabe ressaltar que o PEQH fomenta que o HC gerencie sua hemorrede estadual/regional e, portanto, a operacionalização deste programa (PEQH) é de responsabilidade do HC.

A operacionalização e logística do PNQH e do PEQH são semelhantes, divergindo conforme as características locais da área de abrangência do PEQH. Pela conformação das ações do PNQH e PEQH ao longo dos anos, conclui-se que os programas se constituem como importante ferramenta de gestão, pois permite que os SHH tenham conhecimento de sua Hemorrede, conheçam suas fragilidades e sistematicamente elaborem melhorias para as não conformidades identificadas.

Por fim, ao reconhecer a potencialidade do $\mathrm{PNQH} / \mathrm{PEQH}$, almeja-se que a experiência descrita acima possa incentivar os leitores a buscarem ferramentas de gestão que provoquem transformações em suas práticas de saúde, pois na hematologia e hemoterapia essas estratégias têm sido importante gatilho para superação de entraves da gestão, pois promove a cooperação técnica entre os SHH públicos do país; não possui caráter fiscalizatório e, sim, de apoio aos serviços; e motiva mudanças internas nos processos de trabalho, visando à excelência da qualidade dos produtos e serviços hematológicos e hemoterápicos.

\section{Referências}

AGÊNCIA NACIONAL DE VIGILÂNCIA SANITÁRIA (Brasil). Serviços de hemoterapia cadastrados no Sistema Nacional de Cadastro de Serviço de Hemoterapia - HEMOCAD. Brasília, DF, 2015. Disponível em: <http://wwwl. anvisa.gov.br/anvisa/hemocad/RelatoriosHemocad.jsp >. Acesso em: 13 maio 2016.

BRASIL. Ministério da Saúde. Portaria n ${ }^{\circ}$ 158, de 4 de fevereiro de 2016. Redefine o regulamento técnico de procedimentos hemoterápicos. Diário Oficial da República Federativa do Brasil, Brasília, DF, 5 fev. 2016a. Seção 1, p. 37. Disponível em: <http://pesquisa.in.gov.br/imprensa/jsp/visualiza/index. jsp?jornal=1\&pagina=37\&data=05/02/2016>. Acesso em: 5 mar. 2016. 
BRASIL. Ministério da Saúde. Portaria n ${ }^{\circ}$ 2.712, de 12 de novembro de 2013. Redefine o regulamento técnico de procedimentos hemoterápicos. Diário Oficial [da] República Federativa do Brasil, Brasília, DF, 13 nov. 2013. Seção 1, p. 106. Disponível em: <http://bvsms.saude.gov.br/bvs/saudelegis/gm/2013/ prt2712_12_11_2013.html>. Acesso em: 10 jan. 2016.

BRASIL. Ministério da Saúde. Secretaria de Atenção à Saúde. Departamento de Atenção Especializada e Temática. Guia para implementar avaliações nos serviços de hematologia e hemoterapia na perspectiva do Programa Nacional de Qualificação da Hemorrede. Brasília, DF, 2016b. Disponível em: <http://bvsms. saude.gov.br/bvs/publicacoes/guia_implementar_avaliacoes_servicos_ hematologia.pdf >. Acesso em: 13 maio 2016.

CONSELHO NACIONAL DE SECRETÁRIOS DE SAÚDE (Brasil). Alternativas de gerência de unidades públicas de saúde. Brasília, DF, 1995. Disponível em: <http://www.conass.org.br/biblioteca/pdf/Alternativas-de-Gerencia-deUnidades-Publicas-de-Saude.pdf $>$. Acesso em: 13 maio 2016.

DONABEDIAN, A. Garantía y monitoría de la calidad de la atención médica: un texto introductorio. México: Instituto Nacional de Salud Pública, 1990.

DONABEDIAN, A. The quality of care: how can it be assessed? Journal of the American Medical Association, [Chicago], v. 260, n. 12, p. 1743-1748, 1988.

LEDESMA RODRÍGUEZ, L.; FRANCO CAMA, E. Implantación del sistema de gestión de la calidad ISO 9001:2000 em centros y servicios de transfusión. Madrid: Asociación Española de Hematologia y Hemoterapia: Sociedad Española de Transfusión Sanguínea, 2007.

MAGRETTA, J.; STONE, N. O que é gerenciar e administrar. Tradução de Hugo de Souza Melo. Rio de Janeiro: Campus, 2002.

MALIK, A. M.; SCHIESARI, L. M. C. Qualidade na gestão local de serviços e ações de saúde. São Paulo: Instituto para o Desenvolvimento da Saúde, 1998. (Série Saúde \& Cidadania, v. 3).

MINTZBERG, H. Managing: desvendando o dia a dia da gestão. Tradução de Francisco Araújo da Costa. Revisão técnica de Roberto Fachin. Porto Alegre: Bookman, 2010.

SOBREIRA, C. A. M. O Programa Nacional de Qualificação da Hemorrede $P N Q H$ : estudo de avaliabilidade no âmbito do Hemocentro Coordenador do Ceará. 2015. 100 f. Dissertação (Mestrado em Saúde Coletiva) - Instituto de Saúde Coletiva, Universidade Federal da Bahia, Salvador, 2015. Disponível em: <https://repositorio.ufba.br/ri/bitstream/ri/18320/1/DISS\%20MP.\%20 Christianne\%20Andrezza\%20Sobreira.\%202015.pdf>. Acesso em: 14 abr. 2016. 
TANAKA, O. Y.; MELO, C. M. M. Avaliação de serviços e programas de saúde para a tomada de decisão. In: ROCHA, A. M.; CESAR, C. L. G. (Ed.). Saúde pública: bases conceituais. São Paulo: Atheneu, 2008. p. 119-131.

VIEIRA-DA-SILVA, L. M. Avaliação de políticas e programas de saúde. Rio de Janeiro: Ed. Fiocruz, 2014. 


\title{
A vigilância sanitária e a qualidade na atenção hemoterápica
}

\author{
Helder Teixeira Melo \\ Giselle Bissaro Barban Evangelista
}

\section{Introdução}

Até o século XX as atividades relacionadas a hemoterapia tinham seu caráter empírico, fundamentadas na crença de que o sangue poderia salvar vidas. De fato, o senso comum sobre a questão, levava médicos e práticos a testar procedimentos transfusionais diversos, com finalidades terapêuticas hoje consideradas duvidosas ou até mesmo proibidas, como as transfusões heterólogas (entre espécies diferentes) e as transfusões braço a braço, que ocorriam em técnicas cirúrgicas que permitiam a transfusão direta, utilizando-se a artéria do doador e a veia do receptor por meio de aparelhos especialmente desenvolvidos para este fim. (FUNDAÇÃO PRÓ-SANGUE, [200-])

Nessa questão, Junqueira, Rosenblit e Hamerschlak (2005) dividem a transfusão de sangue, no mundo, em dois períodos distintos: um empírico, que vai até 1900; e, outro científico, de 1900 em diante.

A principal revolução científica, a qual deu início à hemoterapia como especialidade terapêutica, foi a descoberta do Dr. Karl Landsteiner sobre efeitos aglutinantes e grupos sanguíneos no início do século XX. (MELO, 2015) A partir de então, tornou-se possível a realização de provas de compatibilidade 
imunohematológica, resolvendo diversos problemas relacionados a reações transfusionais graves.

Ainda nos primórdios da hemoterapia, a descoberta das soluções anticoagulantes e conservantes, como o difosfato de sódio, e o aperfeiçoamento e desenvolvimento de equipamentos para coleta e armazenamento do sangue, bem como de refrigeração, permitiu a organização dos centros de armazenamento que possibilitavam a formação de estoques de sangue para posterior uso. Já na década de 1930, em todo o mundo e inclusive no Brasil, abriu-se espaço para a criação de estabelecimentos de "saúde", que passaram a ser conhecidos como "bancos de sangue".

Saraiva (2005) ressalta que apesar do pioneirismo da hemoterapia brasileira, a regulamentação estatal não acompanhava o desenvolvimento da especialidade. Melo (2015) reforça que a ausência do poder público e o atraso da regulamentação do setor foram prejudiciais ao desenvolvimento da hemoterapia, tendo como consequência, o estímulo à proliferação de bancos de sangue privados e a comercialização dos produtos hemoterápicos, gerando impactos no processos da doação de sangue. (SARAIVA, 2005)

Somente a partir da promulgação da Lei n ${ }^{\circ} 4.701$, de 28 de junho de 1965, o controle sanitário passou a existir, sendo criado o primeiro ordenamento púlico da área de sangue, com: um órgão normativo e consultivo, ocupando-se do disciplinamento da referida atividade em todo o território nacional; os órgãos de fiscalização, com autoridade de âmbito nacional, estadual, territorial e municipal, atuando no campo da saúde pública; e, órgãos executivos da prática hemoterápica.

Porém, até a década de 1980, não era possível identificar a estruturação de um sistema de serviços de hemoterapia que promovesse a qualificação da produção hemoterápica, em nível nacional, fosse pela padronização de procedimentos técnicos, ou fosse pela aplicação de uma política que garantisse a autossuficiência do país em produtos hemoterápicos para a assistência à saúde.

Outros problemas de ordem técnica relativa à segurança transfusional persistiam, como a remuneração de doadores de sangue e a existência de doadores de substituição, com taxas de até $80 \%$, o que provocava entre $40 \%$ a 70\% de inaptidão nas triagens clínica e laboratorial, e menos 10\% de doadores de repetição nos hemocentros. (HOGAN; GARGARELLA, 1997) 
Ainda mais grave à segurança dos produtos e serviços prestados pela hemoterapia, foi o impacto da eclosão da pandemia mundial do vírus da Imunodeficiência Adquirida (HIV) e da Síndrome da Imunodeficiência Adquirida (AIDS) em meados da década de 1980. Apesar de haver outros patógenos causadores de doenças transmissíveis por transfusão à época, como o vírus da Hepatite B e outros, a comoção social relacionada, tanto ao estigma trazido com a AIDS, quanto a preocupação sanitária tardia, reforçaram radicalmente o controle sorológico dos produtos hemoterápicos.

Além de um extensa regulamentação técnica no setor, a Lei no ${ }^{\circ} .649 / 1988$, estabeleceu "[...] a obrigatoriedade do cadastramento dos doadores de sangue, bem como a realização de exames laboratoriais no sangue coletado, com objetivo de prevenir a propagação de doenças [...]”. (BRASIL, 1988b)

Em seguida, no mesmo ano a Constituição do Brasil, trouxe em seu texto a proibição da comercialização do sangue. Com a proibição da remuneração do doador o país passou a contar exclusivamente com a doação voluntária não remunerada de sangue para o abastecimento dos serviços. (MELO, 2015)

Foi a partir de 1990 que a Saúde Pública no Brasil teve impulso com a promulgação do marco legal do Sistema Único de Saúde (SUS), Lei nº 8.080/1990, que incluiu como prioridades a formulação e execução de uma nova política de sangue para o país, a implementação do Sistema Nacional de Sangue, bem como a implementação de ações de vigilância sanitária no âmbito destas políticas. (BRASIL, 1990)

No contexto, marcado pela regulamentação do SUS, foi proposto um projeto de lei da Câmara dos Deputados iniciado em 1991, para definir os órgãos operacionais das atividades hemoterápicas e da produção de hemoderivados e estabelecer a estrutura de gestão do Sistema Nacional de Sangue, Componentes e Derivados. (MELO, 2015) Projeto o qual, somente foi promulgado dez anos mais tarde, pela Lei $n^{\circ} 10.205$, de 21 de março de 2001 (Lei do Sangue).

Em todo este desenvolvimento da área de sangue a preocupação com a regulação e vigilância sanitária mostrou-se presente por meio do controle e fiscalização de serviços de hemoterapia, produtos e procedimentos utilizados na atenção hemoterápica, com vistas à redução de riscos à saúde. 


\section{A importância da vigilância sanitária do sangue como instrumento de gestão na saúde}

Costa e Rozenfeld (2000) comentam que a Vigilância Sanitária é a forma mais complexa de existência da saúde pública, pois suas ações, de natureza eminentemente preventiva, perpassam todas as práticas médico-sanitárias: promoção, proteção, recuperação e reabilitação da saúde.

A constituição da Vigilância Sanitária é tão antiga quanto à formulação de estratégias políticas de saúde pública, em especial para a prevenção da transmissão de doenças e controle de epidemias. No Brasil, a organização da Vigilância Sanitária remonta ao período da Monarquia, em especial com a chegada da família real portuguesa, em 1808, e a estruturação do Reino Unido de Portugal, Brasil e Algarves, em 1815. À época, o controle sanitário de produtos de importação e da produção de bens e serviços, ganhou importância na prevenção de doenças e epidemias, em especial nos grandes centros.

A evolução da Vigilância Sanitária no país acompanhou o desenvolvimento do próprio tema da saúde, fiscalizando não apenas os bens e produtos circulantes de interesse à saúde coletiva, como também os serviços de saúde utilizados na prestação da assistência às pessoas.

A Lei ${ }^{\circ}$ 8.080, de 19 de setembro de 1990, definiu a Vigilância Sanitária no âmbito do SUS como "[...] um conjunto de ações capaz de eliminar, diminuir, ou prevenir riscos à saúde e de intervir nos problemas sanitários decorrentes do meio ambiente, da produção e circulação de bens e da prestação de serviços de interesse da saúde [...]”. (BRASIL, 1990)

Para a execução destas ações foi criado o Sistema Nacional de Vigilância Sanitária (SNVS), composto por instituições da Administração Pública das três esferas de governo, com atividades de regulação, normatização, controle e fiscalização de produtos, substâncias e serviços de interesse para a saúde. A Lei ${ }^{\circ}$ 9.782, de 26 de janeiro de 1999, estabeleceu ainda, a Política Nacional de Vigilância Sanitária, sob a direção da Agência Nacional de Vigilância Sanitária (Anvisa). (BRASIL, 1999)

A Lei n ${ }^{\circ}$ 9.782/99 criou a Agência Nacional de Vigilância Sanitária (Anvisa) que atualmente é composta pelo Instituto Nacional de Controle de Qualidade em Saúde (INCQS), vinculado à Fundação Oswaldo Cruz (Fiocruz) e 27 órgãos estaduais de vigilância sanitária e também os órgãos municipais. Assim, 
a organização do sistema regulatório é executada por órgãos que, coordenados pela Anvisa, compõem o Sistema Nacional de Vigilância Sanitária (SNVS). (SILVA JÚNIOR; COSTA; BACCARA, 2015)

Apenas para fins de contextualização, é salutar compreender o que envolve as atividades de vigilância sanitária descritas na lei, a fim de evidenciar os impactos da Vigilância Sanitária sobre o campo de atividades da hemoterapia:

- Regulação: compreendida como o modo de intervenção do Estado para impedir possíveis danos ou riscos à saúde da população. A atuação da Vigilância Sanitária se dá por meio da regulamentação, controle e fiscalização das relações de produção; e consumo de bens e serviços relacionados à saúde, bem como registros e autorizações sanitárias para todos os insumos e materiais comercializados referentes ao processamento do sangue;

- Normatização: que consiste na publicação de normas regulatórias estabelecidas pelo Ministério da Saúde com o propósito de padronizar os procedimentos técnicos a serem seguidos por todos os serviços de hemoterapia;

- Controle: que visa garantir a utilização correta de produtos e serviços adequados e com base nos requisitos de boas práticas aplicadas ao ciclo do sangue;

- Fiscalização: executada por meio da inspeção sanitária realizada pelos órgãos reguladores locais, com o objetivo de auditar o cumprimento das normas regulatórias nacionais pela aplicação de roteiros de inspeção e instrumentos de avaliação de risco inerentes ao ciclo do sangue. (SILVA JÚNIOR; COSTA; BACCARA, 2015)

Costa (2009) comenta que em todas as épocas ocorreram intervenções do Poder de Autoridade sobre as práticas de cura, os medicamentos, os alimentos, a água, o ambiente. Com o avanço das forças produtivas, surgiram intervenções sobre a circulação dos meios de transporte, cargas e pessoas, bem como sobre o consumo da força de trabalho, mediante distintas formas de regulação e intervenção nas práticas do mercado. 
Atualmente, a Vigilância Sanitária optou por assumir um caráter mais educativo na promoção da saúde, em especial no que se refere às ações de inspeção para fiscalização na área de sangue. Este caráter educativo, mesmo que positivo sobre as ações de Vigilância Sanitária (VISA) e inovador no processo de saúde, não pode ser compreendido como um relaxamento do Poder de Autoridade (poder de polícia), atribuído às instituições do setor.

Obviamente, o exercício do Poder de Autoridade Sanitária está limitado à questão técnica que envolve o conjunto de ações da VISA e suas consequências políticas e jurídicas. Porém, suas ações visam garantir a redução de riscos relativos à atividade hemoterápica para a população.

Ainda que seja do senso comum que a garantia do acesso da população aos produtos e serviços hemoterápicos seja de competência dos organismos operacionais, isto é, serviços de hemoterapia da Hemorrede Nacional, fato inclusive assegurado no ordenamento jurídico da Hemoterapia, em especial no Decreto $\mathrm{n}^{\circ} 3.990 / 2001$, a garantia de que este acesso se dará de forma efetiva e segura é função partilhada com os órgãos de Vigilância Sanitária; isso, seja no uso de insumos e equipamentos previamente submetidos a registro pela autoridade sanitária, seja na controle e fiscalização de procedimentos e ambientes dos estabelecimentos técnicos, ou mesmo no acompanhamento dos avanços científicos, tecnológicos e inovações no setor.

A importância das ações da Vigilância Sanitária, no acesso a produtos seguros e efetivos na área de sangue, é ressaltada pela Organização Mundial da Saúde (2014) que sugere aos países membros que seus respectivos Ministérios da Saúde tenham uma liderança eficaz e governança no desenvolvimento de um sistema nacional de sangue totalmente integrado ao sistema de saúde, de forma a prover de maneira responsável a segurança transfusional e a disponibilidade de sangue e derivados. Para tanto, além das regulamentações técnicas pertinentes e de um quadro legislativo e regulamentar para o programa nacional de sangue, a promoção da saúde deve ser "regulamentada, fiscalizada e controlada pelo poder público". (DIAS, 2002, p. 17)

Para se alcançar segurança dos produtos sanguíneos a serem utilizados em transfusões, rígidos parâmetros de qualidade devem ser perseguidos. Entende-se por segurança transfusional o conjunto de medidas quantitativas e qualitativas adotadas que vise um menor risco aos doadores e receptores 
de sangue, além da garantia de estoques estratégicos de sangue capazes de atender à demanda transfusional. (O'DWYER; REIS; SILVA, 2010)

Embora haja significativos avanços na busca de segurança transfusional, não existe transfusão isenta de riscos (PIMENTEL, 2006; MURPHY, 2006; SANTOS; MORAES; COELHO, 1992), nesse sentido é de suma importância o cumprimento do disposto nas normas e regulamentos técnicos referentes ao ciclo do sangue, para garantir que os riscos inerentes a todo o processo, que se inicia na captação e seleção de doadores, triagem sorológica, imunohematológica e molecular referente ao teste de ácidos nucléicos, obrigatórios no Brasil a partir de 2012, processamento e fracionamento das unidades coletadas, dispensação, transfusão e avaliação pós transfusional, sejam previstos e evitados. Assim, é claramente percebida a presença das ações de Vigilância Sanitária no planejamento da Política de Sangue para atenção hemoterápica da população, visando sua proteção. (MURPHY; STANWORTH; YAZER, 2011)

\section{A importância da autoridade e regulação sanitária no planejamento das ações na área de sangue}

O papel da vigilância sanitária da área de sangue foi ressaltado em 1999, quando no processo de criação da Anvisa, foi transferido para o referido órgão a condução da Política Nacional de Sangue. O protagonismo da agência reguladora não se deu apenas no âmbito de sua função precípua de regulação, controle e fiscalização, mas também da direção da Política Nacional de Sangue, Componentes e Derivados a partir da promulgação da Lei nº 10.205/2001, reforçado pelo decreto de regulamentação, Decreto $n^{\circ} 3.990 / 2001$ (texto original) até o ano de 2004.

Nesse período verifica-se uma intensa atividade normativa, com a revisão de diversos regulamentos técnicos referentes à execução de procedimentos hemoterápicos, regramentos para utilização de componentes e derivados sanguíneos, regulamentos quanto ao uso e produção de hemoderivados e orientações sobre a estrutura organizacional da Hemorrede, com a internalização de normas internacionais, que culminaram na Resolução RDC n 151 , de 22 de agosto de 2001, que aprovava o Regulamento Técnico sobre Níveis de Complexidade dos Serviços de Hemoterapia (artigo $1^{\circ}$ ) e que veio também estabelecer o padrão de nomenclatura atualmente adotado pela Hemorrede 
Nacional para esses serviços. (AGÊNCIA NACIONAL DE VIGILÂNCIA SANITÁRIA, 2001)

Desde a primeira formação do Decreto ${ }^{\circ}$ 3.990/2001, a importância da Vigilância Sanitária no apoio à formulação do "plano diretor de sangue, componentes e hemoderivados" dos estados e do Distrito Federal, recebe especial destaque, com vistas ao acompanhamento e a avaliação do cumprimento das metas e das ações do SINASAN. Os artigos $5^{\circ}$ e $6^{\circ}$ ressaltam a competência dos gestores estaduais do SUS que devem “[...] coordenar, em seus limites geográficos, as ações na área de sangue, componentes e hemoderivados, incluindo as ações de vigilância sanitária e as atividades voltadas para o atendimento de situações de emergência [...]", além de fazer cumprir as “[...] normas técnicas pelos órgãos executores das ações de hemoterapia, por meio das ações de vigilância sanitária". (BRASIL, 2001a)

Outro destaque à importância da regulação sanitária no planejamento da hemoterapia decorre do Artigo $7^{\circ}$ do referido Decreto $n^{\circ} 3.990 / 2001$, que ao determinar aos gestores do SUS a implantação da estrutura dos sistemas de sangue, "câmaras de assessoramento para formulação da política de sangue, componentes e hemoderivados", explicita em seu parágrafo único que na constituição de tais "câmaras de assessoramento", minimamente devem fazer parte os representantes da "Vigilância Sanitária”, além da própria Hemorrede pública, vigilância epidemiológica, planejamento e controle e avaliação das secretarias estaduais de Saúde. (BRASIL, 2001a)

A formulação de planos nacionais quadrienais para o setor não tem logrado êxito na aprovação e/ou publicação normativa de tais documentos. Ao longo dos anos, percebe-se certa precarização no funcionamento das câmaras de assessoramento da Política de Sangue em alguns entes federativos nas diversas esferas de gestão do SUS, o que pode estar levando a prejuízos na formulação ou mesmo na aplicação destes planos. Esta questão, porém, deve ser tratada pelos gestores do SUS como prioritária, não apenas para o cumprimento do dispositivo regulamentado no Decreto $n^{\circ} 3.990 / 2001$, mas em especial, pela importância do estabelecimento de uma direção político-administrativa efetiva e exitosa para o desenvolvimento da hemoterapia nos estados.

Nesse aspecto o papel da Vigilância Sanitária é mais uma vez relevante, desde a identificação de situações problemáticas na oferta de serviços à população, quando é possível avaliar a precarização da assistência pela incor- 
reção e/ou inadequação de procedimentos em relação às normas técnicas e boas práticas, até a adoção de medidas efetivas para a redução de riscos e agravos à saúde da população.

A segurança transfusional, atualmente, é uma das principais preocupações da sociedade e dos gestores de serviços de saúde. Nos anos 1980, o advento da AIDS trouxe a preocupação com a transmissão transfusional de doenças e consequente aumento nas ações de fiscalização nos serviços, nas ações judiciais e na pressão da mídia evidenciando a situação da hemoterapia daquele período. Saraiva (2005), comenta que em meio ao "radicalismo", equívocos e turbulências da questão da AIDS, esta não era considerada prioritária por alguns representantes do Ministério da Saúde até 1985. "Somente dois anos após, o Ministério da Saúde tornou obrigatória a realização do teste sorológico para a detecção do anticorpo anti-HIV" em bancos de sangue. (SARAIVA, 2005, p. 157)

A preocupação com a transmissão transfusional do HIV foi expressa por meio de ato legislativo na Lei $n^{\circ} 7.649 / 1988$, o qual estabeleceu a obrigatoriedade do cadastramento dos doadores de sangue, bem como a realização de exames laboratoriais no sangue coletado, visando prevenir a propagação de doenças. (MELO, 2015) O descumprimento desta lei implica, inclusive, em sanções criminais aos responsáveis técnicos pelos serviços de hemoterapia.

Foi a partir desse período que houve a busca pelo aperfeiçoamento tecnológico dos conjuntos diagnósticos com o objetivo de torná-los mais sensíveis para detecção precoce dos marcadores infecciosos nas amostras de candidatos à doação de sangue, contribuindo assim com o desenvolvimento de uma das áreas de suma importância nos serviços de hemoterapia, a triagem laboratorial. Ainda, no controle da transmissão de doenças e agravos à saúde, destacam-se as ações de captação e do aprimoramento dos critérios de triagem clínica dos candidatos à doação sob a perspectiva do risco epidemiológico que permitem a seleção de doadores. (DOOD; NOTARI; STRAMER, 2002; BARBAN, 2015)

Importante lembrar que o protagonismo das ações de Vigilância Sanitária na redução de riscos na área de sangue não é limitado à fiscalização das estruturas físicas dos serviços, ou aos riscos de transmissão de patógenos infecciosos por transfusão. Em seu sítio virtual na internet, a Anvisa comenta que 
O uso de sangue, outros tecidos, células e órgãos humanos para tratamento de agravos é uma tecnologia já disponível no Brasil. Para garantir a qualidade e a segurança destes tratamentos, a vigilância sanitária elabora normas e regulamentos técnicos, inspeciona os serviços credenciados, capacita profissionais e monitora a ocorrência de eventos adversos com a utilização das tecnologias disponíveis. (AGÊNCIA NACIONAL DE VIGILÂNCIA SANITÁRIA, [200-])

Na Anvisa, essas atividades são desempenhadas pela área de Sangue, outros Tecidos, Células e Órgãos.

Um importante avanço no campo da segurança da transmissão de agentes infeciosos por transfusão e no controle dos processos laboratoriais, conforme destacado por Sampaio (2013, p. 15) são

[...] os Programas de Avaliação Externa da Qualidade em Serviços de Hemoterapia (AEQ), em sorologia e imuno-hematologia, que foram implantados e coordenados pela Agência Nacional de Vigilância Sanitária (Anvisa), no período de 2001 a 2009 e a partir de 2010 estão sob responsabilidade da CGSH do Ministério da Saúde.

A amplitude das ações de vigilância sanitária está presente desde o processo de registros de equipamentos e insumos para a atividade hemoterápica e fiscalização de sua produção, no funcionamento dos serviços, na responsabilidade técnica, no controle do armazenamento e transporte de insumos hemoterápicos, até a vigilância pós-uso dos produtos e equipamentos e a hemovilângia.

Além disso, o acesso da Autoridade Sanitária aos serviços de saúde torna este ente, o elo mais próximo da atuação de forma direta e imediata no controle e na solução de problemas locais que impactem negativamente na qualidade e segurança da assistência à saúde. No entanto, ainda há deficiência nesse acesso, como, por exemplo, a ausência do controle sanitário na assistência hematológica, uma vez que os serviços assistenciais da Hemorrede, de forma geral não têm sido objeto de verificação das equipes de fiscalização sanitária da área de sangue, a qual tem enfoque na produção hemoterápica e 
por vezes as áreas de serviços de saúde das Vigilâncias Sanitárias não evidenciam que parte da assistência hematológica pública encontra-se concentrada nos serviços de hemoterapia.

\section{Qualificação e aplicação de regras sanitárias nos Serviços de Hemoterapia}

Além do papel normativo de Regulação Sanitária e outras funções já referidas, a colaboração da Vigilância Sanitária também avança tanto no apoio à organização dos Serviços de Hematologia e Hemoterapia quanto no planejamento de ações da Hemorrede.

O controle de áreas e atividades críticas dos Serviços de Hemoterapia é atividade fundamental para garantir a efetividade das ações de saúde executadas pelos serviços e a segurança sanitária no uso dos ambientes, equipamentos e insumos utilizados nos processos de produção do sangue e componentes.

Para exercer a função de fiscalização e controle, importantes ferramentas merecem destaque, como os regulamentos técnicos de boas práticas, transporte de hemocomponentes, orientações para armazenamento de hemocomponentes, roteiros de inspeção e as ações de caráter eminente técnico, sendo capazes de reorientar procedimentos técnicos, promover ações preventivas e corretivas de riscos e agravos - hemovigilância, tecnovigilância e farmacovigilância.

A importância da fiscalização sanitária se dá em diversos campos tanto no ciclo do sangue, considerando a coleta, triagem, processamento, armazenamento e distribuição, como também, nas medidas de proteção ao doador e receptor; pela instituição de critérios de triagem que visam evitar efeitos adversos nos receptores; no gerenciamento de aquisição de insumos, na validação de processos; nos registros referentes às doações e transfusões; nas ações de hemovigilância; na gestão do risco; na proteção dos trabalhadores, não somente no ambiente de trabalho, mas com a identificação dos riscos de exposição e de ergonomia, que possam trazer problemas tardios aos profissionais dessas áreas; na gestão de resíduos de serviços de saúde; no transporte de amostras e hemocomponentes; nas atividades dos serviços de hemoterapia em relação ao meio ambiente. 
Em todas essas etapas do ciclo do sangue e de apoio a estes processos, a importância da regulação e fiscalização sanitária para que as ações sejam planejadas, implementadas e seguidas é primordial na garantia da segurança e qualidade transfusional.

Diversos regulamentos sanitários servem de orientação para tais ações e processos, tanto para as equipes de Vigilância Sanitária na área de sangue, quanto para a organização e planejamento dos serviços de hematologia e hemoterapia no âmbito da Hemorrede. Assim, entre os principais atos normativos sanitários encontrados na área de sangue, de interesse para o planejamento da Hemorrede e estruturação de serviços de hematologia e hemoterapia, destacam-se:

- Resolução RDC/ANVISA n ${ }^{\circ} 34$ de 11 de junho de 2014 - Dispõe sobre as Boas Práticas no Ciclo do Sangue;

- Resolução RDC/ANVISA n 36 de 25 de julho de 2013 - Institui ações para a segurança do paciente em serviços da saúde e dá outras providências;

- Resolução RDC/ANVISA n ${ }^{\circ}$ 306, de 7 de dezembro de 2004 - Dispõe sobre o Regulamento Técnico para o gerenciamento de resíduos de serviços de saúde;

- Resolução RDC/ANVISA n 50 de 21 de fevereiro de 2002 - Dispõe sobre o Regulamento Técnico para planejamento, programação, elaboração e avaliação de projetos físicos de estabelecimentos assistenciais de saúde;

- Resolução RDC $n^{\circ} 151$, de 21 de agosto de 2001 - Aprova o Regulamento Técnico sobre Níveis de Complexidade dos Serviços de Hemoterapia;

- Portaria Conjunta $\mathrm{n}^{\circ}$ 370, de 7 de maio de 2014 - Dispõe sobre o Regulamento Técnico-sanitário para o transporte de sangue e componentes.

Destas normas, é importante destacar a RDC/ANVISA n 34/2014. Resultante de uma evolução normativa da Agência Reguladora, esta resolução 
aplica o conceito de Boas Práticas de Fabricação (BPF) aos produtos hemoterápicos produzidos nos serviços de hemoterapia. Esta norma acompanha o desenvolvimento do Regulamento Técnico de Procedimentos Hemoterápicos, atualizado e publicado periodicamente pelo Ministério da Saúde (atualmente na Portaria GM/MS n ${ }^{\circ}$ 158/2014).

Silva Júnior, Costa e Baccara (2015) comentam que a introdução das BPF, anteriormente pela Agência Estadunidense Food and Drug Administration (FDA) e agora no âmbito dos serviços de hemoterapia brasileiro pela RDC $n^{\circ} 34 / 2014$ da Anvisa, foi importante para o ciclo produtivo, mas a falta de compreensão desse modelo torna os avanços regulatórios fragilizados uma vez que os próprios serviços de hemoterapia não o compreendem. Entretanto, essa é uma discussão imprescindível quando se considera que as práticas adotadas no ciclo do sangue são, em geral, fruto de incorporações técnicas adaptadas da indústria.

\section{Considerações finais}

A prática hemoterápica brasileira tem evoluído não somente em consonância com os demais países e com a comunidade científica internacional, mas também, ao longo desses anos houve uma crescente incorporação da cultura de gestão da qualidade nos processos dos hemocentros. Atualmente é possível avaliar o amadurecimento de alguns conceitos de qualidade, à medida que são discutidos temas como gestão do risco, em que é recomendável a adoção de ações para antecipar a qualquer situação que culmine em risco transfusional.

Nesse sentido, podemos concluir que ao longo dos anos, o papel regulatório e fiscalizador da Vigilância Sanitária tem desenvolvido também um foco mais educativo, servindo de grande alicerce às importantes legislações e à expertise de profissionais nos serviços de hemoterapia que buscam a melhoria contínua dos processos com objetivo de qualidade e de maior segurança.

\section{Referências}

AGÊNCIA NACIONAL DE VIGILÂNCIA SANITÁRIA. Resolução RDC n 151 , de 21 de agosto de 2001. Aprova o Regulamento Técnico sobre Níveis de Complexidade dos Serviços de Hemoterapia, que consta como anexo. Diário 
Oficial [da] República Federativa do Brasil, Poder Executivo, Brasília, DF, 22 ago. 2001. Seção 1, p. 29.

AGÊNCIA NACIONAL DE VIGILÂNCIA SANITÁRIA. Sangue, tecidos, células e órgãos. Brasília, DF, [200-]. Disponível em: <http://portal.anvisa.gov.br/ sangue-tecidos-celulas-e-orgaos $>$. Acesso em: 13 maio 2016.

BARBAN, G. B. Manual técnico para produção e uso do Controle de Qualidade Interno em Testes de Amplificação de Ácidos Nucleicos (CQI-NAT). 2015. 108 f. Dissertação (Mestrado em Hemoterapia e Biotecnologia) - Faculdade de Medicina de Ribeirão Preto, Universidade de São Paulo, Ribeirão Preto, 2015. Disponível em: <http://bdpi.usp.br/item/002714963>. Acesso em: 20 maio 2016.

BRASIL. Constituição da República Federativa do Brasil. Diário Oficial [da] República Federativa do Brasil, Poder Legislativo, Brasília, DF, 5 out. 1988a. Seção 1, p. 1.

BRASIL. Decreto $n^{\circ} 3.990$, de 30 de outubro 2001. Regulamenta o art. 26 da Lei $n^{\circ} 10.205$, de 21 de março de 2001, que dispõe sobre a coleta, processamento, estocagem, distribuição e aplicação do sangue, seus componentes e derivados, estabelece o ordenamento institucional indispensável à execução adequada dessas atividades. Diário Oficial [da] República Federativa do Brasil, Poder Executivo, Brasília, DF, 31 out. 2001 . Seção 1, p. 1.

BRASIL. Lei n ${ }^{\circ}$ 4.701, de 28 de junho de 1965. Dispõe sôbre o exercício da atividade hemoterápica no Brasil e dá outras providências. Coleção de Leis da República Federativa do Brasil, Brasília, DF, v. 6, p. 98, 1 jul 1965.

BRASIL. Lei ${ }^{\circ} 7.649$, de 25 de janeiro de 1988. Estabelece a obrigatoriedade do cadastramento dos doadores de sangue bem como a realização de exames laboratoriais no sangue coletado, visando a prevenir a propagação de doenças, e dá outras providências. Diário Oficial [da] República Federativa do Brasil, Poder Legislativo, Brasília, DF, 27 jan. 1988b. Seção 1, p. 1609.

BRASIL. Lei n 8.080, 19 de setembro de 1990. Dispõe sobre as condições para promoção, proteção e recuperação da saúde, a organização e o funcionamento dos serviços correspondentes e dá outras providências. Diário Ofícial [da] República Federativa do Brasil, Poder Legislativo, Brasília, DF, 20 set. 1990. Seção 1, p. 18055.

BRASIL. Lei $n^{\circ}$ 9.782, de 26 de janeiro de 1999. Define o Sistema Nacional de Vigilância Sanitária, cria a Agência Nacional de Vigilância Sanitária, e dá outras providências. Diário Ofícial [da] República Federativa do Brasil, Poder Legislativo, Brasília, DF, 27 jan. 1999. Seção 1, p. 1. 
BRASIL. Lei ${ }^{\circ} 10.205$, de 21 de março de 2001. Regulamenta o $\S 4^{\circ}$ do art. 199 da Constituição Federal, relativo à coleta, processamento, estocagem, distribuição e aplicação do sangue, seus componentes e derivados, estabelece o ordenamento institucional indispensável à execução adequada dessas atividades, e dá outras providências. Diário Oficial [da] República Federativa do Brasil, Poder Legislativo, Brasília, DF, 22 mar. 2001b. Seção 1, p. 1.

COSTA, E. A. (Org). Vigilância sanitária: temas para debate. Salvador: Edufba, 2009. Disponível em: <http://books.scielo.org/id/6bmrk $>$. Acesso em: 20 maio 2016.

COSTA, E. A.; ROZENFELD, S. Constituição da vigilância sanitária no Brasil. In: ROZENFELD, S. (Org). Fundamentos da vigilância sanitária. Rio de Janeiro: Ed. Fiocruz, 2000. p. 15-40. Disponível em: <http://books.scielo.org/id/ d63fk/04>. Acesso em: 20 maio 2016.

DIAS, H. P. Direitos e obrigações em saúde. Brasília, DF: Anvisa, 2002.

DODD, R. Y.; NOTARI, E. P.; STRAMER, S. L. Current prevalence and incidence of infectious disease markers and estimated window-period risk in the American Red Cross blood donor population. Transfusion, v. 42, n. 8, p. 975979, Aug. 2002.

FUNDAÇÃO HEMOCENTRO DE RIBEIRÃO PRETO. Ribeirão Preto, [200-]. Disponível em: <http://pegasus.fmrp.usp.br/projeto/legislacao.htm>. Acesso em: 9 maio 2016.

FUNDAÇÃO PRÓ-SANGUE. Estudantes. São Paulo, [200-]. Disponível em $<$ http://www.prosangue.sp.gov.br/artigos/estudantes >. Acesso em: 13 maio 2016.

HOGAN, V.; GARGARELLA, G. Revisão do Sistema Nacional de Sangue. Brasília, DF, 1997. Relatório destinado ao Ministério da Saúde.

JUNQUEIRA, P. C.; ROSENBLIT, J.; HAMERSCHLAK, N. História da hemoterapia no Brasil. Revista Brasileira de Hematologia e Hemoterapia, [São Paulo], v. 27, n. 3, p. 201-207, jul./set. 2005. Disponível em: <http://www. scielo.br/scielo.php?script=sci_arttext\&pid=S1516-84842005000300013\&lng =en\&nrm=iso>. Acesso em: 2 maio 2016.

MELO, H. T. Mapeamento do ordenamento jurídico da política nacional de sangue e da regulamentação técnica na área do sangue e derivados. 2015. 102 f. Dissertação (Mestrado em Hemoterapia e Biotecnologia) - Faculdade de Medicina de Ribeirão Preto, Universidade de São Paulo, Ribeirão Preto, 2015. Disponível em: <http://www.teses.usp.br/teses/disponiveis/17/17155/tde22062015-215957/pt-br.php>. Acesso em: 26 maio 2016. 
MURPHY, W. Managing threats rather than risks in blood transfusion: robust design for a complex system. Transfusion, [S.1.], v. 46, n. 11, p. 2011-2013, 2006.

MURPHY, M. F.; STANWORTH, S. J.; YAZER, M. Transfusion practice and safety: current status and possibilities for improvement. Vox Sanguinis, [Oxford], v. 100, n. 1, p. 46-59, 2011.

O’DWYER, G.; REIS, D. C. de S.; SILVA, L. L. G da. Integralidade, uma diretriz do SUS para a vigilância sanitária. Ciência \& Saúde Coletiva, Rio de Janeiro, v. 15, p. 3351-3360, 2010. Suplemento 3.

ORGANIZAÇÃO MUNDIAL DA SAÚDE. Blood transfusion safety: blood system strengthening. Geneva, 2014. Disponível em: <http://www.who.int/ bloodsafety/transfusion_services/blood_systems/en/>. Acesso em: 11 jun. 2014.

PIMENTEL, M. A. A questão do sangue: rumos das políticas públicas de hemoterapia no Brasil e no exterior. 2006. 150 f. Tese (Doutorado em Saúde Coletiva) - Instituto de Medicina Social, Universidade Estadual do Rio de Janeiro, Rio de Janeiro, 2006.

SAMPAIO, D. de A. Cenário político, social e cultural da hemoterapia no Brasil. In: BRASIL. Ministério da Saúde. Técnico em hemoterapia: livro texto. Brasília, DF, 2013. p. 7-18.

SANTOS, L. A. de C.; MORAES, C.; COELHO, V. S. P. Os anos 80: a politização do sangue. Physis: Revista de Saúde Coletiva, Rio de Janeiro, v. 2, n. 1, p. 107149, 1992.

SARAIVA, J. C. P. A história da hemoterapia no Brasil. Revista Brasileira de Hematologia e Hemoterapia, [São Paulo], v. 27, n. 3, p. 153-158, 2005.

SILVA JÚNIOR, J. B.; COSTA, C. da S.; BACCARA, J. P. de A. Regulação de sangue no Brasil: contextualização para o aperfeiçoamento. Revista Panamericana de Salud Pública, Washington, v. 38, n. 4, p. 333-338, 2015. 


\title{
Estratégias metodológicas adotadas para os cursos em Planejamento e Gestão em Saúde
}

\author{
Mariluce Karla Bomfim de Souza \\ Jussara Cargnin Ferreira
}

\section{Introdução}

A cooperação técnica assumida pelo Instituto de Saúde Coletiva da Universidade Federal da Bahia em resposta à solicitação da Coordenação Geral de Sangue e Hemoderivados do Ministério da Saúde (CGSH/MS) vem desde junho de 2014 cumprindo uma agenda de atividades que parte das reflexões sobre a importância do processo de planejamento até a elaboração de produtos dessa parceria.

Assim, além dos encontros realizados e da oferta dos cursos nas capitais de cinco estados, no ano de 2015, um produto, de natureza pedagógica e instrumental, foi elaborado para o direcionamento do curso e utilização pelos docentes, facilitadores e cursistas. O "Guia para estudos" dos cursos de Atualização em Planejamento e Gestão em Sistemas de Saúde foi elaborado por uma equipe de técnicos da CGSH/MS, gestores de hemorredes estaduais (Minas Gerais, Ceará e Santa Catarina) e três docentes e pesquisadoras do Instituto de Saúde Coletiva, da Universidade Federal da Bahia.

Na sua estrutura, o guia apresenta como elementos pré-textuais uma lista de siglas e uma lista de ícones, esta com o objetivo de sinalizar o leitor e di- 
namizar a leitura a partir de imagens que indicam curiosidades, observações, glossário, estudo de caso, marcador de tempo, vídeos, leituras recomendadas, atividades de dispersão e encerramento de atividades.

Na parte textual, o guia está organizado em duas partes, sendo a primeira dedicada às orientações gerais com descrição dos objetivos e competências esperadas dos cursistas, bem como, dos atores envolvidos e da estrutura e programação dos cursos. Detalhadamente, a descrição sobre estrutura apresenta, sobre os momentos presenciais e os momentos de dispersão, a metodologia, os recursos didáticos e os meios de avaliação do curso.

O desenho dos cursos prevê em seu formato Momentos Presenciais (M1, M2, M3) e Momentos de Dispersão (D1, D2) distribuídos em três ciclos de formação $\left(1^{\circ}, 2^{\circ}\right.$ e $3^{\circ}$ ciclo) que totalizam 92 horas. Para os Momentos Presenciais estão previstas atividades de interação e dinâmica da turma, abordagem dos conteúdos de forma expositiva e dialógica e estudos de caso. Quanto aos Momentos de Dispersão espera-se a aproximação com a prática e a relação com o conteúdo teórico. Tais momentos são intercalados aos momentos presenciais de modo a permitir tal práxis, além de apoiar o desenvolvimento das tarefas de dispersão por meio da orientação sistemática dos facilitadores na plataforma Moodle.

Quadro 1 - Ciclos e respectivos momentos dos Cursos de Planejamento e Gestão em Saúde

\begin{tabular}{|l|l|l|}
\hline 10 CICLO & $\begin{array}{l}\text { Bases para o planejamento nos serviços de } \\
\text { hemoterapia e hematologia no âmbito do Sistema } \\
\text { Único de Saúde. }\end{array}$ & $M 1\left(1^{\circ}\right.$ e $2^{\circ}$ dia); DI \\
\hline 20 CICLO & $\begin{array}{l}\text { Gestão e Planejamento em Saúde: elementos para a } \\
\text { construção do plano como produto. }\end{array}$ & $M 2\left(1^{\circ}\right.$ e $2^{\circ}$ dia); D己 \\
\hline \multirow{2}{*}{ 3o CICLO } & $\begin{array}{l}\text { Sistematização de proposta para o planejamento nos } \\
\text { serviços de hemoterapia e hematologia no âmbito do } \\
\text { SUS. }\end{array}$ & $M 3\left(1^{\circ}\right.$ e $2^{\circ}$ dia $)$ \\
\hline
\end{tabular}

Fonte: Souza e colaboradores (2015).

A metodologia utilizada para o desenvolvimento do curso fundamenta-se na problematização, a qual tem sido proposta como "metodologia de ensino, de estudo e de trabalho", podendo ser entendida como um conjunto de métodos, técnicas, procedimentos ou atividades intencionalmente selecionadas e 
organizadas de acordo com a natureza do problema em estudo e as condições gerais dos participantes. (BERBEL, 1998)

O uso desta metodologia deve partir de um tema, neste caso, o planejamento, de modo que os cursistas olhem atentamente e registrem sistematizadamente sua percepção sobre a parcela da realidade em que aquele tema está sendo vivido. Portanto, parte do princípio de que o cursista é um agente ativo da própria aprendizagem e é capaz de agir intencionalmente para transformar a sua prática, de modo que no compartilhamento das experiências torna-se possível novas reflexões, elaboração de soluções e intervenções em acordo com a demanda da realidade.

Nessa perspectiva, a mediação do processo ensino/aprendizagem é feita pelo docente com o apoio de facilitadores e mediadores, cabendo a estes estimular nos cursistas ${ }^{1}$ a reflexão, pensamento, questionamentos e discussões sobre o planejamento e a Gestão do Sistema e Serviços de Saúde. Tais estímulos e provocações à discussão se dão a partir das abordagens sobre o conteúdo, estudos de caso e leitura da realidade.

O grupo de facilitadores é formado por profissionais da Hemorrede Pública Nacional vinculados à áreas técnicas ou de gestões, com experiência em planejamento, os quais foram preparados para atuar de forma específica no projeto. O grupo de mediadores encontra-se estabelecido de forma a manter o apoio sistemático da CGSH para o desdobramento local das atividades. Assim, para cada Hemorrede Estadual envolvida, além de uma dupla de docentes, conta-se com dois facilitadores e um mediador, sendo este último o elemento que, de forma compartilhada com o ISC, coordena, acompanha e avalia todo o escopo das atividades desenvolvidas.

Sob o formato de "curso" a atualização e, portanto, a capacitação sobre o processo de planejamento e gestão do sistema, e serviços de saúde inclui a abordagem sobre as bases conceituais e teóricas relacionadas ao planejamento no âmbito do SUS. Bem como, os elementos metodológicos para sua aplicação e elaboração do plano como um produto da construção coletiva dos atores envolvidos na sua formulação.

1 A turma de "cursistas" por estado é constituída por gestores e profissionais dos serviços da Hemorrede do respectivo estado, bem como, gestores e técnicos que atuam no sistema de saúde. Conselheiros de saúde também participam dos cursos. 
Para abordagem do conteúdo e programação proposta são utilizadas as seguintes estratégias metodológicas: dinâmica de integração; leitura individual; leitura coletiva; trabalhos de grupo; aulas expositivas dialogadas; estudo de caso. As dinâmicas de integração são propostas com o fim de estimular a participação e expressão dos cursistas sobre a experiência "formativa" em ato; as leituras individuais e coletivas paragrafadas prometem a discussão, o questionamento e o esclarecimento de dúvidas, assim como as aulas expositivas dialogadas; e, os trabalhos de grupo orientados pelo estudo de caso são pretenciosos em provocar no cursista a reflexão sobre uma situação fictícia, mas que remete às situações da realidade e do cotidiano do trabalho de cada cursista, com ênfase na área da Hematologia e Hemoterapia.

Com destaque ao estudo de caso, foi elaborada uma situação hipotética a partir de um estado cunhado como "globulina", para o qual foram desenhados o território estadual, sua divisão regional, a capacidade instalada em serviços de saúde, disponibilidade de leitos e produção de serviços e ações. O estudo de caso foi elaborado e validado pelo grupo de técnicos da CGSH/MS e gestores envolvidos na concepção do Projeto.

Figura 1 - Mapa das macrorregiões de Saúde apresentado no estudo de caso do estado de Globulina

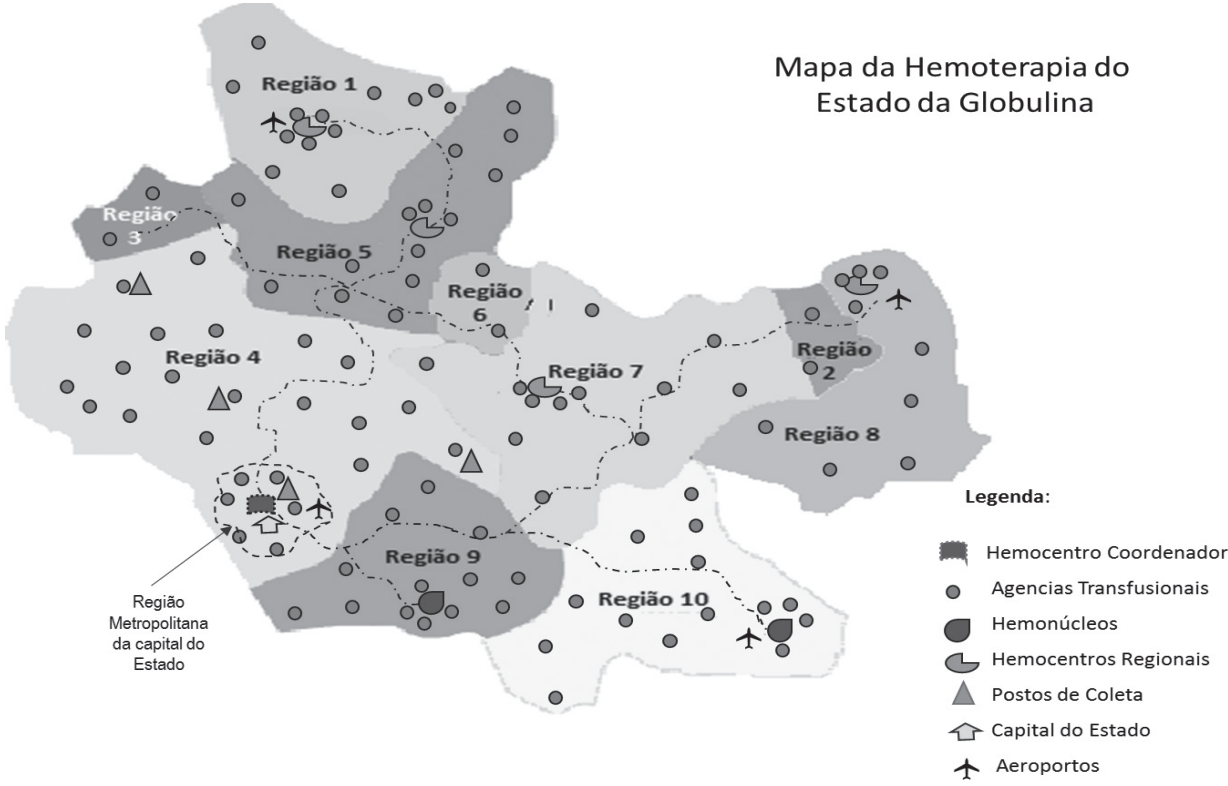

Fonte: Santos e colaboradores (2015). 
O estudo de caso caracteriza-se como um "instrumento pedagógico que apresenta um problema sem solução pré-definida”, exigindo raciocínio crítico e argumentativo dos cursistas para identificá-lo e analisá-lo, bem como desenvolver argumentos lógicos, tomar decisões e propor soluções.

O estudo de caso, bem como, os textos para leitura e atividades propostas estão dispostos no "Guia para estudos", principal recurso didático disponibilizado aos cursistas no primeiro dia (M1) do curso, na versão impressa. Em sua descrição completa, consta como elemento pós-textual do guia, além da extensa lista de referências indicadas e o levantamento da legislação específica da área de sangue e outras normas relacionadas que se constituem como suporte de leitura para o desenvolvimento das atividades propostas.

Também se constitui como elemento pós-textual do guia e de fundamental importância para a análise de situação de saúde, programação e planejamento das hemorredes, os parâmetros para o dimensionamento das necessidades de adequação da rede de serviços de hematologia e hemoterapia, considerando a Portaria $\mathrm{n}^{\circ} 1.631 / 2015$ que recentemente revogou a Portaria $\mathrm{n}^{\circ} 1.101 / 2002$.

O objetivo principal da utilização dos parâmetros é auxiliar os cursistas na direção do conhecimento sobre a rede de serviços hematológicos e hemoterápicos e as suas respectivas necessidades, de forma a compor a análise da situação de saúde do estado. O documento dos parâmetros destaca ainda a importância da exploração das bases de dados populacionais, hemoterápicos e hospitalares para a obtenção das informações desejadas.

Para os momentos de dispersão (D1 e D2), o desenho do curso propõe atividades a serem desenvolvidos in loco, ou seja, nos estados no qual os cursos são ofertados. Assim, visando instrumentalizar o acompanhamento pelos facilitadores, utiliza-se o ambiente virtual - Moodle - o qual funciona como espaço de interação entre cursistas e facilitadores e a orientação e o acompanhamento para a realização das atividades. 
Figura 2 - Página de acesso ao ambiente virtual Moodle do Planeja Sangue

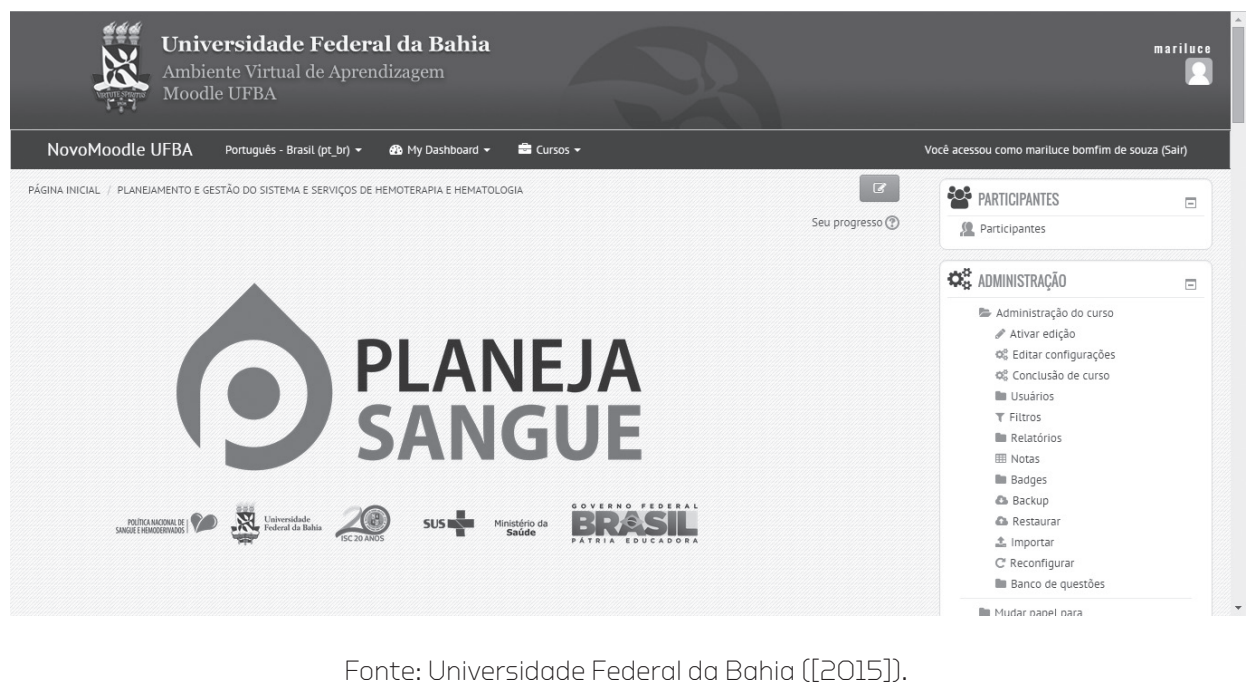

O uso do ambiente virtual está indicado na programação do guia sob o formato de atividades descritas como "Orientação da atividade de dispersão”. Para o desenvolvimento das atividades de dispersão faz-se necessária a utilização do guia, tendo em vista o suporte teórico para a discussão sobre análise de situação de saúde proposta no primeiro momento de dispersão (D1) e o desenho de estratégias de ação para enfrentamento dos principais problemas de saúde relacionados com os serviços de hematologia e hemoterapia da Hemorrede estadual, objetivo a ser alcançado no D2.

Quadro 1 - Objetivos do Momento de Dispersão (D1)

\begin{tabular}{|c|c|}
\hline Objetivo geral & Objetivos específicos \\
\hline \multirow{5}{*}{$\begin{array}{l}\text { Analisar a situação } \\
\text { de saúde da } \\
\text { população e dos } \\
\text { serviços de cada } \\
\text { região do estado. }\end{array}$} & Caracterizar o território estadual por região de abrangência. \\
\hline & $\begin{array}{l}\text { Identificar informações sobre a infraestrutura instalada - recursos humanos; situação } \\
\text { sanitária; sistema de informação; e qualidade. }\end{array}$ \\
\hline & $\begin{array}{l}\text { Descrever a situação da rede de serviços de hemoterapia e hematologia do estado } \\
\text { por região de abrangência - assistência hemoterápica e hematológica (referência/ } \\
\text { contrarreferência), utilizando a matriz de competência dos pontos de atenção. }\end{array}$ \\
\hline & $\begin{array}{l}\text { Identificar informações sobre os dados de produção: consultas, transfusão, capacidade } \\
\text { da imuno-hematologia e sorologia, processamento de hemocomponentes estoque e } \\
\text { distribuição de hemocomponentes, plasma excedente para produção de hemoderivados. }\end{array}$ \\
\hline & $\begin{array}{l}\text { Calcular os parâmetros para dimensionamento das necessidades de adequação da rede de } \\
\text { serviços de hematologia e hemoterapia. }\end{array}$ \\
\hline
\end{tabular}

Fonte: Universidade Federal da Bahia [[2015]]. 
Quadro 2 - Objetivos para o Momento de Dispersão (D2)

\begin{tabular}{|c|c|}
\hline Objetivo geral & Objetivos específicos \\
\hline \multirow{4}{*}{$\begin{array}{l}\text { Desenhar } \\
\text { estratégias de ação } \\
\text { para enfrentamento } \\
\text { dos principais } \\
\text { problemas de } \\
\text { saúde relacionados } \\
\text { com os serviços } \\
\text { de hemoterapia } \\
\text { da Hemorrede } \\
\text { estadual. }\end{array}$} & $\begin{array}{l}\text { Descrever e explicar os principais problemas de saúde identificados a partir da análise de } \\
\text { situação de saúde. }\end{array}$ \\
\hline & Traçar os objetivos considerando os problemas identificados. \\
\hline & Enumerar as operações para o enfrentamento dos problemas. \\
\hline & $\begin{array}{l}\text { Envolver diferentes atores - gestores e técnicos da Hemorrede estadual juntamente com } \\
\text { Vigilância Sanitária, vigilância epidemiológica, planejamento e controle e avaliação - na } \\
\text { discussão sobre os problemas e suas operações de enfrentamento. }\end{array}$ \\
\hline
\end{tabular}

Fonte: Universidade Federal da Bahia ([2015]).

Portanto, diante das atividades presenciais e de dispersão propostas, bem como dos recursos didáticos e metodológicos adotados, tendo em vista os objetivos traçados e as competências esperadas dos cursistas, se exige um acompanhamento e avaliação de todo o processo de desenvolvimento do curso. Nesse sentido, propôs-se a avaliação formativa, entendendo-a como parte integrante do processo de ensino/aprendizagem, ocorrendo durante todo o desenvolvimento do curso, por considerar que o cursista aprende ao longo do processo e reestrutura o seu conhecimento por meio das atividades que executa. Este modo de avaliação tem como finalidade fundamental "a função ajustadora do processo de ensino-aprendizagem para possibilitar que os meios de formação respondam as características dos cursistas". (JORBA; SANMARTÍ, 2003, p. 123) As atividades devem levar os cursistas à reflexão sobre os conteúdos e a aplicação dos conhecimentos gerados, conduzindo-os ao desenvolvimento das competências esperadas.

\section{Apresentação da programação dos cursos: visualizando as atividades propostas}

O “Guia para estudos” apresenta, em sua primeira parte, a programação do curso, indicando o formato em três ciclos de formação, durante os quais são desenvolvidas atividades de aprendizagem distribuídas nos turnos diários com horário programado para cada atividade. A duração de cada atividade é estabelecida como proposta, podendo ser readequada de acordo com as características e o ritmo de trabalho de cada turma. 
As pouco mais de 30 atividades programadas estão descritas detalhadamente no guia, com marcação de tempo, descrição, objetivo e sugestão metodológica para o respectivo desenvolvimento. Ao longo da apresentação das atividades estão incluídos dez textos como base para leitura e discussão, curiosidades com referências de estudiosos, glossários, exercícios e o estudo de caso com questões relacionadas ao tema abordado a fim de estimular a reflexão dos cursistas e provocar a relação teórico-prática. Vale destacar que tais atividades foram validadas em oficina realizada com representantes das hemorredes estaduais brasileiras no mês de abril de 2015, em encontro ocorrido em Salvador, Bahia, Brasil.

Quadro 3 - Programação dos cursos por ciclo segundo horário e identificação e
descrição das atividades propostas no "Guia de estudos"

$1{ }^{\circ} \mathrm{CICLO}$ : BASES PARA O PLANEJAMENTO NOS SERVIÇOS DE HEMOTERAPIA E HEMATOLOGIA NO ÂMBITO DO SISTEMA ÚNICO DE SAÚDE

$1^{\circ} \mathrm{DIA}-\mathrm{MI}$

\begin{tabular}{|c|c|c|}
\hline $\begin{array}{l}\text { Horário } \\
\text { programado }\end{array}$ & Atividades & Descrição \\
\hline \multirow{2}{*}{8 h30 às 9 h30 } & Atividade 1 & Acolhida dos participantes - boas vindas do grupo e dinâmica de integração \\
\hline & Atividade 2 & Apresentação dos objetivos e metodologia do curso \\
\hline $9 h 30$ às llh & Atividade 3 & Exposição dialogada sobre a Situação de Saúde no Brasil \\
\hline llh às lich & Atividade 4 & Trabalho de grupo com plenária interna \\
\hline 13 h30 às 15 h30 & Atividade 5 & $\begin{array}{l}\text { Perguntas e respostas sobre o Sistema Único de Saúde e os Serviços de } \\
\text { Hematologia e Hemoterapia no SUS }\end{array}$ \\
\hline 15 h30 às $16 h 30$ & Atividade 6 & $\begin{array}{l}\text { Leitura coletiva sobre a Situação dos Serviços de Hematologia e } \\
\text { Hemoterapia }\end{array}$ \\
\hline $16 h 30$ às $18 \mathrm{~h}$ & Atividade 7 & Exposição dialogada sobre Redes de Atenção à Saúde \\
\hline $18 \mathrm{~h}$ às $18 \mathrm{~h} 30$ & Atividade 8 & Avaliação do dia \\
\hline \multicolumn{3}{|r|}{$2^{\circ} \mathrm{DIA}-\mathrm{Ml}$} \\
\hline \multirow{2}{*}{$8 h 30$ às 9 h30 } & \multirow{2}{*}{ Atividade 9} & Acolhida dos participantes - dinâmica de integração \\
\hline & & Apresentação da Estrutura da Hemorrede Estadual \\
\hline $9 h 30$ às $10 h 30$ & Atividade 10 & $\begin{array}{l}\text { Trabalho de grupo - O Sistema de Saúde e a Estrutura Operacional } \\
\text { disponível para o fortalecimento da Hemorrede estadual }\end{array}$ \\
\hline
\end{tabular}




\begin{tabular}{|c|c|c|}
\hline 10h30 às llhl5 & Atividade 11 & Plenária interna sobre as atividades 7 e 10 desenvolvidas pelos cursistas \\
\hline 11 lis às l2h & Atividade 12 & $\begin{array}{l}\text { Exposição dialogada sobre o Processo Saúde-doença-cuidado e as } \\
\text { interfaces com a Hemorrede }\end{array}$ \\
\hline $13 h 30$ às 15h & Atividade 13 & $\begin{array}{l}\text { Exposição dialogada sobre as bases e os aspectos conceituais, } \\
\text { metodológicos, técnicos e práticos do planejamento }\end{array}$ \\
\hline 15h às l6h & Atividade 14 & $\begin{array}{l}\text { Leitura coletiva sobre os Usos da Epidemiologia para o Planejamento em } \\
\text { Saúde }\end{array}$ \\
\hline $16 h$ às $17 \mathrm{~h}$ & Atividade 15 & $\begin{array}{l}\text { Exposição dialogada sobre os parâmetros para o dimensionamento de } \\
\text { necessidades da Rede de Serviços de Hemoterapia e Hematologia }\end{array}$ \\
\hline $17 \mathrm{~h}$ às $18 \mathrm{~h} 30$ & Atividade 16 & Orientação da atividade de dispersão \\
\hline \multicolumn{3}{|r|}{ DISPERSÃO - D1 } \\
\hline \multicolumn{3}{|c|}{$\begin{array}{l}2^{\circ} \text { CICLO: GESTÃO E PLANEJAMENTO EM SAÚDE: ELEMENTOS PARA A CONSTRUÇÃO DO PLANO } \\
\text { COMO PRODUTO }\end{array}$} \\
\hline \multicolumn{3}{|r|}{$1^{\circ} \mathrm{DIA}-\mathrm{MZ}$} \\
\hline $8 h 30$ às $9 h$ & \multirow{2}{*}{ Atividade 17} & Acolhida dos participantes - dinâmica de integração \\
\hline $9 h$ às $10 h$ & & Resgate da atividade de dispersão \\
\hline lOh às llh & Atividade 18 & Leitura coletiva sobre Planos Diretores \\
\hline llh às leh & \multirow{2}{*}{ Atividade 19} & \multirow{2}{*}{$\begin{array}{l}\text { Trabalho de grupo - identificação/priorização de problemas e elaboração } \\
\text { da programação operativa }\end{array}$} \\
\hline $13 h 30$ às $16 h$ & & \\
\hline 16h às $18 \mathrm{~h}$ & Atividade 20 & Plenária interna sobre Programação em Saúde \\
\hline $18 \mathrm{~h}$ às $18 \mathrm{~h} 30$ & Atividade 21 & Avaliação do dia \\
\hline \multicolumn{3}{|r|}{$2^{\circ} \mathrm{DIA}-\mathrm{M} 2$} \\
\hline 08h30 às $9 h$ & Atividade ટટ & Acolhida dos participantes - dinâmica de integração \\
\hline $9 h$ às $10 h 30$ & Atividade 23 & $\begin{array}{l}\text { Exposição dialogada sobre Trabalho em Equipe e Educação Permanente } \\
\text { em Saúde }\end{array}$ \\
\hline $10 h 30$ às leh & Atividade 24 & $\begin{array}{l}\text { Trabalho de grupo sobre Cultura Organizacional, Liderança e Comunicação } \\
\text { em Saúde. }\end{array}$ \\
\hline $13 h 30$ às 15h & Atividade 25 & Exposição dialogada sobre Tomada de Decisão e Participação em Saúde \\
\hline 15h às $16 h$ & Atividade 26 & $\begin{array}{l}\text { Leitura individual ou coletiva sobre Planejamento de Investimentos e } \\
\text { Internalização de Planos Diretores }\end{array}$ \\
\hline 16h às 17 h30 & Atividade 27 & $\begin{array}{l}\text { Exposição dialogada sobre Avaliação em Saúde e sua relação com o } \\
\text { Planejamento em Saúde }\end{array}$ \\
\hline $17 h 30$ às $18 h 30$ & Atividade 28 & Orientação da atividade de dispersão \\
\hline \multicolumn{3}{|r|}{ DISPERSÃO - D2 } \\
\hline
\end{tabular}




\begin{tabular}{|c|c|c|}
\hline \multicolumn{3}{|c|}{$\begin{array}{l}3^{\circ} \text { CICLO: SISTEMATIZAÇÃO DE PROPOSTA PARA O PLANEJAMENTO NOS SERVIÇOS DE HEMOTERAPIA E } \\
\text { HEMATOLOGIA NO ÂMBITO DO SUS }\end{array}$} \\
\hline \multicolumn{3}{|r|}{$1^{\circ} \mathrm{DIA}-\mathrm{M3}$} \\
\hline 8 h30 às 9 h & Atividade 29 & Acolhida dos participantes - dinâmica de integração \\
\hline 9h às $10 \mathrm{~h}$ & \multirow{3}{*}{ Atividade 30} & Resgate das atividades de dispersão \\
\hline lOh às li2h & & \multirow{2}{*}{ Oficina de sistematização dos produtos finais } \\
\hline $13 \mathrm{~h} 30$ às $18 \mathrm{~h} 30$ & & \\
\hline \multicolumn{3}{|r|}{$2^{\circ} \mathrm{DIA}-\mathrm{M3}$} \\
\hline 8 h30 às llh & Atividade 31 & Plenária de socialização dos produtos finais \\
\hline llh às leh & Atividade 32 & Avaliação final do Curso \\
\hline
\end{tabular}

Fonte: Souza e colaboradores (2015).

\section{Produto dos cursos de Planejamento e Gestão em Saúde: proposta preliminar do Plano Diretor das hemorredes estaduais}

Desde a concepção do projeto, na condição de "proposta de atualização", a CGSH/MS tinha como expectativa que os cursos proporcionassem aos gestores e técnicos participantes a aprendizagem das bases teóricas e metodológicas para o processo de planejamento e também que subsidiassem a elaboração do Plano Diretor das Hemorredes Estaduais envolvidas.

Nesse sentido, todo o processo de produção, reflexão e discussão do conhecimento sobre planejamento e gestão, além das atividades realizadas com base na realidade de cada estudo serviu para a concretização do desenho preliminar dos planos diretores nos cinco estados em que foram ofertados os cursos no ano de 2015, sendo apresentados em plenária externa, aberta a convidados - gestores, conselheiros, associações, etc - no último dia do curso, durante o M3.

A fim de orientar os cursistas na sistematização das atividades desenvolvidas e das discussões geradas nos momentos presenciais, propôs-se um documento orientador para o desenho da proposta preliminar do Plano Diretor como produto esperado ao final do curso (M3). O documento orientador apresenta inicialmente o plano diretor (I) como um instrumento de gestão e, 
portanto, um elemento norteador do planejamento e das práticas para a organização e operacionalização da assistência hemoterápica e atenção hematológica; em seguida, provoca os cursistas a partir do questionamento sobre a importância de plenária para a socialização dos produtos finais do curso (II), tendo em vista que trata da apresentação do desenho do plano; e, finalmente detalha orientações para a elaboração de um plano diretor com a respectiva proposição de estrutura do documento (III), desde os elementos pré-textuais até os pós-textuais.

\section{I) O que é o Plano Diretor?}

O Plano Diretor é um documento que expressa a política da organização e determina um conjunto de instruções, definidas de forma compartilhada, utilizando-se os meios disponíveis e favoráveis para alcançar seus objetivos, dentro de uma abrangência geográfica delimitada. Portanto, para além dos objetivos, deve explicitar as estratégias e oferecer instrumentos necessários para que os mesmos sejam cumpridos.

Desta forma, o Plano Diretor configura-se num instrumento efetivo e norteador para o planejamento da atenção hematológica e hemoterápica nos estados e Distrito Federal e, deve estar articulado com as diretrizes da Política Nacional de Sangue e Hemoderivados.

Os planos diretores regionais de sangue dos estados e do Distrito Federal devem conter uma descrição detalhada baseada em análise da situação de saúde da população. Esta análise da situação de saúde da população deve ter como base o levantamento do cenário existente e do que mais será necessário para assegurar a atenção adequada à saúde da população. Assim, deve-se realizar a análise situacional para definir metas a serem alcançadas em um determinado período. A partir daí, define-se as estratégias, ações e os recursos necessários para garantir a execução da Política de Sangue e Hemoderivados, sugerindo orientação dos investimentos estruturantes necessários a serem feitos pelas três esferas de governo, quando pertinente.

De acordo com o Decreto $n^{\circ} 3.990 / 2001$ em seu artigo $5^{\circ}$, compete aos estados e ao Distrito Federal, no âmbito do Sinasan, a gestão, a coordenação e a elaboração do plano diretor de sangue, componentes e hemoderivados, bem como promover, em articulação com o Ministério da Saúde, o acompa- 
nhamento e a avaliação do cumprimento das metas e das ações do Sinasan, tendo dentre suas atribuições: adequar, em articulação com os municípios, os parâmetros assistenciais do plano diretor estadual de sangue, componentes e hemoderivados, incluindo a assistência hemoterápica no estado; e, acompanhar e avaliar o cumprimento das metas estabelecidas no plano diretor estadual de sangue e hemoderivados. (BRASIL, 2001)

Em seu artigo $7^{\circ}$, o decreto refere que a construção do plano é conduzida pela hemorrede estadual juntamente com vigilância sanitária, vigilância epidemiológica, planejamento e controle e avaliação e atores que são considerados relevantes em cada plano. (BRASIL, 2001) Entretanto, na prática, garantir que os diferentes segmentos da sociedade participem nas atividades de planejamento, execução e acompanhamento da Política de Sangue e Hemoderivados é um grande desafio. O plano deve ser homologado pelo Conselho Estadual de Saúde e aprovado pelo Ministério da Saúde, segundo parecer técnico. (BRASIL, 2001)

\section{II] Por que uma plenária para socialização dos produtos finais do curso?}

Independente da obrigatoriedade da elaboração do Plano Diretor pelos estados e Distrito Federal, é desejável que todos os gestores conheçam a sua realidade, se dediquem a reduzir as desigualdades e não meçam esforços para melhorar a qualidade de vida da população.

A atividade de elaborar e/ou revisar o Plano Diretor de Sangue e Hemoderivados é uma oportunidade para estabelecer um processo permanente de construir políticas, avaliar ações e corrigir rumos. Além de servir para incentivar: (i) capacitação de gestores e equipes locais; (ii) sistematização e revisão de normas e portarias e; (iii) integração da política setorial de sangue e hemoderivados, com os orçamentos anuais Lei Orçamentária Anual (LOA) e Plano Plurianual (PPA) bem como com o Plano Estadual de Saúde, o Plano Diretor de Regionalização da saúde (PDR) e a Programação Pactuada Integrada (PPI).

Democratizar e explicitar as decisões são ações fundamentais para que todos se comprometam com processo de construção do Sistema de Sangue e Hemoderivados, tornando a definição de políticas um trabalho compartilhado e fazendo com que todos, sintam-se responsáveis e responsabilizados com o sucesso desta política. 


\section{III] Qual a estrutura de um Plano Diretor? Quais orientações podem ser consideradas para sua elaboração?}

O processo de planejamento deve aproximar a teoria da prática, num movimento dialógico de construção (TEIXEIRA, 2010), que utiliza o enfoque estratégico situacional e considera a participação social na definição, implementação e avaliação das ações. Nesse sentido, a Teixeira (2010) propõe movimentos para o processo de elaboração de um plano, o qual deve partir da construção de uma proposta de planejamento integrado e da análise de situação de saúde.

Os movimentos para este processo de construção compartilhada devem considerar as demandas e recomendações das conferências de saúde, bem como os problemas "discutidos e chancelados" nas reuniões/oficinas realizadas com distintos atores - conselheiros, gestores, técnicos, etc., para, então, definir linhas de ação, compromissos, objetivos e ações, considerando, portanto, a viabilidade financeira-orçamentária. (TEIXEIRA, 2010)

A partir dessa compreensão, sugere-se a seguir a estrutura ${ }^{2}$ de um plano diretor estadual, com respectivas orientações para a sua elaboração. Este plano deve ter no mínimo: a) Elementos pré-textuais; b) Elementos textuais: introdução/apresentação; análise da situação da saúde; módulos operacionais; diretrizes, objetivos e metas; monitoramento e avaliação do plano diretor; planejamento de investimentos; c) Elementos pós-textuais.

a) Elementos pré-textuais:

- Capa: logo e nome da instituição, nome do serviço, título do plano, local, data;

- Contracapa: diretores, gerentes, coordenadores, equipe de elaboração/colaboradores;

- Lista de siglas: siglas utilizadas no texto, colocadas por extenso;

2 A proposta de estrutura de Plano Diretor para as Hemorredes foi elaborada a partir de um trabalho conjunto da equipe de coordenação e da equipe de elaboração do Planeja Sangue. 
- Lista de tabelas e/ou gráficos e/ou mapas: identificação das tabelas, gráficos, mapas e figuras na sequência de apresentação ao longo do plano;

- Sumário: capítulos, paginação.

b) Elementos textuais:

- Apresentação: resgatar os princípios e diretrizes que norteiam a Política do Sangue no estado, apresentar a importância do processo de planejamento e da elaboração do plano, referir o Decreto $n^{\circ} 3990 / 2001$, descrever a metodologia para a elaboração do plano fazendo menção às atividades realizadas a partir da participação de profissionais e representantes de diferentes espaços da configuração institucional do estado no curso "Planeja Sangue";

- Análise da situação de saúde: o consolidado da análise situacional deve considerar a divisão regional segundo o Plano Diretor Estadual de Saúde. Deve conter descrição e análise do(a):

- Perfil demográfico e epidemiológico por região de saúde: extensão territorial, divisão regional e distâncias entre as regiões, densidade demográfica, população - concentração e características relevantes, projeções de crescimento, fecundidade, natalidade, envelhecimento, expectativa de vida, dentre outros;

- Estrutura e organização dos serviços de saúde no sus estadual: cenário da capacidade instalada, condições de infraestrutura por região, disposição da rede de atenção estadual - unidades e serviços hospitalares por nível de complexidade de leitos conforme os Parâmetros SUS (BRASIL, 2015) anteriormente recomendados pela Portaria $\mathrm{n}^{\circ} 1.101$ de junho de 2002 , atenção especializada e atenção básica, urgência e emergência, configuração dos serviços públicos e privados considerando a atenção hematológica e a distribuição dos serviços hemoterápicos nas regiões do estado; 
- Características da Hemorrede Estadual: 1. Histórico e objetivos da Hemorrede estadual; 2. Gestão da Hemorrede estadual: descrever a hierarquia do sistema, a natureza jurídica da Hemorrede, a relação entre os integrantes do sistema e a forma de contratualização com os serviços, a governança do sistema, bem como, a configuração dos processos de gestão e qualificação das pessoas - tipos de vínculo, perfil da força de trabalho, perfil de formação, da qualidade, de gestão dos recursos, de materiais e serviços, de infraestrutura física, de equipamentos e informática, sobre a existência de planos de contingência, gerenciamento de resíduos, biossegurança, logística, marketing, sistemas de informação (SUS e próprios da Hemorrede) ensino e pesquisa, atenção hemoterápica ciclo do sangue - do doador ao receptor - e hematológica (ciclo do paciente) e outros; 3. Análise da disposição/oferta dos serviços e ações para a atenção hematológica e hemoterápica no estado: elaborar texto de análise considerando as informações levantadas em relação aos parâmetros da atenção hemoterápica utilizados, devendo-se adotar tabelas, gráficos e matrizes (planilhas). Para o dimensionamento da atenção hematológica, recomenda-se ressaltar ainda a importância de se realizar análise conjunta dos parâmetros populacionais, de infraestrutura e de assistência levantados, inclusive considerando, a partir de tal análise, quais as pactuações e articulações necessárias com os demais pontos de atenção da rede, com os gestores das secretarias estaduais, com os gestores dos serviços de hematologia e hemoterapia, visando, contudo, à melhoria e aperfeiçoamento da oferta de ações e serviços da atenção hematológica. Descrever a análise da situação sanitária dos serviços, - destacar os que estão adequados e as não conformidades -, mencionar os resultados de avaliação do Programa Nacional de Qualificação da Hemorrede, resultados dos testes de proficiência dos programas de avaliação externa da qualidade e os resultados das inspeções sanitárias; descrever a necessidade de adequações da estrutura, com implantações de novas unidades assisten- 
ciais ou transformações das existentes e, nos locais em que não existir unidades fixas de coleta, avaliar a realização de coletas externas. Analisar a distribuição de oferta e da necessidade regionalizada, considerando as ações e atividades ${ }^{3}$ a partir do cálculo das necessidades com base nos parâmetros - considerar coleta, processamento, sorologia e imuno-hematologia, laboratório NAT, coleta de sangue e perfil das doações - considerar a racionalização e o aperfeiçoamento das redes de produção de hemocomponentes sem prejuízo à descentralização e hierarquização da assistência, considerar a otimização de recursos necessários para implantação ou adequação de um serviço, garantindo uma produção mínima que justifique os recursos de investimento que necessariamente serão mobilizados para sua implantação. Sugere-se comparar a realidade apresentada com os parâmetros e o índice populacional, deficiências de unidades hemoterápicas, distância e demais necessidades apresentadas.

- Módulos operacionais4: a partir da análise de situação de saúde, identificação e priorização de problemas e das intervenções sobre o estado de saúde e sobre a organização do sistema, consideradas a divisão regional de saúde, deve-se adotar a definição de objetivos e dos planos ou módulos operacionais, os quais devem ser detalhados pelos objetivos específicos, diretrizes, metas, ações, responsáveis, prazos e indicadores. Tais aspectos podem ser organizados nos seguintes recortes indicando cada plano ou módulo operacional: (1) Gestão do Sistema; (2) Linhas de Atenção à Saúde - Fluxo do Paciente (3) Produção e Distribuição de Sangue - Ciclo do Sangue;

3 Coleta; Processamento; Sorologia e Imuno-hematologia do doador; Laboratório NAT; Perfil das doações de sangue, considerando a cobertura populacional; Fontes de Recursos.

4 A proposta de "modularização" do produto do planejamento consiste no entendimento do plano como "modular", composto de módulos operacionais que sintetizam os elementos do processo de trabalho previsto (objetivos, atividades, produtos e resultados, responsáveis, participantes, prazos e recursos), flexibilizando a organização e facilitando a participação de distintos sujeitos sociais, bem como um ordenamento espaço-temporal em função do desenho estratégico. (TEIXEIRA, 2001, p. 8) 
(4) Aquisição e Distribuição de Hemoderivados; (5) Rede de Serviços - Infraestrutura Física e de Equipamentos; (6) Sistema de Informação e Infraestrutura de Informática; (7) Gestão do Trabalho e a Qualificação de Recursos Humanos; (8) Risco Epidemiológico e Sanitário; (9) Investimentos em Hemoterapia e Hematologia.

Quadro 4 - Exemplo/modelo para elaboração de módulo operacional

\begin{tabular}{|l|l|}
\hline Módulo Operacional I - GESTÃo DA HEMORREDE NO SUS ESTADUAL \\
\hline $\begin{array}{l}\text { Diretriz l - Fortalecer a Gestão da Hemorrede Estadual no âmbito do Sistema Único de Saúde e no contexto da } \\
\text { regionalização }\end{array}$ \\
\hline Objetivo 1.1 - Aprimorar a Gestão da Hemorrede estadual no âmbito do Sistema Único de Saúde \\
\hline Indicador de monitoramento: \\
\hline Responsáveis: & Projeto/ \\
\hline Meta: & Atividade PPA \\
\hline Ações & \\
\hline Implementação da gestão por competências e modernização... & \\
\hline Fortalecimento das ações...
\end{tabular}

Fonte: Salvador (2014).

- Monitoramento e avaliação do plano diretor: para acompanhar e avaliar o cumprimento das metas estabelecidas nos planos diretores deve-se definir um conjunto de indicadores, determinando claramente as fontes de obtenção e o método de cálculo, os quais serão monitorados e avaliados constantemente. É fundamental estabelecer um pacto de indicadores referente ao ciclo de sangue e a cobertura da atenção hemoterápica e hematológica. O acompanhamento e avaliação do processo de execução das atividades propostas deve, por sua vez, ser desenvolvido a partir da montagem de um conjunto de mecanismos que envolvem alguns tipos de controle, dentre eles, o controle dos procedimentos burocráticos utilizados normalmente na administração pública, os quais devem obedecer as leis e normas vigentes; o controle gerencial que implica no estabelecimento de mecanismos que permitam o alcance da chamada "eficiência alocativa" (produtividade ao menor custo); o controle de qualidade voltado à garantir a eficácia técnica e a qualidade das ações executadas, baseando-se 
na aplicação das normas existentes e da elaboração e aplicação de normas que impliquem na utilização do conhecimento científico disponível e das tecnologias mais adequadas; e, o controle social que se refere ao acompanhamento e avaliação da gestão e execução das políticas e das atividades, sendo realizado pelos órgãos colegiados previstos na legislação do SUS, isto é, os Conselhos de Saúde. (TEIXEIRA, 2001, p. 23-24) A análise sistemática dos dados e informações disponíveis será fundamental para apoiar as instâncias de decisão. É de fundamental importância (1) verificar a execução das metas previstas no Plano Diretor e avaliar se as ações desenvolvidas pela Hemorrede estão beneficiando os cidadãos e se melhoram a saúde da população; (2) acompanhar os indicadores pactuados; (3) verificar o cumprimento da Lei Complementar $n^{\circ} 141 / 2012$ por parte dos estados e municípios; e (4) verificar a necessidade de reorientação estratégica das ações frente a novos cenários, sejam políticos, econômicos, sociais, epidemiológicos ou de catástrofes. Nos estados e no Distrito Federal o monitoramento e avaliação do Plano Diretor serão executados pela Câmara de Assessoramento da Política de Sangue e Hemoderivados a qual cuidará do acompanhamento de diretrizes e metas a serem desdobradas em programas e/ou projetos.

- Planejamento de investimentos ou viabilidade financeiro-orçamentária do Plano Diretor Estadual de Saúde: demonstrar onde estão alocados os recursos orçamentários que conferem suporte financeiro à execução das ações estratégicas propostas para o alcance das metas e resultados esperados para o período. Deve-se apresentar os gastos com a atenção hematológica e hemoterápica. Recuperar o que já está assegurado como fontes de recursos que financiam o serviço. Desenvolver a análise dos investimentos previstos e realizados na estruturação da rede considerando o Plano Plurianual (PPA) vigente. De acordo com o Decreto $n^{\circ} 3990 / 2001$ o financiamento para a execução dos planos, acontecerá com recursos provenientes da União, da participação dos Estados, do Distrito Federal e dos municípios, de acordo com a legislação vigente. O repasse dos recursos da União para a área de sangue e hemoderivados está condicionado à aprova- 
ção do plano diretor estadual de sangue e hemoderivados. Sugere-se a previsão dos recursos orçamentários necessários para alcançar as metas previstas no Plano de Investimentos. O mesmo deve ser planejado para quatro anos, em conformidade com o Plano Plurianual (PPA). O Plano Anual de Investimento deve tomar como base o planejamento elaborado no Plano Plurianual. O mesmo deverá trazer informações referentes aos recursos orçamentários necessários para o alcance das metas pactuadas e previstas para área de Hematologia e Hemoterapia, no que se refere aos investimentos a serem realizados no exercício de vigência da Lei Orçamentária Anual. No Plano Anual de Investimentos ficam evidenciadas as metas que devem ser cumpridas, em que prazos e que ações e orçamento serão necessários para este fim.

c) Elementos pós-textuais:

- Apêndices: apresentação de gráficos, tabelas, figuras e/ou mapas;

- Anexos: documentos parciais ou na íntegra.

\section{Referências}

AGÊNCIA NACIONAL DE VIGILÂNCIA SANITÁRIA. Resolução RDC n 151, de 21 de agosto de 2001. Aprova o Regulamento Técnico sobre Níveis de Complexidade dos Serviços de Hemoterapia, que consta como anexo. Diário Oficial [da] República Federativa do Brasil, Poder Executivo, Brasília, DF, 22 ago. 2001. Seção 1, p. 29.

BERBEL, N. A. N. A problematização e a aprendizagem baseada em problemas: diferentes termos ou diferentes caminhos? Interface: Comunicação, Saúde e Educação, Botucatu, v. 2, n. 2, p. 139-154, fev. 1998.

BRASIL. Decreto $\mathrm{n}^{\circ} 3.990$, de 30 de outubro de 2001. Regulamenta o art. 26 da Lei $n^{\circ} 10.205$, de 21 de março de 2001, que dispõe sobre a coleta, processamento, estocagem, distribuição e aplicação do sangue, seus componentes e derivados, estabelece o ordenamento institucional indispensável à execução adequada dessas atividades. Diário Oficial [da] República Federativa do Brasil, Poder Executivo, Brasília, DF, 31 out. 2001. Seção 1, p. 1. 
BRASIL. Ministério da Saúde. Portaria $n^{\circ}$ 1.631, de $1^{\circ}$ de outubro de 2015. Aprova critérios e parâmetros para o planejamento e programação de ações e serviços de saúde no âmbito do SUS. Diário Oficial [da] República Federativa do Brasil, Brasília, DF, 2 out. 2015. Seção 1, p. 38.

JORBA, J.; SANMARTÍ, N. A função pedagógica da avaliação. In: BALLESTER, M. et al. Avaliação como apoio à aprendizagem. Porto Alegre: Artmed, 2003. p. 23-45.

MATUS, C. Teoria da ação e teoria do planejamento. In: MATUS, C. Política, planejamento \& governo. Brasília, DF: Ipea, 1996. p. 81-98.

SALVADOR (BA). Prefeitura Municipal. Secretaria Municipal de Saúde. Plano municipal de saúde 2014-2017. Salvador, 2014.

SANTOS, C. M. et al. Estudo de caso. In: SOUZA, M. K. B. et al. (Org.). Planeja Sangue: cursos em planejamento e gestão de sistema e serviços de saúde: guia para estudos. [S.1.]: Salvador, 2015. p. 127-132.

SOUZA, M. K. B. et al. (Org.). Planeja Sangue: cursos em planejamento e gestão de sistema e serviços de saúde: guia para estudos. [S.1.]: Salvador, 2015.

TEIXEIRA, C. F. Planejamento municipal em saúde. Salvador: Instituto de Saúde Coletiva da Universidade Federal da Bahia, 2001.

TEIXEIRA, C. F. (Org.). Planejamento em saúde: conceitos, métodos e experiências. Salvador: Edufba, 2010.

UNIVERSIDADE FEDERAL DA BAHIA. Moodle. Salvador, [2015]. Disponível em: <www.novomoodle.ufba.br >. Acesso em: 1 set. 2015. 


\title{
Notas sobre a implementação dos cursos em Planejamento e Gestão em Saúde e caracterização das Hemorredes estaduais ${ }^{1}$
}

\author{
Mariluce Karla Bomfim de Souza \\ Márcia Teixeira Gurgel do Amaral \\ Bárbara de Jesus Simões \\ Jussara Cargnin Ferreira
}

\section{Introdução}

O Projeto Planeja Sangue foi concebido por iniciativa da Coordenação Geral de Sangue e Hemoderivados do Ministério da Saúde (CGSH/MS) que visa apoiar as Hemorredes Estaduais, de maneira teórico-instrumental, para a concepção de Planos Diretores Estaduais de Sangue e Hemoderivados. Este plano é requisito legal na área de hematologia e hemoterapia, porém é limitado ao cotidiano das Hemorredes, devido à incipiente cultura institucional do planejamento nos serviços e pela complexidade encontrada para sua elaboração.

1 Agradecimentos: as autoras registram os agradecimentos aos gestores e/ou representantes das Hemorredes dos cinco estados: Nilza Sampaio e Aurora Cavalcanti (Bahia); Flora Sabino (Pernambuco); Sandra Sobreira (Paraíba); Gabrielle Duarte (Roraima); e, Alzira Saldanha (Mato Grosso) quanto à atualização das informações relacionadas à rede de serviços hemoterápicos. Agradecimento também a estudante Andréa Laís Santos e Santos pela atualização dos quadros relacionados à caracterização dos estados. 
As práticas de planejamento adotadas pela CGSH/MS, a partir do ano de 2008, foram norteadas pelo pressuposto da superação do planejamento normativo, envolvendo de forma sistemática a participação dos gestores da Hemorrede Pública Nacional e a força de trabalho da própria coordenação, consolidando ao longo do período, o uso de estratégias de fomento ao pensar coletivo e ampliado para o enfrentamento de situações-problema demandadas no âmbito do Sistema Nacional do Sangue.

No contexto citado, foi estabelecida cooperação técnica com o Instituto de Saúde Coletiva da Universidade Federal da Bahia (ISC/UFBA) visando o desenvolvimento de cursos de Atualização em Planejamento e Gestão de Sistema e Serviços de Saúde, que passou a ser denominado e conhecido como Planeja Sangue.

O desenvolvimento do Planeja Sangue para gestores e técnicos das hemorredes estaduais, ao longo do ano de 2015, permitiu a aproximação com a realidade dos estados, bem como o conhecimento sobre suas características demográficas, organização do sistema e distribuição dos serviços, de acordo com a divisão do estado em regiões de saúde, com especial atenção aos serviços de hematologia e hemoterapia.

Cada estado tem estabelecido, a partir de seu Plano Diretor de Regionalização da Saúde, o desenho destas regiões, de modo que a elaboração e o acompanhamento dos cursos permite conhecer as distintas realidades configuradas.

O presente capítulo contempla, por conseguinte, notas de registro sobre o processo de implementação do Planeja Sangue em Hemorredes estaduais do território nacional. Além disso, é apresentada uma breve caracterização destas hemorredes, para as quais foi ofertado o curso em Planejamento e Gestão no ano de 2015.

\section{Notas de registro sobre a implementação do Planeja Sangue}

A parceria e a articulação entre o Instituto de Saúde Coletiva da Universidade Federal da Bahia, reconhecido pela oferta/realização de cursos de graduação e pós-graduação e desenvolvimento de pesquisas, e a Coorde-

2 O curso de graduação em Saúde Coletiva, autorizado através da Portaria $n^{\circ} 813$, de 24 de agosto de 2007, do Ministério de Estado da Educação, DOU n 165 de 27.08.2007. (UNIVERSIDADE FEDERAL DA BAHIA, 2015) 
nação-Geral de Sangue e Hemoderivados do Ministério da Saúde, permitiu a implementação do Planeja Sangue na Hemorrede Pública Nacional, iniciando-se o trabalho, no ano de 2015, nos estados da Bahia, Roraima, Mato Grosso, Pernambuco e Paraíba.

A oferta dos cursos, após o aceite das Hemorredes Estaduais, se deu por meio de edital público para cada um dos estados citados, com o fomento à representação dos serviços de hematologia e hemoterapia dos diversos níveis de complexidade, obtendo-se a participação de profissionais e gestores dos Hemocentros Coordenadores (HC), Hemocentros Regionais (HR), Núcleos de Hemoterapia (NH), Unidades de Coleta e Transfusão (UCT), Agências Transfusionais (AT) e demais diretorias e coordenações estaduais como Planejamento, Atenção Básica (AB), Vigilância Sanitária (VISA) e Vigilância Epidemiológica (VE), além de organizações de representação de usuários e Conselho Estadual de Saúde, sendo registradas pequenas variações da participação destes segmentos nos estados.

A distribuição quantitativa ${ }^{3}$ dos participantes, bem como os municípios que representaram cada estado, pode ser observada a seguir:

- Bahia: 38 participantes de 20 municípios;

- Roraima: 48 participantes de 3 municípios;

- Mato Grosso: 53 participantes de 19 municípios;

- Pernambuco: 42 participantes de 09 municípios;

- Paraíba: 77 participantes de 17 municípios.

Pode-se observar a variação no número de participantes em cada estado, o que pressupõe motivos distintos, por exemplo: disponibilidade para a participação dos cursistas em todos os momentos presenciais; quantitativo de profissionais nos serviços da Hemorrede; extensão territorial do estado; agenda concorrida pelos compromissos profissionais e/ou pessoais, dentre outros. Quanto aos municípios que foram representados em cada estado,

3 Este quantitativo de participantes e de municípios refere-se aos dados coletados da lista de participantes do Momento presencial 1 (M1) e da lista de inscritos no curso por estado, respectivamente. 
pressupõe que a diferença pode ser atribuída à distribuição e localização dos serviços da Hemoterapia em cada território estadual.

No processo de implementação do Planeja Sangue, em 2015, foram registradas variadas observações de formato, de método e de logística levadas à discussão com a equipe técnica e de coordenação para ajustes imediatos, quando possíveis, e para discussão no Encontro de Avaliação agendado para o mês de novembro daquele ano.

No que tange ao formato da oferta do curso desenhado em três momentos presenciais (M1, M2, M3) e dois momentos de dispersão (D1, D2) foi possível observar sua aplicação no que havia sido proposto, contemplando o acesso e revisão às bases teóricas para o planejamento e a imersão na realidade, iluminados por tais conhecimentos para o desenvolvimento do processo de planejamento regional e desenho preliminar dos planos diretores da Hemorrede.

A execução do curso dentro do formato proposto foi possível pelos métodos utilizados. Para cada cursista foi disponibilizado um "Guia para estudos", de Souza e colaboradores (2015) e o cadastro para acesso a plataforma Moodle que possibilitou o espaço de interação entre cursistas e facilitadores durante os momentos de dispersão.

O arcabouço teórico apresentado no guia e discutido com os docentes nos momentos presenciais, bem como, a realidade problematizada em trabalhos de grupo e estudo de caso, esclareceu os cursistas sobre o desenvolvimento do processo de planejamento em saúde. Além disso, a análise da situação de saúde local proposta nos momentos M1 e D1 possibilitou a percepção ampliada sobre o seu estado e, a partir do desenho de objetivos, estratégias de ações e proposição de intervenções e análise da viabilidade, foi elaborada a proposta preliminar de Plano Diretor para a Hemorrede Estadual.

A variedade na composição das turmas, para além daqueles trabalhadores inseridos nos serviços de hemoterapia, era uma situação prevista e, por isso, o desenho do curso com os recursos e métodos propostos foi elaborado a fim de incluir e comprometer todos os participantes no (re)conhecimento do estado, dos serviços hemoterápicos e da atenção hematológica dentro do Sistema Único de Saúde.

No "Guia de Estudos" o capítulo Estudo de caso (2015) foi um dos recursos utilizados durante o momento presencial e que oportunizou o conhecimento daqueles cursistas que não atuam diretamente nos serviços de Hemo- 
terapia e o (re)conhecimento dos trabalhadores e gestores que lidam no seu cotidiano com as questões e os problemas relacionados à política do sangue, sejam eles nos serviços de atenção às pessoas com alguma doença hematológica, seja nos serviços hemoterápicos.

Quanto à logística para a realização dos cursos, para cada estado foi disponibilizada uma equipe constituída por: dois docentes e um técnico administrativo do ISC/UFBA; dois facilitadores técnicos atuantes nas diferentes Hemorredes estaduais; e, um mediador da CGSH/MS. No dia anterior ao início de cada momento presencial toda a equipe se deslocava para a capital do estado no qual o curso foi ofertado levando o material impresso (guias, declarações, etc.) e outros necessários para a sua operacionalização. Aos cursistas, também cabia tal deslocamento. Assim, providências de passagens e translados para a equipe, bem como, alimentação e hospedagem para equipe e cursistas faziam parte da agenda de atividades para a execução dos cursos.

Portanto, todas as notas de registro sobre sua implementação, especificamente sobre formato, método e logística foram discutidas no Encontro de Avaliação do Planeja Sangue que aconteceu em Salvador nos dias 27 e 28 de novembro de 2015 com a participação dos coordenadores institucionais, mediadores, facilitadores e docentes. Este encontro marcou o encerramento da agenda do "Planeja Sangue" de 2015 e representou importante momento de avaliação das ações e atividades implementadas durante o ano. Em síntese, foi apontado pelos presentes a eficácia do método utilizado, contudo, evidenciou-se a necessidade de aperfeiçoamento na operacionalização de questões de logística e também pequenos ajustes na distribuição e carga horária dos conteúdos, entretanto, sem modificação do formato geral da proposta.

Ressalta-se, que a etapa de avaliação permeou todos os momentos presenciais e de dispersão dos cursos e direcionou o trabalho realizado pelo grupo coordenador durante a execução dos mesmos. A "avaliação" implica no posicionamento positivo ou negativo em relação ao objeto, ato ou curso da ação que está sob julgamento, requerendo, portanto, uma tomada de posição favorável ou desfavorável ao que está sendo avaliado, logo, uma decisão de ação. (LUCKESI, 2003)

Diante das experiências vivenciadas e conclusão da oferta de cinco cursos, os resultados e impactos só poderão ser aferidos em médio e longo prazo, visto que a institucionalização das práticas de planejamento requer 
mudanças nas pessoas e nas organizações e que a proposta de Plano Diretor desenhada preliminarmente no decorrer dos cursos deverá ser finalizada e, portanto, legitimada nas instâncias formais do Sistema Único de Saúde. No entanto, acredita-se que sem um instrumento formal de planejamento não há como pautar a área de sangue como prioridade da agenda governamental, daí a relevância do Planeja Sangue como instrumento de qualificação da gestão da Hemorrede pública nacional.

\section{Caracterização das Hemorredes Estaduais}

Para a organização das Hemorredes Estaduais, a distribuição dos serviços de hematologia e hemoterapia deve seguir a regulamentação contida na Portaria/GM n ${ }^{\circ} 1.631$, de $1^{\circ}$ de outubro de 2015, provendo essa assistência aos usuários do Sistema Único de Saúde. Ressalta-se, que a divisão por macrorregiões e regiões de saúde deve assegurar atendimento às necessidades dos munícipes que delas fazem parte, principalmente no que se refere às ações de média densidade tecnológica, caracterizando-se como referência, nesse nível de atenção à saúde, para a população local.

De acordo com a Lei $n^{\circ} 10.205 / 2001$, cabem aos estados, além do Distrito Federal e municípios, por meio de suas secretarias de saúde ou equivalentes, a coordenação e execução das ações correspondentes a Política de Sangue, Componentes e Hemoderivados no seu âmbito de atuação, em articulação com o Ministério da Saúde. (BRASIL, 2001) No entanto, historicamente, o desenho e a implantação dos hemocentros coordenadores datam de períodos anteriores a lei.

O Projeto Planeja Sangue, em 2015, ofertou cursos voltados para planejamento e gestão de hemorredes em cinco estados, a saber: Bahia (BA); Pernambuco (PE); Paraíba (PB); Roraima (RR); e, Mato Grosso (MT); contemplando, portanto, três regiões geográficas brasileiras - Nordeste, Norte e Centro-Oeste, respectivamente.

A seguir apresenta-se uma breve caracterização das hemorredes nas quais os cursos foram ofertados.

\section{I) Hemorrede do estado da Bahia}

A Bahia, maior estado do nordeste brasileiro em termos demográficos, com população que ultrapassa 15 milhões de habitantes (IBGE, [201-]), con- 
centra aproximadamente $7,3 \%$ do total de habitantes do país. (BAHIA, 2012b) Dos 417 municípios, cerca de $60 \%$ possui menos de 20.000 habitantes, e, aproximadamente, $30 \%$ da população do estado reside em zona rural. (IBGE, 2011)

O quadro abaixo mostra dados sobre o perfil do estado que permitem conhecer suas características, inclusive sobre renda per capita, esperança de vida ao nascer, mortalidade infantil, coletas de sangue e taxa de doação de sangue.

Quadro 1 - Perfil estadual por área, população, renda per capita, esperança de vida ao nascer, mortalidade infantil, coleta e taxa de doação de sangue, Bahia, 2016

\begin{tabular}{|c|c|}
\hline Superfície territorial ${ }^{[1]}$ & $564.733,081 \mathrm{~km}^{2}$ \\
\hline População ${ }^{[1]}$ & 15.203.934de habitantes \\
\hline Rendimento per capita da população residente (reais) ${ }^{[1]}$ & $R \$ 736,00$ \\
\hline Esperança de vida ao nascer [2] & $\begin{array}{l}67,7 \text { anos (homens) } \\
76,4 \text { anos (mulheres) }\end{array}$ \\
\hline Mortalidade infantil [3] & 20,1/1.000 nascidos vivos \\
\hline Coleta de sangue anual ${ }^{(4)}$ & 208.181 coletas \\
\hline Taxa de doação ${ }^{(4]}$ & 13,76/1.000 habitantes \\
\hline
\end{tabular}

(1) e (2) IBGE ([2O1-]); (3) Brasil (2012); (4) Brasil (2015).

Fonte: elaborado pelos autores com base em IBGE ([201-]) e Brasil (2012, 2015).

Segundo o Plano Diretor de Regionalização da Saúde, a Bahia está dividida em 9 macrorregiões e 28 regiões ${ }^{4}$ de saúde, no qual encontram-se distribuídos os serviços, de acordo com a oferta disponibilizada pelos municípios e a capacidade instalada.

Em dezembro de 2014, a Lei Estadual nº 13.204 determinou a extinção das Diretorias Regionais de Saúde (Dires) e a criação dos Núcleos Regionais de Saúde (NRS) que têm por finalidade acompanhar as atividades de regulação e vigilância sanitária, bem como ações relativas à Coordenação de Monitoramento de Prestação de Serviços de Saúde; à Central de Aquisições e Contratações da Saúde; e à Corregedoria da Saúde, contribuindo para o fortalecimento da gestão junto aos Municípios. (BAHIA, 2014)

4 As regiões de saúde do estado da Bahia estão definidas na Resolução da CIB nº 275/2012. (BAHIA, 2012a) 
$\mathrm{O}$ atendimento às demandas de sangue e hemocomponentes da rede pública, em Salvador e região metropolitana, teve início em janeiro de 1983, em uma área adaptada do Hospital Geral Roberto Santos. Em 26 de julho de 1989, foi criada a Fundação de Hematologia e Hemoterapia da Bahia (Hemoba), tendo por finalidade exercer atividades de hematologia e hemoterapia em todo Estado, inclusive o desenvolvimento de ensino e pesquisa. Em 1992, a Fundação Hemoba passou a funcionar em espaço próprio e atualmente, tem unidades hemoterápicas distribuídas em diversas regiões do estado. (FUNDAÇÃO DE HEMATOLOGIA E HEMOTERAPIA DO ESTADO DA BAHIA, 2016)

O Quadro 2 mostra a distribuição das unidades de assistência hemoterápica, classificadas de acordo com a Resolução da Diretoria Colegiada (RDC) da Anvisa, $n^{\circ} 151$, de 21 de agosto de 2001, existentes no estado e que compõem a rede Hemoba.

Quadro 2 - Distribuição dos serviços de hematologia e hemoterapia do Sistema Único de Saúde nas macrorregiões, Bahia, 2016

\begin{tabular}{|c|c|}
\hline Macrorregiões & Quantidade/Unidades por nível de complexidade/municípios \\
\hline Centro Leste & O3 UCT (Feira de Santana; Itaberaba; Seabra) \\
\hline Centro-Norte & Oટ UCT (Irecê; Jacobina) \\
\hline \multirow[t]{2}{*}{ Extremo Sul } & Ol HR (Eunápolis) \\
\hline & Ol UCT (Teixeira de Freitas) \\
\hline \multirow[t]{3}{*}{ Leste $^{*}$} & $\mathrm{Ol} \mathrm{HC} \mathrm{(Salvador)}$ \\
\hline & O3 UC (OI UC SAC/Cajazeiras; OI UC Hospital Santo Antônio; OI UC Subúrbio) \\
\hline & Oટ UCT (Camaçari; Santo Antônio de Jesus) \\
\hline Nordeste & Oટ UCT (Alagoinhas; Ribeira do Pombal) \\
\hline Norte & O3 UCT (Juazeiro; Paulo Afonso; Senhor do Bonfim) \\
\hline Oeste & Ol UCT (Barreiras) \\
\hline Sudoeste & O4 UCT (Brumado; Guanambi; Itapetinga; Vitória da Conquista) \\
\hline \multirow[t]{2}{*}{ Sul } & Ol UC (Valença) \\
\hline & Ol UCT (Jequié) \\
\hline
\end{tabular}

* Na Macrorregião Leste, estão disponíveis O2 UC - Hemóvel (veículo para realização de coletas externas).

Fonte: Fundação de Hematologia e Hemoterapia do Estado da Bahia (2016). 
A divisão por macrorregiões e regiões de saúde deve ser no sentido de garantir atendimento às necessidades dos munícipes que delas fazem parte, principalmente no que se refere às ações de média densidade tecnológica, caracterizando-se como referência nesse nível de atenção à saúde para a população local e apresentando algum grau de resolutividade. Essa mesma lógica deveria corresponder à distribuição dos serviços para atenção hematológica e também dos serviços hemoterápicos.

\section{II) Hemorrede do estado de Pernambuco}

Também na região Nordeste, o curso foi ofertado ao estado de Pernambuco. A população do estado é estimada em mais de nove milhões de habitantes (IBGE, [201-]), distribuídos em 184 municípios e um território estadual - Fernando de Noronha -, sendo, pouco mais de $80 \%$, considerados municípios de pequeno porte. (PERNAMBUCO, 2012)

Outras informações sobre superfície territorial, renda per capita, esperança de vida ao nascer, mortalidade infantil, coletas e taxa de doação de sangue, possibilitam caracterizar mais amplamente o estado de Pernambuco, conforme mostra o quadro a seguir.

Quadro 3 - Perfil estadual por área, população, renda per capita, esperança de vida ao nascer, mortalidade infantil, coleta e taxa de doação de sangue, Pernambuco, 2016

\begin{tabular}{|l|l|}
\hline Superfície territorial ${ }^{[1]}$ & $98.076,109 \mathrm{~km}^{2}$ \\
\hline População $^{[1]}$ & 9.345 .173 de habitantes \\
\hline Rendimento per capita da população residente (reais) [1] & $R \$ 822,00$ \\
\hline Esperança de vida ao nascer [2] $^{[2]}$ & $\begin{array}{l}66,8 \text { anos (homens] } \\
75,5 \text { anos (mulheres) }\end{array}$ \\
\hline Mortalidade infantil $^{[3]}$ & $15,6 / 1.000$ nascidos vivos \\
\hline Coleta de sangue anual $^{[4]}$ & 224.564 coletas \\
\hline Taxa de doação ${ }^{(4)}$ & $24,20 / 1.000$ habitantes \\
\hline
\end{tabular}

(1) e (2) IBGE ([2O1-]); (3) Brasil (2O12); (4) Brasil (2O15).

Fonte: elaborado pelos autores com base em IBGE ([201-]] e Brasil (2012, 2015].

Pernambuco está dividido em quatro macrorregiões e 12 regiões de saúde, conforme estratégia de regionalização e em consonância com o PDR/PE. 
No âmbito técnico administrativo, as regiões estão sob a coordenação das respectivas Gerências Regionais de Saúde (Geres) que têm a missão de planejar, executar, acompanhar, monitorar e avaliar as ações e serviços e elaborar as diretrizes da política estadual em cada região de saúde. (PERNAMBUCO, 2011, 2012)

O Hemocentro de Pernambuco (Hemope) foi o primeiro a ser implantado no Brasil, fundado em 25 de novembro de 1977. Posteriormente, por força de lei complementar em 1990, o Hemope recebeu nova denominação, enquanto entidade dotada de personalidade jurídica de direito público, de caráter científico, tecnológico, educacional e de prestação de serviços, sem fins lucrativos, vinculada à Secretaria de Saúde do Estado (BRASIL, 2010), por meio de administração indireta fundacional.

Atualmente, a Hemorrede Estadual de Pernambuco dispõe da seguinte distribuição de serviços, por macrorregiões de saúde.

Quadro 4 - Distribuição dos serviços de hematologia e hemoterapia do Sistema Único de Saúde nas macrorregiões, Pernambuco, 2016

\begin{tabular}{|c|c|}
\hline Macrorregiões [e regiões] & Quantidade/Unidades por nível de complexidade/municípios \\
\hline \multirow{4}{*}{$\begin{array}{l}\text { I - Metropolitana } \\
\text { (regiões I, II, III e XII) }\end{array}$} & $\mathrm{Ol} \mathrm{HC} \mathrm{(Recife)}$ \\
\hline & Ol UCT (Recife) \\
\hline & O己 AT Regional (Palmares; Limoeiro) \\
\hline & O4 AT (Recife; Jaboatão dos Guararapes; Cabo de Santo Agostinho; Tamandaré) \\
\hline \multirow{2}{*}{$\begin{array}{l}\text { II - Agreste } \\
\text { (regiões IV e V) }\end{array}$} & O己 HR (Caruaru; Garanhuns) \\
\hline & Oટ AT (Petrolândia; Caruaru) \\
\hline \multirow{3}{*}{$\begin{array}{l}\text { III - Sertão } \\
\text { (regiões VI, Xe XI) }\end{array}$} & Ol HR (Serra Talhada) \\
\hline & Ol NHR (Arcoverde) \\
\hline & Ol AT (Quixaba) \\
\hline \multirow{3}{*}{$\begin{array}{l}\text { IV - Vale do São Francisco e } \\
\text { Araripe } \\
\text { [regiões VII, VIII e IX] }\end{array}$} & O1 NHR (Salgueiro) \\
\hline & O己 HR (Petrolina; Ouricuri) \\
\hline & O3 AT (Araripina; Cabrobó; Belém do São Francisco) \\
\hline
\end{tabular}

Fonte: Fundação Hemocentro de Pernambuco (2016). 


\section{III] Hemorrede Estadual da Paraíba}

Outro estado do Nordeste brasileiro, para o qual o curso foi ofertado, foi a Paraíba. O referido estado é composto por 223 municípios, com população estimada em 2015 de aproximadamente 4 milhões de habitantes. (IBGE, [201-])

O estado da Paraíba foi caracterizado, ainda, pelas informações de superfície territorial, renda per capita, esperança de vida ao nascer, mortalidade infantil, coletas e taxa de doação de sangue, apresentadas no quadro abaixo.

Quadro 5 - Perfil estadual por área, população, renda per capita, esperança de vida ao nascer, mortalidade infantil, coleta e taxa de doação de sangue, Paraíba, 2016

\begin{tabular}{|l|l|}
\hline Superfície territorial (1) & $56.469,744\left(\mathrm{~km}^{2}\right)$ \\
\hline População (1) & 3.972 .202 de habitantes \\
\hline Rendimento per capita da população residente (reais) (1) & R $\$ 776,00$ \\
\hline Esperança de vida ao nascer (2) & $\begin{array}{l}67,4 \text { anos (homens) } \\
75,0 \text { anos (mulheres) }\end{array}$ \\
\hline Mortalidade infantil (3) & $17,5 / 1.000$ nascidos vivos \\
\hline Coleta de sangue anual (4) & 80.338 coletas \\
\hline Taxa de doação (4) & $20,37 / 1.000$ habitantes \\
\hline
\end{tabular}

(1) e (2) IBGE ([2O1-]); (3) Brasil (2O12); (4) Brasil (2O15).

Fonte: elaborado pelos autores com base em IBGE ([201-]) e Brasil (2012, 2015).

O modelo de reorganização da saúde, no estado da Paraíba, foi estruturado pelo Núcleo de Desenvolvimento das Regiões, dentro da Gerência de Planejamento e Gestão, e pelas Gerências Regionais de Saúde, sob a justificativa de que "cada gerência regional conta com uma capacidade funcional instalada, capaz de articular o processo gerencial das ações técnico-administrativas da saúde". (PARAÍBA, 2008, p. 15)

Constituído por 4 macrorregiões e 16 regiões de saúde, o estado tem distribuído os serviços de hemoterapia, considerando as tipologias de serviços previstos na $\mathrm{RDC} \mathrm{n}^{\circ} 151 / 2001$, conforme quadro a seguir: 
Quadro 6 - Distribuição dos serviços de hematologia e hemoterapia do Sistema Único de Saúde nas macrorregiões, Paraíba, 2016

\begin{tabular}{|l|l|}
\hline Macrorregiões & Quantidade/Unidades por nível de complexidade/municípios \\
\hline \multirow{3}{*}{ João Pessoa } & Ol HC (João Pessoa) \\
\cline { 2 - 2 } & O2 NH (Guarabira, Itabaiana) \\
\cline { 2 - 2 } & 14 AT (João Pessoa) \\
\hline Campina Grande & O1 HR (Campina Grande) \\
\cline { 2 - 2 } & O2 NH (Picuí, Monteiro) \\
\cline { 2 - 3 } & O9 AT (Campina Grande) \\
\hline Patos & O4 NH (Patos, Itaporanga, Princesa Isabel, Piancó) \\
\hline Sousa & NH (Sousa, Cajazeiras, Catolé do Rocha) \\
\cline { 2 - 3 } & O1 AT (Pombal) \\
\hline
\end{tabular}

Fonte: Paraíba [2016].

O Hemocentro da Paraíba (Hemoíba) foi criado, por meio da Lei $n^{\circ} 6.306$ de 2 de fevereiro de 1991, para ser referência na assistência hemoterápica no estado. No entanto, a interiorização da Hemorrede ocorreu a partir de 1996, com o objetivo de atender a toda população, ficando distribuída nos municípios sede dos Núcleos Regionais de Saúde (NRS). Atualmente, a Hemorrede é a única fornecedora de produtos hemoterápicos da rede pública e em quase totalidade da rede privada de serviços de saúde. (BRASIL, 2010)

\section{IV) Hemorrede do estado de Roraima}

Com uma população estimada em pouco mais de meio milhão de habitantes em 2015, o estado de Roraima, da região Norte do Brasil, possui grande extensão territorial com baixa densidade demográfica, quando comparado aos demais estados onde o curso foi ofertado. A rede de serviços de saúde se distribui em 15 municípios, em duas macrorregiões, segundo o Plano Diretor de Regionalização, sendo a maior parte dos serviços localizados na capital do estado.

O estado de Roraima foi caracterizado, também, pelas informações de superfície territorial, renda per capita, esperança de vida ao nascer, mortalidade infantil, coletas e taxa de doação de sangue, apresentadas no quadro abaixo. 
Quadro 7 - Perfil estadual por área, população, renda per capita, esperança de vida ao nascer, mortalidade infantil, coleta e taxa de doação de sangue, Roraima, 2016

\begin{tabular}{|c|c|}
\hline Superfície territorial ${ }^{[1]}$ & $224.303,187\left(\mathrm{~km}^{2}\right)$ \\
\hline População ${ }^{[1]}$ & 505.665 de habitantes \\
\hline Rendimento per capita da população residente (reais) ${ }^{[1]}$ & R\$1.008,00 \\
\hline Esperança de vida ao nascer [2] & $\begin{array}{l}\text { 66,9 anos (homens) } \\
72,5 \text { anos (mulheres) }\end{array}$ \\
\hline Mortalidade infantil ${ }^{(3)}$ & $15,4 / 1.000$ nascidos vivos \\
\hline Coleta de sangue anual ${ }^{[4]}$ & 11.398 coletas \\
\hline Taxa de doação ${ }^{(4)}$ & 22,94/ 1.000 habitantes \\
\hline
\end{tabular}

(1) e (2) IBGE ([2O1-]); (3) Brasil (2012); (4) Brasil (2015).

Fonte: elaborado pelos autores com base em IBGE ([201-]) e Brasil (2012, 2015).

O Hemocentro de Roraima (Hemoraima) foi inaugurado em setembro de 1992 e está vinculado à Secretaria Estadual de Saúde de Roraima. Atualmente, a Hemorrede Estadual conta com serviços conforme a distribuição regional apresentada no quadro a seguir.

Quadro 8 - Distribuição dos serviços de hematologia e hemoterapia do Sistema Único de Saúde nas macrorregiões, Roraima, 2016

\begin{tabular}{|l|l|}
\hline Macrorregiões & Quantidade/Unidades por nível de complexidade/municípios \\
\hline Centro Norte & O1 HC (Boa Vista) \\
\cline { 2 - 2 } & O3 AT (Boa Vista) \\
\cline { 2 - 2 } & O4 NH (Boa Vista) \\
\hline Sul & O1 AT (Rorainópolis) \\
\hline
\end{tabular}

Fonte: elaborado pelas autoras.

\section{V) Hemorrede do estado de Mato Grosso}

A população urbana do estado de Mato Grosso triplicou de tamanho entre os anos de 1980 e 2010, sendo, em 2015, 3.265.486 habitantes, distribuídos em 141 municípios. (IBGE, [201-]; MATO GROSSO, 2013) 
Da mesma forma que os demais estados participantes do Planeja Sangue, o estado do Mato Grosso foi caracterizado pelas informações de superfície territorial, renda per capita, esperança de vida ao nascer, mortalidade infantil, coletas e taxa de doação de sangue, apresentadas no quadro abaixo.

Quadro 9 - Perfil estadual por área, população, renda per capita, esperança de vida ao nascer, mortalidade infantil, coleta e taxa de doação de sangue, Mato Grosso, 2016

\begin{tabular}{|c|c|}
\hline Superfície territorial ${ }^{(1)}$ & $903.378,292\left(\mathrm{~km}^{2}\right)$ \\
\hline População (1) & 3.265.486 de habitantes \\
\hline Rendimento per capita da população residente (reais] (1]) & $R \$ 1.055,00$ \\
\hline Esperança de vida ao nascer (2) & $\begin{array}{l}69,5 \text { anos (homens) } \\
75,9 \text { anos (mulheres) }\end{array}$ \\
\hline Mortalidade infantil ${ }^{[3]}$ & 18,5/1.000 nascidos vivos \\
\hline Coleta de sangue anual ${ }^{[4]}$ & 80.759 coletas \\
\hline Taxa de doação ${ }^{[4]}$ & 25,05/ 1.000 habitantes \\
\hline
\end{tabular}

(1) e (2) IBGE ([2O1-]); (3) Brasil (2012); (4) Brasil (2015).

Fonte: elaborado pelos autores com base em IBGE ([201-]) e Brasil (2012, 2015).

No âmbito da regionalização da saúde, o referido estado está organizado em 16 regiões de saúde, considerados espaços estratégicos para a gestão e desenvolvimento integrado das políticas de saúde. Cada região possui Escritório Regional de Saúde (ERS) que responde pela condução da política estadual de saúde, em nível regional, e pela coordenação e articulação técnica e política junto aos municípios de abrangência. (MATO GROSSO, 2013, p. 157)

Em 15 de março de 1994, foi instituído o Hemocentro Coordenador do Estado de Mato Grosso - Hemomat o qual, dez anos depois, teve a sua estrutura organizacional modificada recebendo nova denominação pela redação da Lei Complementar $\mathrm{n}^{\circ} 180$, de 13 de julho de 2004, passando a ser denominado MT - Hemocentro. (MATO GROSSO, 2016) Atualmente, a Hemorrede Estadual é composta por 1 Hemocentro Coordenador, 17 Unidades de Coletas e Transfusão e 29 agências Transfusionais, conforme a distribuição apresentada no quadro a seguir. 
Quadro 10 - Distribuição dos serviços de hematologia e hemoterapia do Sistema Único de Saúde nas macrorregiões, Mato Grosso, 2016

\begin{tabular}{|c|c|}
\hline Regiões & Quantidade/Unidades por nível de complexidade/municípios \\
\hline Norte Araguaia Carajás & Ol AT (São Félix do Araguaia) \\
\hline Sudoeste & O己 AT (Comodoro; Pontes e Lacerda) \\
\hline \multirow[t]{2}{*}{ Oeste } & Ol AT (São José dos Quatro Marcos) \\
\hline & O己 UCT (Cáceres; Mirassol D’Oeste) \\
\hline \multirow[t]{2}{*}{ Noroeste } & O己 AT (Aripuanã; Brasnorte) \\
\hline & Ol UCT (Juína) \\
\hline \multirow[t]{2}{*}{ Médio Norte } & O3 AT (Campo Novo do Parecis; Sapezal) \\
\hline & O己 UCT (Barra do Bugres; Tangará da Serra) \\
\hline Alto Tapajós & OI UCT (Alta Floresta) \\
\hline Vale do Arinos & OI UCT (Juara) \\
\hline Vale do Peixoto & O3 AT (Guarantã do Norte; Peixoto de Azevedo; Terra Nova do Norte) \\
\hline \multirow[t]{2}{*}{ Norte } & Ol AT (Marcelândia) \\
\hline & OI UCT (Colíder) \\
\hline \multirow[t]{2}{*}{ Teles Pires } & O己 AT (Lucas do Rio Verde; Nova Mutum) \\
\hline & O己 UCT (Sinop; Sorriso) \\
\hline Centro Norte & O3 AT (Diamantino; Nobres; Nortelândia) \\
\hline \multirow[t]{3}{*}{ Baixada Cuiabana } & Ol HC (Cuiabá) \\
\hline & O3 AT (Cuiabá; Poconé; Várzea Grande) \\
\hline & Ol UCT (Cuiabá) \\
\hline \multirow[t]{2}{*}{ Baixo Araguaia } & O己 AT (Confresa; Vila Rica) \\
\hline & Ol UCT (Porto Alegre do Norte) \\
\hline \multirow[t]{2}{*}{ Médio Araguaia } & Ol AT (Canarana) \\
\hline & Ol UCT (Água Boa) \\
\hline \multirow[t]{2}{*}{ Sul } & $\begin{array}{l}\text { O5 AT (Alto Araguaia; Campo Verde; Paranatinga; Poxoréo; } \\
\text { Rondonópolis) }\end{array}$ \\
\hline & O3 UCT (Jaciara, Primavera do Leste e Rondonópolis) \\
\hline \multirow{2}{*}{ Garças Araguaia } & Ol AT (Nova Xavantina) \\
\hline & O1 UCT (Barra do Garças) \\
\hline
\end{tabular}

Fonte: Mato Grosso (2016).

A cobertura hemoterápica do estado de Mato Grosso é realizada majoritariamente pela Hemorrede Pública (70,9\%) e complementada pela rede privada em 29,1\%. Quanto à atenção hematológica, o HC concentra o atendimento ambulatorial hematológico de todo o estado, incluindo exames diagnósticos 
e acompanhamento de portadores de Hemoglobinopatias, Coagulopatias, dentre outras doenças hematológicas. (MATO GROSSO, 2013)

\section{Considerações finais}

Como foi possível verificar, o desenho do curso, que origina o Projeto Planeja Sangue, apresenta uma proposta mista, envolvendo o ensino presencial e à distância e baseia-se numa estratégia ativa de aprendizagem, demandando um trabalho complexo para os cursistas, principalmente durante os momentos de dispersão, etapa na qual o apoio sistemático dos facilitadores torna-se essencial. A introdução do uso de metodologias de aprendizagem desta natureza tem sido adotada de forma gradativa nas ações de educação promovidas pela CGSH para a força de trabalho da Hemorrede Pública Nacional.

No caso aqui abordado, conforme já comentado, além da adequação à consecução dos objetivos traçados, evidenciada no processo avaliativo realizado ao final de 2015 pelo grupo de coordenação do projeto, a estratégia obteve excelente nível de adesão, bem como o reconhecimento dos cursistas, revelado por meio das avaliações orais, que ressaltaram sua importância para o desenvolvimento de habilidades para o trabalho coletivo. Além disto, a percepção sobre a oportunidade de discussão de problemas e soluções comuns junto aos pares da Hemorrede Estadual e demais segmentos envolvidos no processo de trabalho do curso a situa como uma oportunidade de ampliação do debate intrasetorial.

As dificuldades constatadas receberam tratamento, sendo estabelecidas soluções tal o empenho e experiência dos gestores, pontos focais e cursistas das hemorredes envolvidas, a expertise teórico metodológica da equipe do Instituto de Saúde Coletiva e o perfil profissional selecionado para a composição do grupo de mediadores e facilitadores das oficinas.

Observou-se a necessidade de desenvolvimento de parâmetros para a atenção hematológica de forma a instrumentalizar a análise da situação de saúde nessa perspectiva, a exemplo das referências já utilizadas no campo da atenção hemoterápica. Para tanto, encontra-se instituído grupo técnico para o desenvolvimento das referências ora citadas.

Uma limitação evidenciada, ao final do trabalho em 2015, foi a formatação final dos Planos Diretores pelas Hemorredes, demandando assim uma pro- 
posta já elaborada de acompanhamento e monitoramento, a ser adotada a partir de 2016, após o término do Momento Presencial 3, assegurando o apoio dos facilitadores até a conclusão efetiva dos Planos.

A continuidade do projeto está assegurada no planejamento da CGSH, de acordo com a disponibilidade futura de recursos para sua efetivação. Pretende-se, para o ano seguinte, em 2016, a oferta dos cursos de Planejamento e Gestão em outros sete estados (Rio de Janeiro, Mato Grosso do Sul, Piauí, Alagoas, Santa Catarina, Espírito Santo e Rio Grande do Sul).

Espera-se que as informações produzidas pelas Hemorredes, no Planeja Sangue, adquiram relevância como fonte de informação para a gestão da Política Nacional de Sangue e Hemoderivados e o aperfeiçoamento e fortalecimento das Hemorredes públicas estaduais.

\section{Referências}

AGÊNCIA NACIONAL DE VIGILÂNCIA SANITÁRIA. Resolução RDC nº 151, de 21 de agosto de 2001. Aprova o Regulamento Técnico sobre Níveis de Complexidade dos Serviços de Hemoterapia, que consta como anexo. Diário Oficial [da] República Federativa do Brasil, Poder Executivo, Brasília, DF, 22 ago. 2001. Seção 1, p. 29.

BAHIA. Lei $n^{\circ} 13.204$, de 11 de dezembro de 2014. Modifica a estrutura organizacional da Administração Pública do Poder Executivo Estadual e dá outras providências. Salvador, 2014.

BAHIA. Resolução CIB n ${ }^{\circ} 275$, de 15 de agosto de 2012. Aprova as regiões de saúde do Estado da Bahia e a instituição das Comissões Intergestores Regionais. Salvador, 2012a. Disponível em: <http://wwwl.saude.ba.gov.br/ mapa_bahia/docs/RESOLU\%C3\%87\%C3\%83O\%20275_15.08.2012_Aprova\%20 Regi\%C3\%B5es\%20de\%20Sa\%C3\%BAde\%20e\%20CIR.pdf >. Acesso em: 14 set. 2013.

BAHIA. Secretaria de Saúde do Estado da Bahia. Plano Estadual de Saúde da Bahia: 2012-2015. Salvador, 2012b.

BRANDÃO, I. C. A. et al. Análise da organização da rede de saúde da Paraíba a partir do modelo de regionalização. Revista Brasileira de Ciências da Saúde, Paraíba, v. 16, n. 3, p. 347-352, 2012.

BRASIL. Lei $n^{\circ} 10.205$, de 21 de março de 2001. Regulamenta o $§ 4^{\circ}$ do art. 199 da Constituição Federal, relativo à coleta, processamento, estocagem, distribuição e aplicação do sangue, seus componentes e derivados, 
estabelece o ordenamento institucional indispensável à execução adequada dessas atividades, e dá outras providências. Diário Oficial [da] República Federativa do Brasil, Poder Legislativo, Brasília, DF, 22 mar. 2001. Seção 1, p. 1. Disponível em <http://www.planalto.gov.br/ccivil_03/leis/leis_2001/110205. htm>. Acesso em: 10 nov. 2015.

BRASIL. Ministério da Saúde. Portaria $n^{\circ} 1.631$, de $1^{\circ}$ de outubro de 2015. Aprova critérios e parâmetros para o planejamento e programação de ações e serviços de saúde no âmbito do SUS. Diário Oficial [da] República Federativa, Brasília, DF, 2 out. 2015. Seção 1, p. 38.

BRASIL. Ministério da Saúde. Rede Interagencial de Informações para a Saúde. Indicadores de mortalidade. Brasília, DF, 2012. Disponível em: <http:// tabnet.datasus.gov.br/cgi/idb2012/c01b.htm>. Acesso em: 19 nov. 2016.

BRASIL. Ministério da Saúde. Secretaria de Atenção à Saúde. Departamento de Atenção Especializada. Gestão de hemocentros: relatos de práticas desenvolvidas no Brasil: I curso de especialização em gestão de hemocentros: resumos das monografias finais. Brasília, DF, 2010. 674 p. Disponível em: <http://bvsms.saude.gov.br/bvs/publicacoes/gestao_ hemocentros_praticas_brasil.pdf $>$. Acesso em: 10 mar. 2016.

BRASIL. Ministério da Saúde. Secretaria de Atenção à Saúde. Departamento de Atenção Especializada e Temática. Caderno de informação: sangue e hemoderivados: dados de 2014. 9. ed. Brasília, DF, 2015. 154 p. Disponível em: $<$ http://bvsms.saude.gov.br/bvs/publicacoes/caderno_informacao_sangue hemoderivados_dados_201_9ed.pdf >. Acesso em: 19 nov. 2016.

FUNDAÇÃO DE HEMATOLOGIA E HEMOTERAPIA DO ESTADO DA BAHIA. Plano diretor de sangue, componentes e derivados do estado da Bahia: 20162019. Salvador, 2016.

FUNDAÇÃO HEMOCENTRO DE PERNAMBUCO. Plano diretor de sangue, hemocomponentes e hemoderivados. Recife, 2016. No prelo.

FUNDAÇÃO HEMOCENTRO DE PERNAMBUCO. Recife, [200-]. Disponível em: <http://www.hemope.pe.gov.br/fund-interiorizacao.php >. Acesso em: 3 mar. 2016.

IBGE. Censo demográfico 2010: características da população e dos domicílios: resultados do universo. Rio de Janeiro, 2011.

IBGE. Estados @. Rio de Janeiro, [201-]. Disponível em: <http://www.ibge.gov. br/estadosat/perfil.php>. Acesso em: 19 nov. 2016. 
IBGE. Rio de Janeiro, [200-]. Disponível em: <http://cod.ibge.gov.br >. Acesso em: 10 mar. 2016.

LUCKESI, C. C. Avaliação da aprendizagem na escola: reelaborando conceitos e recriando a prática. Salvador: Malabares, 2003.

MATO GROSSO. Secretaria de Estado de Saúde. Hemocentro: quem somos. Cuiabá, [200-]. Disponível em: <http://www.saude.mt.gov.br/hemocentro/ pagina/70/quem-somos>. Acesso em: 10 mar. 2016.

MATO GROSSO. Secretaria de Estado de Saúde. Plano estadual de saúde de Mato Grosso: 2012-2015. Cuiabá, 2016. No prelo.

MATO GROSSO. Secretaria de Estado de Saúde. Superintendência de Políticas de Saúde. Plano estadual de saúde de MT: 2012-2015. Cuiabá, 2013.

PARAÍBA. Secretaria de Estado da Saúde. Gerência de Planejamento e Gestão. Sub-Gerência de Programação e Organização da Assistência. Núcleo de desenvolvimento das regiões de saúde. Plano diretor de regionalização da Paraíba. João Pessoa, 2008.

PERNAMBUCO. Secretaria Estadual de Saúde. Plano estadual de saúde: 20122015. Recife, 2012.

PERNAMBUCO. Secretaria de Saúde. Plano diretor de regionalização. Recife, 2011.

SANTOS, C. M. et al. Estudo de caso. In: SOUZA, M. K. B. et al. (Org.). Planeja Sangue: cursos em planejamento e gestão de sistema e serviços de saúde: guia para estudos. [S.l.]: Salvador, 2015. p. 127-132.

SOUZA, M. K. B. et al. (Org.). Planeja Sangue: cursos em planejamento e gestão de sistema e serviços de saúde: guia para estudos. [S.l.]: Salvador, 2015.

UNIVERSIDADE FEDERAL DA BAHIA. Instituto de Saúde Coletiva. Regimento do curso de graduação em Saúde Coletiva. Salvador, 2015. 


\title{
Cursos em Planejamento e Gestão em Saúde: uma proposta de educação permanente em saúde?
}

\author{
Mariluce Karla Bomfim de Souza \\ Isabela Cardoso de Matos Pinto
}

\section{Introdução}

A construção do Sistema Único de Saúde vem imprimindo uma série de desafios para a gestão do trabalho e da educação nesta área, exigindo constantes reflexões sobre as práticas que conformam o modelo de atenção e os desafios a serem enfrentados para a mudança/transformação dos processos de formação de pessoal em todos os níveis. Questões como o papel das instituições gestoras na formulação e implementação de políticas que direcionem a formação de pessoal, a constituição de redes descentralizadas de formação das equipes multiprofissionais e dos trabalhadores de saúde, a reorientação dos processos de "educação permanente" dos trabalhadores da saúde, a incorporação de novas tecnologias no processo educacional, fazem parte desse debate.

O processo de estruturação dos Serviços de Hemoterapia e Hematologia em rede demanda contínuo aumento da capacidade operacional do atendimento hemoterápico e hematológico, o que justifica o desenvolvimento de estratégias metodológicas para qualificação e capacitação técnica dos gestores e profissionais de saúde envolvidos com tais serviços nos estados e municípios. 
Nesse sentido, uma das estratégias utilizadas para o aperfeiçoamento das práticas conforme solicitação da Coordenação Geral de Sangue e Hemoderivados do Ministério da Saúde (CGSH/MS) ao Instituto de Saúde Coletiva da Universidade Federal da Bahia foi a realização dos cursos de Atualização em Planejamento e Gestão de Sistema de Saúde já ofertados para cinco estados brasileiros no ano e 2015. ${ }^{1}$

Denominado como "curso", uma das categorias de atividades de "extensão"2 da universidade, desde a sua elaboração, desenho e programação almejava-se uma proposta ousada de Educação Permanente em Saúde (EPS) que provocasse nos participantes a criticidade e a problematização do cotidiano do trabalho a fim de produzir mudanças.

Este capítulo propõe uma reflexão aos leitores sobre os cursos em Planejamento e Gestão em Saúde, apresentados como um dos caminhos para o fortalecimento das Hemorredes. Portanto, instiga-se tal reflexão a partir da apresentação dos elementos conceituais e metodológicos que definem os processos de Educação Permanente em Saúde, assim como o destaque para a realidade e o cotidiano das práticas como ponto de partida para as mudanças e as competências esperadas a serem desenvolvidas ao longo do processo conforme proposição dos cursos. Assim, afirma-se que não se pretende aqui responder a questão do título, por ora, e sim provocar a reflexão sobre uma proposta de qualificação e aperfeiçoamento das práticas de trabalhadores da saúde, inovadora na área da Hematologia e Hemoterapia.

\section{Educação permanente em saúde: do que se trata?}

O debate acerca da necessidade de atualização e capacitação dos profissionais e trabalhadores de saúde vem sendo alimentado nos últimos 40anos

1 Ver Capítulos 5 e 6 deste livro.

2 A Resolução $n^{\circ}$ 2/2012 aprova o Regulamento de Extensão Universitária da Universidade Federal da Bahia (UFBA). Dentre as ações de extensão universitária descritas no artigo $6^{\circ}$ estão os cursos, definidos como "atividades sistematizadas de caráter didático, que objetivam a disseminação de princípios, conceitos, fundamentos, métodos e tecnologias para público-alvo definido". A Resolução acrescenta como uma das modalidades dos cursos de extensão universitária, os cursos de educação permanente, destinados a difundir conhecimentos e técnicas nas várias áreas das ciências, das artes e da cultura, mediante treinamento e capacitação direcionados à população de modo geral, dentro da compreensão de educação ao longo da vida, de acordo com a definição de educação permanente da UNESCO. (UNIVERSIDADE FEDERAL DA BAHIA, 2012) 
por iniciativas dos organismos internacionais da área, inclusive no contexto latino-americano. Já no início da década de 1970 a XIX Conferência Sanitária Pan Americana de Saúde apontava a necessidade de apoiar os governos em seus esforços para planificar, implantar e melhorar os mecanismos de atualização dos trabalhadores de saúde. (HADDAD; ROSCHKE; DAVINI, 1994) No entanto, esses mecanismos respondiam a determinados profissionais e não contemplavam elementos comuns do processo de trabalho.

Em 1975 a Organização Pan-Americana da Saúde (OPAS) elabora diretrizes para formulação do plano de educação continuada para as equipes de saúde, e em 1978 a Educação Continuada é institucionalizada nas Instituições de Saúde. A partir de 1979, esse arcabouço conceitual da educação continuada começa a dialogar com os princípios fundamentais da educação de adultos e reestrutura-se. Assim, no âmbito da OPAS vai se conformando uma "nova" concepção de educação continuada, que passa a se chamar Educação Permanente. Com isso, alguns autores - Ribeiro e Motta (1996); Ricas (1994) - se preocuparam em diferenciar os conceitos de educação continuada e permanente.

O termo "continuada", segundo Ricas (1994) citado por Ribeiro e Motta (1996, p. 2), “[...] englobaria as atividades de ensino após o curso de graduação, com finalidades mais restritas de atualização, aquisição de novas informações e/ou atividades de duração definida" - enfoque mais técnico. Segundo Motta (1998) citado por Motta, Buss e Nunes (2001), o termo "permanente", largamente difundido pela OPAS, e que aponta para o "enfoque integrado: técnico-organizacional e político":

[...] teria como referência uma estratégia de reestruturação e desenvolvimento dos serviços, a partir de uma análise dos determinantes sociais e econômicos, mas, sobretudo de transformação de valores e conceitos dos profissionais. Propõe transformar o profissional em sujeito, colocando-o no centro do processo de ensino/aprendizagem. (MOTTA, 1998 apud MOTTA; BUSS; NUNES, 2001)

As ações de educação continuada, portanto, caracterizam-se pela formação pontual com o objetivo de responder as lacunas na atuação técnica dos profissionais. Todavia, os esforços de vincular a formação e o processo ensi- 
no-aprendizagem às situações de trabalho seriam superados pela educação permanente, que contemplaria assim, a integração de aspectos técnicos com aspectos políticos - relativos à responsabilização compartilhada entre profissionais e educadores com o processo educativo.

O conceito de educação permanente em saúde destaca a relação entre a educação e o trabalho, e, portanto, a articulação da formação com a mudança no conhecimento e no exercício profissional. Nesse sentido, enquanto proposta de ação estratégica reúne os saberes técnicos e científicos, as dimensões éticas da vida, do trabalho, do homem, da saúde, da educação e das relações.

Embora nem todos os autores que trabalham com esse tema chamem a atenção para os múltiplos aspectos envolvidos nesta concepção, quais sejam eles, os aspectos técnicos, organizacionais e políticos do processo de trabalho que ancoram - ou melhor, devem ancorar - os processos de Educação Permanente, é importante registrar algumas contribuições mais difundidas e analisá-las.

Davini (1995, p. 10), por exemplo, chama a atenção para os Programas de Educação Permanente que se baseiam na perspectiva "integral" de análise do contexto e das práticas, visando melhoria do processo de trabalho da equipe e qualidade da atenção e transformação do serviço de saúde, daí que "a educação é integrada aos processos de trabalho nos serviços de saúde”. Para tanto, buscam diferentes fontes de informação para serem atualizados, buscam formação permanente para o trabalho em organizações cada vez mais complexas, integrar-se a distintos grupos sociais que permitam comunicar-se e participar assumindo responsabilidades na transformação das instituições (técnico, organizacional e político).

No Brasil, a EPS foi lançada como política nacional em 2003, mas sua institucionalização tem como marco referencial a publicação da Portaria GM/ MS n 198, de 13 de fevereiro de 2004, que institui a Política Nacional de Educação Popular em Saúde (PNEPS) como estratégia de formação e desenvolvimento de trabalhadores para o SUS, operacionalizada por novas práticas pedagógicas e de saúde e objetivando a transformação das práticas. Em 2007 foi revisto e nova portaria foi publicada incorporando modificações na Política.

A Educação Permanente em Saúde caracteriza-se pela capacidade de contribuir para a transformação dos processos formativos, das práticas peda- 
gógicas e de saúde e para a organização dos serviços. (BRASIL, 2004) Tendo em vista o trabalho, a EPS se constitui como prática de ensino-aprendizagem e como política. Como prática, parte da realidade vivida, considera os problemas do cotidiano do trabalho e as experiências dos atores envolvidos; tem base no ensino problematizador da realidade e da aprendizagem significativa, produz conhecimento e mudança como resposta às perguntas geradas na vivência do dia a dia do trabalho. E, como política, envolve a contribuição do ensino e construção do SUS, logo considera a articulação entre ensino, trabalho e cidadania, e a vinculação entre formação, gestão setorial, atenção à saúde e participação social.

A associação entre o ensino, o sistema de saúde e suas práticas, a gestão e a participação social consideradas na perspectiva política da EPS constitui, segundo Ceccim (2004-2005) o conceito de quadrilátero da formação. Nesse sentido, o ensino deve tomar por base uma concepção construtivista - interacionista, de problematização das práticas e dos saberes - e incentivadora da produção de conhecimento dos serviços e da produção de conhecimento por argumentos de sensibilidade; as práticas de atenção à saúde devem considerar e assumir os desafios da integralidade, da humanização e da inclusão da participação dos usuários no planejamento terapêutico; a gestão deve considerar o modo criativo e original para a rede de serviços, assegurar redes de atenção às necessidades em saúde e considerar na avaliação a satisfação dos usuários; e, a participação social com visão ampliada das lutas por saúde e à construção do atendimento às necessidades sociais por saúde. (CECCIM, 2004-2005)

A caracterização de cada realidade, a identificação da vulnerabilidade social dos problemas de saúde e a reflexão sobre o desempenho nos serviços são imprescindíveis para a Educação Permanente para os profissionais de saúde. (FACCHINI et al., 2006) A constatação da insatisfação dos distintos atores envolvidos ou insuficiência dos serviços em dar conta dos desafios do trabalho, bem como, o estranhamento de saberes caracteriza o movimento de mudança das práticas.

O eixo central da política de educação permanente é o trabalho cujo processo contempla as dimensões técnicas, éticas, políticas, culturais e sociais como condições para o desenvolvimento dos trabalhadores da saúde. $\mathrm{O}$ aprender e ensinar acontece no cotidiano do trabalho, cujo ambiente deve ser 
favorável à motivação, comprometimento e desempenho das pessoas através de um processo pedagógico visando a valorização e desenvolvimento do trabalhador. Assim, o processo pedagógico, portanto, acontece no âmbito e no contexto do processo de trabalho, visto que trabalhar é se educar no seu sentido mais abrangente de aprendizado de ser, de aprender, de dar significado ao seu viver.

\section{Cursos de atualização em planejamento e gestão de sistema de saúde: o cotidiano dos serviços e as práticas de trabalho como ponto de partida para a produção de mudanças}

A proposta de oferta de cursos de atualização em planejamento e gestão foi desenhada a partir da constatação da realidade plural e polimorfa dos estados brasileiros, distribuídos nas cinco regiões geográficas, os quais apresentam diferentes situações de saúde e de organização e gestão do sistema de saúde; bem como, fragilidades nas estruturas de planejamento das instituições e organizações de saúde e, portanto, pouca valorização do planejamento no processo de gestão em saúde.

Retomando as prerrogativas da Educação Permanente em Saúde (EPS) que deve considerar a realidade de modo a problematizá-la e criticá-la, os cursos de atualização cujo objeto do processo educativo é o planejamento em saúde, convergem na sua proposição, de modo a utilizar estratégias metodológicas que estimulam os participantes "cursistas" a refletirem sobre a realidade estadual, o cotidiano do trabalho e as práticas de planejamento e gestão, sendo o ponto de partida para tal reflexão a análise da situação de saúde.

Segundo Paim e Almeida Filho (2014) a análise de situação de saúde compreende a identificação dos problemas de saúde da população que compõem o perfil epidemiológico, suas necessidades, bem como a explicação desses problemas e necessidades, e as oportunidades e facilidades para a intervenção. Portanto, a "situação" deve ser definida a partir dos sujeitos envolvidos, os quais percebem o cotidiano de diferentes formas e são influenciados pelo lugar de onde vêm. Nesse sentido, a proposta de educação permanente para profissionais de saúde provoca a reflexão sobre o que se sente no dia a dia do trabalho e tensiona saberes e, ainda, o que há por saber. (CECCIM; FERLA, 2009) 
Assim como na EPS, a tensão de saberes, o estranhamento e o (re)conhecimento da realidade também são propostas no planejamento estratégico. De acordo com Matus (1993), o planejamento estratégico situacional pode ser elaborado em quatro momentos não lineares. O primeiro, que explica a realidade a partir da leitura e percepção de problemas pelos diversos sujeitos posicionados no contexto; o momento normativo que define o que deve ser, os objetivos, o desenho e os cursos de ação com expressão do que deve ser feito sobre e para tal realidade; o momento estratégico que desenha as possibilidades diante da análise da viabilidade e do que pode ser feito; e, o momento tático-operacional que se caracteriza pelo fazer requerendo ajustes, adaptações, flexibilidade, informações, acompanhamento e avaliação.

A proposição metodológica do enfoque estratégico situacional para o planejamento em saúde, segundo Teixeira (2010) tem vários argumentos favoráveis como a possibilidade de compreensão dos problemas e oportunidades reais de intervenção; a constituição do processo de planejamento em "momentos que se interpenetram"; a "modularização" operacional do plano considerando atores, espaço e tempo para a sua execução; e as noções sobre a gestão do plano e gerência das operações como possibilidade para as mudanças das práticas institucionais na direção da democratização das relações e da intensificação das ações comunicativas.

Portanto, na perspectiva de elaborar e executar uma proposta de educação permanente em saúde a oferta dos "cursos" em discussão tomou por referência o enfoque estratégico situacional, de modo que exigiu uma engenharia pedagógica com disposição de diferentes recursos didáticos. A equipe de elaboração reuniu-se por várias vezes para o desenvolvimento de oficinas para a construção de uma matriz pedagógica, tendo como principais produtos o desenho das estratégias metodológicas do curso $^{3}$ e das competências esperadas dos cursistas.

\section{Competências para a concretização de uma proposta de Educação Permanente em Saúde}

Segundo Ropé e Tanguy (1997) o conjunto de conhecimentos, qualidades, capacidades e aptidões que habilitam para a discussão e decisão que concer-

3 Apresentadas no capítulo 5. 
ne a um ofício define o termo competência. As competências, portanto, mobilizam um conjunto de recursos cognitivos - saberes, capacidades, informações, etc - para solucionar com pertinência e eficácia uma série de situações, desse modo, estão ligadas a contextos culturais, profissionais e condições sociais. (PERRENOUD, 1999)

Ser competente diz respeito ao saber fazer, ou seja, a capacidade de aplicabilidade e contextualização dos afazeres, assim como, a mobilização de recursos, identificação dos meios e estratégias e desenho das ações para solucionar problemas. Nesse sentido, os conhecimentos teóricos bem fundamentados e os saberes contextualizados possibilitarão o desenvolvimento de habilidades para lidar com as situações diversas apresentadas no cotidiano do trabalho.

A fundamentação teórica que sustenta os "cursos" contempla a análise de situação de saúde, segundo contribuições de Ribeiro (2014), Paim e Almeida Filho (2014); a discussão sobre o Sistema Único de Saúde e os desafios para a constituição e consolidação das redes de atenção iluminada pelas contribuições teóricas de Paim e colaboradores (2011) e Mendes (2009, 2010); a abordagem sobre o cuidado com base em Pinheiro (2009). As bases teóricas e metodológicas sobre programação e planejamento em saúde tomam por referência Teixeira $(2001,2010)$ que discute o planejamento estratégico a partir de Matus (1993), além de Paim (2006); dentre outros fundamentos teóricos, como cultura institucional; tomada de decisão; trabalho em equipe (PEDDUZI, 2001); educação permanente (CECCIM, 2004-2005); comunicação em saúde (RANGEL, 2012); participação; e, avaliação em saúde. (VIEIRA-DA-SILVA, 2014)

A fim de estimular a reflexão sobre a fundamentação teórica proposta e de forma contextualizada e articulada com a realidade prática, foram desenhadas estratégias metodológicas e pedagógicas para o desenvolvimento dos "cursos" aplicadas em três ciclos de desenvolvimento, ${ }^{4}$ com momentos presenciais para apresentação e discussão da fundamentação teórica, discussão de caso e orientação das atividades, intercalados com momentos de dispersão que provocam a reflexão e articulação da realidade do território estadual com o conteúdo teórico discutido.

4 Ver Capítulo 5. 
Os momentos de dispersão caracterizam-se pela (re)leitura da situação de saúde do território estadual, tal como, da identificação e (re)conhecimento dos problemas de saúde e de serviços de saúde, de modo que os exercícios propostos levam os cursistas a tais reflexões e discussões, assim como a identificação de estratégias e recursos para a proposição de ações apresentadas em desenho preliminar de um plano diretor para a Hemorrede Estadual. Portanto, o registro e a experiência de desenvolvimento de tais atividades são levadas e apresentadas pelos cursistas nos momentos presenciais, com oportunidade de nova discussão e reflexões compartilhadas com os docentes, facilitadores e, também, os moderadores da Coordenação Geral de Sangue e Hemoderivados do Ministério da Saúde.

Assim, diante da fundamentação teórica, do desenho pedagógico e das estratégias metodológicas para o desenvolvimento dos cursos, espera-se que ao final do processo os participantes/cursistas estejam aptos:

Analisar a situação de saúde e suas tendências, as repercussões sobre as condições de saúde da população e sobre o sistema de saúde, bem como a disposição dos serviços de hematologia e hemoterapia levando em conta o recorte territorial e o fortalecimento das redes regionalizadas no estado; Realizar atividades de planificação e programação das ações da saúde de acordo com a noção de território e suas relações com o processo saúde-doença-cuidado, tendo como referência a integralidade do cuidado à saúde; Tomar decisões, comunicar-se e planejar de forma efetiva e eficaz; Trabalhar em equipe e interagir com profissionais dos diversos serviços do sistema de saúde considerando valores como a participação e a corresponsabilização dos seus integrantes; Atuar para o fortalecimento da cultura de planejamento institucional com enfoque na constituição das redes de atenção; Envolver a população na identificação das necessidades, monitoramento e avaliação dos planos de saúde; Aplicar conhecimentos das bases conceituais e metodológicas do Planejamento em Saúde no cotidiano das práticas; Aplicar os conhecimentos da Epidemiologia para o estudo e entendimento das condições de saúde da população, considerando os processos de decisão e planejamento do sistema de saúde; Utilizar, incorporar e avaliar 
tecnologias de comunicação e informação pertinentes ao processo de planejamento em saúde; Reconhecer e atuar nas estruturas consultivas e deliberativas (ex. conselhos) do SUS, considerando o fortalecimento da rede de atenção à saúde; Formular e utilizar indicadores para o acompanhamento e avaliação do trabalho; Participar com responsabilidade e compromisso das ações de educação permanente em saúde. (SOUZA et al., 2016, p. 10-11)

Diante do desenho dos "cursos" - formato, estratégias metodológicas, fundamentação teórica, recursos didáticos, atores envolvidos, competências esperadas - pode-se perceber que a execução de um projeto desta envergadura se constitui como desafio, no entanto, sua contribuição se dará no sentido de colaborar para a incorporação de tecnologias de gestão e mudanças de práticas político-gerenciais no âmbito do sistema público de saúde.

\section{Considerações finais}

O desenvolvimento da educação permanente abre possibilidade de uma pedagogia do trabalho que favoreça a democratização das relações entre as equipes buscando a gestão participativa e solidária; aplicação da metodologia da problematização visando a constituição de sujeitos críticos, reflexivos e propositivos, a qualificação das práticas e dos processos de trabalho; utilização de tecnologias educacionais inovadoras, que possibilitem a construção de redes integradas de educação-trabalho, e articulação em rede de cooperação técnica.

Diante do exposto, percebe-se que o sucesso da atividade educativa requer a construção permanente de um pacto entre gestores e trabalhadores do SUS, tendo em vista a implementação das propostas de mudança do modelo de atenção e da melhoria da qualidade e da humanização do trabalho em saúde.

\section{Referências}

BRASIL. Ministério da Saúde. Portaria $n^{\circ} 4.279$, de 30 de dezembro de 2010. Estabelece diretrizes para a organização da Rede de Atenção à Saúde no âmbito do Sistema Único de Saúde (SUS). Diário Oficial [da] República Federativa do Brasil, Brasília, DF, 31 dez. 2010. Seção 1, p. 88. 
BRASIL. Ministério da Saúde. Secretaria de Gestão do Trabalho e da Educação na Saúde. Departamento de Gestão da Educação na Saúde. Política de educação e desenvolvimento para o SUS: caminhos para a educação permanente em saúde: pólos de educação permanente em saúde. Brasília, DF, 2004. (Série C: projetos, programas e relatórios).

CECCIM, R. B. Educação permanente em saúde: desafio ambicioso e necessário. Interface: Comunicação, Saúde e Educação, Botucatu, v. 9, n. 16, p. 161-67, set./fev. 2004-2005.

CECCIM, R. B.; FERLA, A. A. Educação permanente em saúde. In:

DICIONÁRIO da Educação Profissional em Saúde. Rio de Janeiro: Fiocruz, 2009. Disponível em: <http://www.epsjv.fiocruz.br/dicionario/verbetes/ edupersau.html>. Acesso em: 18 mar. 2016.

CECCIM, R. B.; FEUERWERKER, L. C. M. O quadrilátero da formação para a área de saúde: ensino, gestão, atenção e controle social. Physis: Revista de Saúde Coletiva, Rio de Janeiro, v. 14, n. 1, p. 41-65, 2004.

DAVINI, M. C. Educación permanente en salud. Washington, D.C.:

Organización Panamericana de la Salud, 1995. (Serie PALTEX para ejecutores de programas de salud, n. 38).

FACCHINI, L. A. et al. Desempenho do PSF no Sul e no Nordeste do Brasil: avaliação institucional e epidemiológica da atenção básica à saúde. Ciência \& Saúde Coletiva, Rio de Janeiro, v. 11, n. 3, p. 669-681, 2006.

FARIA, R. M. B. Institucionalização da política de educação permanente para o Sistema Único de Saúde: Brasil, 1997-2006. Tese (Doutorado em Ciências) Faculdade de Medicina, Universidade de São Paulo, São Paulo, 2008.

HADDAD, A. E. et al. (Org.). A trajetória dos cursos de graduação na área da saúde: 1991-2004. Brasília, DF: Inep, 2006.

HADDAD, J.; ROSCHKE, M. A. C.; DAVINI, M. C. (Ed.). Educación permanente de personal de salud. Washington, D.C.: Organización Panamericana de la Salud, 1994. (Série desarrollo de recursos humanos, n. 100).

MATUS, C. Política, planejamento \& governo. Brasília, DF: Ipea, 1993.

MENDES, E. V. As redes de atenção à saúde. Belo Horizonte: Escola de Saúde Pública de Minas Gerais, 2009.

MENDES, E. V. As redes de atenção à saúde. Ciência \& Saúde Coletiva, Rio de Janeiro, v. 15, n. 5, p. 2297-2305, 2010. 
MOTTA, J. I. J.; BUSS, P.; NUNES, T. C. M. Novos desafios educacionais para a formação de recursos humanos em saúde. Olho Mágico, Londrina, v. 8, n. 3, set./dez. 2001. Disponível em: <http://www.uel.br/ccs/olhomagico/v8n3/ enfoque.htm>. Acesso em: 30 jan. 2016.

PAIM, J. S. Planejamento para não especialistas. In: CAMPOS, G. W. de S. et al. (Org.). Tratado de saúde coletiva. São Paulo: Hucitec; Rio de Janeiro: Ed. Fiocruz, 2006. p. 767-782.

PAIM, J. S.; ALMEIDA FILHO, N. Análise da situação de saúde: o que são necessidades e problemas de saúde. In: PAIM, J. S.; ALMEIDA FILHO, N. de. Saúde coletiva: teoria e prática. Rio de Janeiro: MedBook, 2014. cap. 3, p. 29-39.

PAIM, J. S. et al. O sistema de saúde brasileiro: história, avanços e desafios. The Lancet, [S.l.], 2011.

PEDUZZI, M. Equipe multiprofissional de saúde: conceito e tipologia. Revista de Saúde Pública, São Paulo, v. 35, n. 1, p. 103-109, 2001.

PERRENOUD, P. Construir competências desde a escola. Tradução de Bruno Charles Magne. Porto Alegre: Artmed, 1999.

PINHEIRO, R. Cuidado em saúde: cuidado e a vida cotidiana. In: DICIONÁRIO de Educação Profissional em Saúde. Rio de Janeiro: Fiocruz, 2009. Disponível em: <http://www.epsjv.fiocruz.br/dicionario/verbetes/ cuisau.html >. Acesso em: 16 mar. 2015.

RANGEL, M. L. Comunicação, educação e saúde: exercício para percepção e ação nas interfaces. Salvador, 2012. Mimeografado.

RIBEIRO, E. C. O.; MOTTA, J. I. J. Educação permanente como estratégia na reorganização dos serviços de saúde. Revista Divulgação em Saúde para Debate, Rio de Janeiro, n. 12, p. 39-44, jul. 1996.

RIBEIRO, G. S. Problemas de saúde da população brasileira e seus determinantes. In: PAIM, J. S.; ALMEIDA FILHO, N. Saúde coletiva: teoria e prática. Rio de Janeiro: MedBook, 2014. cap. 8, p. 97-119.

RICAS, J. A deficiência e a necessidade: um estudo sobre a formação continuada de pediatras em Minas Gerais. 1994. 232 f. Tese (Doutorado em Pediatria) - Faculdade de Medicina de Ribeirão Preto, Universidade de São Paulo, São Paulo, 1994.

ROPÉ, F.; TANGUY, L. (Org.). Saberes e competências: o uso de tais noções na escola e na empresa. Campinas: Papirus, 1997. 
SOUZA, M. K. B. et al. (Org.). Planeja Sangue: cursos em planejamento e gestão de sistema e serviços de saúde: guia para estudos. 2. ed. rev. [S.1.]: Salvador, 2016.

TEIXEIRA, C. F. (Org.). Planejamento em saúde: conceitos, métodos e experiências. Salvador: Edufba, 2010.

TEIXEIRA, C. F. Planejamento municipal em saúde. Salvador: Instituto de Saúde Coletiva da Universidade Federal da Bahia, 2001.

UNIVERSIDADE FEDERAL DA BAHIA. Conselho Acadêmico de Pesquisa e Extensão. Resolução $n^{\circ}$ 2/2012. Aprova o Regulamento de Extensão Universitária da Universidade Federal da Bahia (UFBA). Salvador, 19 nov. 2012.

VIEIRA-DA-SILVA, L. M. Avaliação de políticas e programas de saúde. Rio de Janeiro: Ed. Fiocruz, 2014. 


\section{Sobre os autores}

\section{Ana Angélica Ribeiro de Meneses e Rocha}

Graduada em Medicina pela Universidade Federal de Sergipe (1977). Doutora em Saúde Pública na área de Política, Planejamento e Gestão em Saúde pelo Instituto de Saúde Coletiva da Universidade Federal da Bahia (ISC/ UFBA). Pesquisadora e vice-coordenadora do Programa Integrado de Ensino, Pesquisa e Cooperação Técnica Comunidade Família Saúde (FASA/ISC/ UFBA).

\section{Bárbara de Jesus Simões}

Graduada em Enfermagem e Obstetrícia pela Universidade de Brasília (UnB) (1999). Especialista em Gestão de Hemocentros pela Universidade de Pernambuco (UPE) (2011); e Regulação e Vigilância Sanitária em Hemoterapia e Transplante pela Universidade Estadual Paulista (Unesp) (2008). Mestre Saúde Coletiva - Vigilância Sanitária: serviços de saúde pela Universidade de Brasília (UnB) (2002) e mestre em Hemoterapia e Biotecnologia pela Universidade de São Paulo (USP) (2015). Desde 2008, atua como consultora na Coordenação-Geral de Sangue e Hemoderivados do Ministério da Saúde, sendo responsável, no período de 2012 a 2013, pela área de Gestão da Informação e de 2013 a 2016, pela assessoria técnica em Hemoterapia. 


\section{Cláudio Medeiros Santos}

Graduado em Direito pela Universidade Estadual de Montes Claros (Unimontes). Possui mestrado profissional em Saúde Coletiva área concentração Gestão de Sistemas de Saúde, com ênfase em Gestão de Serviços de Hemoterapia do Instituto de Saúde Coletiva (ISC) da Universidade Federal da Bahia (UFBA). Atuou por 22 anos na Fundação Centro de Hematologia e Hemoterapia de Minas Gerais Fundação Hemominas, como servidor concursado, ocupando cargos de chefe de seção, supervisão e assessor da presidência. Desde 2008 atua como consultor técnico em Qualidade e Gestão, na Coordenação Geral de Sangue e Hemoderivados.

\section{Giselle Bissaro Barban Evangelista}

Graduada em Biomedicina pelo Centro Universitário Barão de Mauá (2008). Aprimoramento profissional em Hemoterapia no Hospital das Clínicas da Faculdade de Medicina de Ribeirão Preto (HC-Rib. Preto) (2010). Especialista em Hematologia e Banco de sangue pela Academia de Ciência e Tecnologia (AC\&T) (2010). Biologista no laboratório do Teste do Ácido Nucléico (Hemocentro de Rib. Preto) (2011). Mestre em Ciências na área de Hemoterapia e Medicina Transfusional pela Faculdade de Medicina de Ribeirão Preto da Universidade de São Paulo (FMRP/USP) (2014). Assessora técnica em Hemoterapia no Ministério da Saúde (2011-2017).

\section{Glauciene Analha Leister}

Graduada em Enfermagem pela Universidade Estadual de Campinas (2008). Mestre em Saúde Coletiva pela Escola de Enfermagem da Universidade de São Paulo (2012). Desde 2013, atua como analista técnica de Políticas Sociais no Ministério da Saúde, com lotação na Coordenação-Geral de Sangue e Hemoderivados, em que desenvolve atividades de assessoramento e no Programa Nacional de Qualificação da Hemorrede.

\section{Helder Teixeira Melo}

Graduado em Farmácia e Bioquímica pelo Centro Universitário Planalto do Distrito Federal (Uniplan) (2002). Bacharel em Teologia pelo Seminário Presbiteriano de Brasília (SPB) (2008). Especialista em Regulação e Vigilância 
Sanitária em Hemoterapia e Transplantes pela Universidade Estadual de São Paulo (Unesp) (2008), Especialista em Gestão da Qualidade para Acreditação de Serviços de Saúde pela Faculdade Ciências Médicas de Minas Gerais (Feluma) (2012). Mestre em Ciências na área de Hemoterapia e Medicina Transfusional pela Faculdade de Medicina de Ribeirão Preto da Universidade de São Paulo (FMRP/USP) (2015). Assessor técnico em hematologia e hemoterapia no Ministério da Saúde (desde 2005).

\section{Isabela Cardoso de Matos Pinto}

Graduada em Serviço Social pela Universidade Católica do Salvador (1985). Mestre em Saúde Coletiva pela Universidade Federal da Bahia (UFBA) (1991). Doutora em Administração Pública pela UFBA (2004). Professora adjunta do Instituto de Saúde Coletiva da Universidade Federal da Bahia. Diretora do Instituto de Saúde Coletiva da Universidade Federal da Bahia (ISC-UFBA), desde 2013 e docente do Programa de Pós Graduação em Saúde Coletiva ISC/UFBA. Coordenadora da linha de Pesquisa Gestão, Trabalho e Educação na Saúde vinculada ao Programa Integrado de Política, Planejamento, Gestão e Avaliação do ISC/UFBA.

\section{Jane Terezinha Martins}

Graduada em Farmácia (1979) e Bioquímica, habilitação em Análises Clínicas pela Universidade Federal de Santa Catarina (UFSC) (1981). Especialista em gestão em Saúde. Master in Business Administration (MBA) pela Universidade do Desenvolvimento do Estado de Santa Catarina (2003). Farmacêutica do Centro de Hematologia e Hemoterapia de Santa Catarina (Hemosc) de 1989 a 2016. Gerente Técnica do HEMOSC de 1994 a 2007. Consultora Técnica da Coordenação Geral de Sangue e Hemoderivados, responsável pela área técnica de Hemoterapia de 2008 a 2011, e responsável pelo Programa Nacional de Qualificação da Hemorrede (PNQH) desde 2008.

\section{Júnia Guimarães Mourão Cioffi}

Graduada em Medicina pela Universidade Federal de Minas Gerais (1986). Especialista em Pediatria (1989), e em Hematologia e Hemoterapia (2007). Mestre em Administração Pública, com ênfase em Gestão de Políticas Sociais, 
pela Fundação João Pinheiro (2005). Presidente da Fundação Hemominas desde 2011, e médica hematologista colaboradora do Ministério da Saúde junto à Gerência Geral de Sangue, Outros Tecidos e Órgãos, da Anvisa e à Coordenação da Política de Sangue e Hemoderivados do Ministério da Saúde. Membro da Diretoria da Associação Brasileira de Hematologia e Hemoterapia (ABHH), biênio 2015 a 2017.

\section{Jussara Cargnin Ferreira}

Graduada pela Universidade Federal de Santa Catarina como Assistente Social (1986). Especialista em Gestão de Hemocentros pela Universidade de Pernambuco (2010). Mestre em Saúde Coletiva pelo ISC/UFBA (2014). Atuou no Centro de Hematologia e Hemoterapia de Santa Catarina de 1998 a 2007 desenvolvendo atividades na área da promoção da doação voluntária de sangue e coordenando a Divisão de Recursos Humanos. De 2008 a 2016 foi consultora técnica da Coordenação Geral de Sangue e Hemoderivados do Ministério da Saúde (CGSH/MS), sendo responsável pela área de Gestão de Pessoas da CGSH e de Educação Permanente voltada à Hemorrede Nacional. Atualmente exerce funções na área de Ensino e Pesquisa do Centro de Hematologia e Hemoterapia de Santa Catarina, participando também como membro do Comitê de Ética e Pesquisa desta instituição.

\section{Márcia Teixeira Gurgel do Amaral}

Graduada em Letras pela Universidade Federal do Ceará (1986). Especialista em Administração Hospitalar pela Universidade de Ribeirão Preto (Unaerp) (1996) e em Gestão de Hemocentros pela Universidade Federal de Pernambuco (2006) e em Economia da Saúde pela Universidade Estadual do Ceará. Mestre em Saúde Pública pela Universidade Estadual do Ceará (2003). Atua desde 2007 a 2016 na Coordenação Geral de Sangue e Hemoderivados do Ministério da Saúde, com ênfase em gestão de projetos, sendo também a responsável pela área de Gestão Financeira e Assessoria Técnica à Hemorrede Pública Nacional. Atualmente, responde pela Diretoria de Administração da Fundação Pró-Sangue (FPS) - Hemocentro de São Paulo. 


\section{Mariluce Karla Bomfim de Souza}

Graduada em Enfermagem pela Universidade Estadual de Santa Cruz (2001). Especialista em Educação em Saúde Pública (2002). Mestre em Enfermagem pela Escola de Enfermagem da UFBA (2007) e em Saúde Coletiva pela Universidade Estadual de Feira de Santana (2007). Doutora em Saúde Pública na área de Política, Planejamento e Gestão em Saúde pelo Instituto de Saúde Coletiva da Universidade Federal da Bahia (ISC/UFBA) (2011). E possui Pós-doutorado pela Universidad Complutense de Madrid (2017). Professora adjunta do ISC/UFBA. Atuou entre 2014 a 2017 na Coordenação do Projeto Planeja Sangue em Cooperação Técnica do Instituto de Saúde Coletiva da Universidade Federal da Bahia com a Coordenação Geral de Sangue e Hemoderivados do Ministério da Saúde do Brasil. 


\section{Colofão}

Formato: 17 x $24 \mathrm{~cm}$ Tipologia: TT Tricks / Torque Papel: Alcalino $75 \mathrm{~g} / \mathrm{m}^{2}$ (miolo) Cartão Supremo $300 \mathrm{~g} / \mathrm{m}^{2}$ (capa)

Impressão: EDUFBA

Capa e acabamento: I. Bigraf

Tiragem: 300 